\title{
Giving Life to the Labour Process: Transgenic Biotechnology and the Meaning of Nature
}

\author{
by
}

Kenneth Fish

BA, Simon Fraser University, 1997

MA, Simon Fraser University, 1999

\author{
THESIS SUBMITTED IN PARTIAL FULFILLMENT OF \\ THE REQUIREMENTS FOR THE DEGREE OF \\ DOCTOR OF PHILOSOPHY \\ in the department \\ of \\ SOCIOLOGY AND ANTHROPOLOGY
}

(c) Kenneth Fish 2008

Carleton University

\footnotetext{
All rights reserved. This work may not be reproduced in whole or in part, by photocopy or other means, with permission of the author.
} 


$\begin{array}{ll}\begin{array}{l}\text { Library and } \\ \text { Archives Canada }\end{array} & \begin{array}{l}\text { Bibliothèque et } \\ \text { Archives Canada }\end{array} \\ \begin{array}{l}\text { Published Heritage } \\ \text { Branch }\end{array} & \begin{array}{l}\text { Direction du } \\ \text { Patrimoine de l'édition }\end{array} \\ \begin{array}{l}\text { 395 Wellington Street } \\ \text { Ottawa ON K1A 0N4 }\end{array} & \begin{array}{l}\text { 395, rue Wellington } \\ \text { Ottawa ON K1A ON4 }\end{array} \\ \text { Canada } & \begin{array}{l}\text { Canada } \\ \end{array}\end{array}$

Yourfile Votre référence ISBN: 978-0-494-36784-1 Ourfile Notre référence ISBN: 978-0-494-36784-1

NOTICE:

The author has granted a nonexclusive license allowing Library and Archives Canada to reproduce, publish, archive, preserve, conserve, communicate to the public by telecommunication or on the Internet, loan, distribute and sell theses worldwide, for commercial or noncommercial purposes, in microform, paper, electronic and/or any other formats.

The author retains copyright ownership and moral rights in this thesis. Neither the thesis nor substantial extracts from it may be printed or otherwise reproduced without the author's permission.
AVIS:

L'auteur a accordé une licence non exclusive permettant à la Bibliothèque et Archives Canada de reproduire, publier, archiver, sauvegarder, conserver, transmettre au public par télécommunication ou par l'Internet, prêter, distribuer et vendre des thèses partout dans le monde, à des fins commerciales ou autres, sur support microforme, papier, électronique et/ou autres formats.

L'auteur conserve la propriété du droit d'auteur et des droits moraux qui protège cette thèse. $\mathrm{Ni}$ la thèse ni des extraits substantiels de celle-ci ne doivent être imprimés ou autrement reproduits sans son autorisation.
In compliance with the Canadian

Privacy Act some supporting forms may have been removed from this thesis.

While these forms may be included in the document page count, their removal does not represent any loss of content from the thesis.
Conformément à la loi canadienne sur la protection de la vie privée, quelques formulaires secondaires ont été enlevés de cette thèse.

Bien que ces formulaires aient inclus dans la pagination, il n'y aura aucun contenu manquant.

\section{Canadä}




\begin{abstract}
This dissertation reveals the degree to which biotechnology constitutes a disjuncture in the meaning of nature. The theoretical framework for the analysis is developed through a particular interpretation of Marx, for whom technology, as a central component of the labour process, reveals the active relation of human beings to nature. Biotechnology is conceptualized specifically as 'transgenic biotechnology' in order to capture what is unique about the genetic engineering and employment of microbes, plants, and animals as 'living factories'. The analysis draws upon, but moves beyond, extant labour process theory, the constructivist tradition in science studies, and recent developments in environmental sociology.
\end{abstract}

Central to the analysis is a comparison of a labour process centered on transgenic biotechnology with previous forms of the labour process. On the one hand, a transgenic labour process is distinct from uses of life in fermentation, agriculture, and animal husbandry by virtue of its repositioning of living nature as an industrial technology, a living factory for the production of biopharmaceuticals and other substances. On the other hand, these living factories are distinct from non-living industrial technologies by virtue of their capacities for self-movement, -mediation, and -reproduction. These capacities imply a unique form of industrial labour concerned with the manipulation and regulation of biological processes of growth and development.

This unique form of the labour process constitutes a disjuncture in the meaning of nature and the relation of nature to capitalism. In harnessing the movement of living nature as a productive force, transgenic biotechnology reveals like never before the degree to which the labour process is itself a force of nature infused with human purpose, 
thereby thoroughly destabilizing the notion of an ontologically distinct 'nature', independent from human productive activity and technology. Implicit in this ontological disjuncture is a destabilization of the distinction between capitalism and nature, as the self-movement of life that is the essence of nature becomes a material moment in the selfexpansion of capital. I conclude that this disjuncture in the meaning of nature requires that questions concerning the broader political economy of biotechnology be conceptualized in a way that gives analytical primacy to the materiality of a labour process centered on life. 


\section{Acknowledgements}

It is a shame that prose so easily conceals the messy process of its creation. In addition to the usual intellectual struggles involved in academic research, this document emerged in the midst of death, birth, divorce, marriage, failure, success, heartache, and bliss. There is not a single aspect of my life that has not been transformed on the way and I want to thank all of those who came along for the ride.

I want to thank my supervisor, Wallace Clement, for his warmth, encouragement, and continuous support during a long and sometimes difficult process of research and writing. Wally is an inspiration and a model of what an academic can, and should, be. I am grateful to the other members of my committee, Neil Gerlach and Carlos Novas, for providing insightful and challenging comments on the dissertation that helped me clarify and strengthen the argument.

In addition to the formal members of my committee, I want to thank my teacher and friend Gary Teeple. I was fortunate to meet Gary early on in my academic career and he continues to challenge me, intellectually and otherwise. He is a scholar and a gentleman in the best senses of these words. Others whose insights, comments and criticisms, are reflected in this work include Vincent Mosco, Simon Dalby, Vivian Shalla, Jeff Francis, and Dwayne Winseck.

My time in Ottawa could not have been the same without the friendship of Willow Scobie and Al Vachon. They made a cold place feel like home. Thanks also to Janet Siltanen for providing research opportunities and a smile that always made everything seem okay.

Thanks to Darren and Melissa Moi and all of my other friends in Vancouver for their love and support during the 'research and 'write-up' phases of the process. Thanks to the members of the formidable rock ' $n$ ' roll juggernaut Boomchang - Chris and Bob Fowlie, Tim Vogel, and unofficial member Al Fleming - for giving me the chance to live my rock star dream.

My family has always been a source of unflinching support and I would like to thank my mom, dad, and sister. I would also like to thank my grandmother, Phyllis House, who did not live to see the finished result.

I have been lucky enough to spend the entirety of my university student career in the arms of Tracy Williamson. We met in high school and moved in together as undergraduates. We were married as graduate students and she was willing to give up her career, friends, and family, to travel east with me in search of a PhD. Now, as this long process comes to an end we have added two beautiful boys to our little family - Maclean and Keaton - and I am complete.

My love, there are no words. 


\section{Table of Contents}

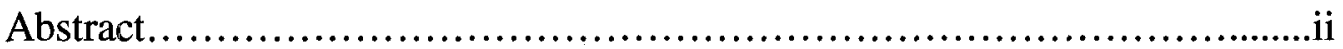

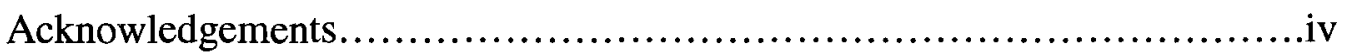

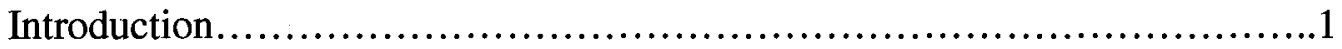

Chapter 1 - Technology, the Labour Process and the Question of Nature.......12

The First Historical Act and the Origin of Nature.....................13

The Labour Process as a Metamorphosis of Nature......................17

Capitalism and the Labour Process....................................22

Large-Scale Industry and the Nature of Technology....................28

Chapter 2 - Conceptualizing Living Technologies..........................42

Biotechnology ..................................................... 43

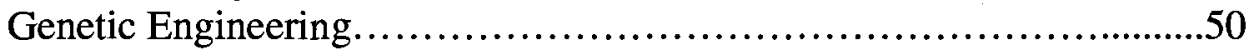

The Transgenic Labour Process......................................59

Chapter 3 - Putting the Material back into Historical Materialism................71

The Ontological Blindspots of Labour Process Studies..................72

Technoscience and the Construction of Nature.........................80

The Fertile Ground of Environmental Sociology........................93

Chapter 4 - Harnessing Life as a Force of Production............................97

The Industrial Logic of Transgenic Production........................98

The Factories are Alive: Transgenic Microbial Production.................102

The Machine is the Garden: Transgenic Plant Production................111

Brave New Barnyard: Transgenic Animal Production.....................122

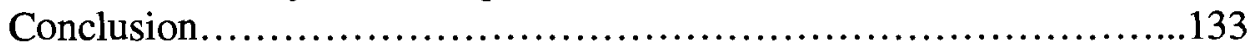

Chapter 5 - Transgenic Biotechnology as a Force of Nature....................134

Breaking the Machine Metaphor....................................135

Transgenic Biotechnology as a Self-Acting Instrument of Production...138

Consuming Raw Materials, or Just Plain Eating?.......................152

Self-Replicating Production Systems................................162

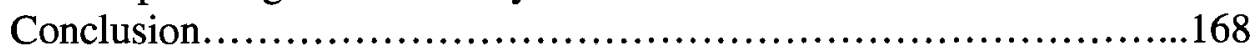

Chapter 6 - The Relation of Living Labour to Transgenic Biotechnology.......169

Engineering Life...............................................170 
Transgenic Biotechnology and Eco-Regulation.........................183

Transgenic Labour as Regulatory Labour................................190

De-Skilling and Automating Synthetic-Regulatory Labour..............196

Chapter 7 - The Labour Process as a Living Force of Nature....................207

Promethean Marxism and the Transformation of Nature..................208

Green Marxism and the Violation of Nature ...........................213

Benton and Eco-Regulation............................................216

The Role of Biological Metaphors in Marx's Analysis of the Labour

Process.................................................................221

Transgenic Biotechnology and the Forces of Nature....................227

Chapter 8 - Transgenic Biotechnology and the Living Materiality of Capital.....231

The False Dichotomy of Capitalism and Nature........................232

Biotechnology and the Mode of Development..........................236

Biotechnology and the Production of Living Nature as a Commodity....240

Transgenic Biotechnology and Living Nature as Fixed Capital...........246

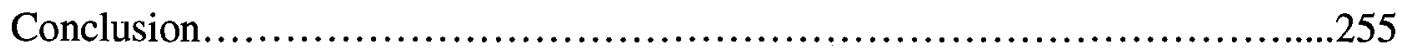

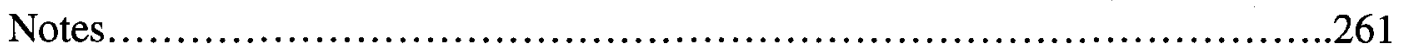

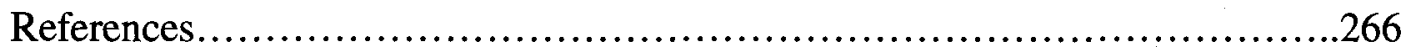




\section{Introduction}

Nature can confront us as a question in two senses. On the one hand, the question can concern what should be done about nature. This is the kind of question to which Francis Bacon's 'mechanical arts' are the answer. "You have but to follow and as it were hound nature in her wanderings," suggests Bacon, "and you will be able, when you like, to lead and drive her afterwards to the same place again" (qtd. in Leiss 1974, 59). But it is no less the kind of question to which 'environmentalism' is the answer in light of the numerous 'environmental problems' that have forced their way onto the political agenda over the past few decades. Rather than 'followed and hounded', nature is here to be respected, protected, and saved. As one of the more blunt slogans has it: "No Compromise in the Defense of Mother Earth!" (Earth First). While these views have come to be associated with opposing sides of the political debate over 'nature', they share a commitment to doing something about it and, whether this 'something' is framed in terms of mastery or protection, they generally share a similar view of what 'it', or 'she', is.

On the other hand, the question of nature can concern the meaning of the term itself; the 'itness' of nature, rather than taken-for-granted, can itself be the object of inquiry. Here nature confronts us as an ontological category that distinguishes a particular part of reality from that which is unnatural, or at least not natural. This is the kind of question most often associated with the abstract speculation of philosophers, or at most with a "few prominent and deliberately crazy scholars in science studies" (Haraway 1997, 8); but it is in fact a question that has always been, if only implicitly, central to sociological thought. 
True, much has been made by 'ecologists' of the absence of 'nature' in the sociological canon, but these critiques generally assume a particular meaning of nature that is largely at odds with the presuppositions of the discipline and then interpret the absence of this nature as an absence of nature per se; that is, they simply ignore the question of the meaning of nature and proceed as if the only question worth asking concerned what should be done about 'it'. What they often fail to recognize is that the answer to this political question always presupposes a particular answer to the question concerning the meaning of nature, and that the various traditions in sociological theory simply provide, or at least imply, a different kind of answer to this latter question. ${ }^{1}$

The present work draws on one such tradition, the Marxian, to grasp the significance of biotechnology for the question of nature in this second, more ontological sense. This focus is itself somewhat unusual insofar as those most interested in biotechnology are generally those environmentalists who eschew such ontological questions in favour of the more political question concerning nature. Biotechnology is variously regarded as 'tampering with', 'violating', or 'risking to upset the sacred balance of' nature and the answer to the question concerning what should be done generally takes the form of 'regulating', 'democratizing', or doing away with the technology all together. ${ }^{2}$ The assumption underlying all of these political missions is that 'nature' is ontologically distinct from 'biotechnology' - an object that can be violated by the technology, but one that nevertheless remains independent of it.

The notion that biotechnology, or any technology for that matter, might itself have something to do with the meaning of nature, with what constitutes nature in the first place, is one that is less familiar, not only to environmentalists, but also to those 
ostensibly concerned with more ontological questions concerning nature. For not only does it suggest that the question concerning the meaning of nature is a question worth asking, but that nature, rather than a static category of things, is itself variable, and, even more strange, that this variation has something to do with technology. Of course the substance of both the 'variation' and the 'something' in this claim are as yet unclear, but they will become clearer as the analysis proceeds.

Despite the absence of these more ontological questions, the popular discourse surrounding biotechnology does suggest that there is something decidedly different about biotechnology in its involvement with nature. For molecular biologists Lee Silver "biotechnology - the practical child of molecular biology - gives 'man' nearly-unlimited power as a God-like animator who can alter and create new forms of life" (2006). On the other hand, religious leaders opposed to the technology are "keenly aware of the profound consequences of shifting authorship from God to scientists and transnational companies and are determined to hold the line against any attempt by 'man' to stake his own claim as the prime mover and sovereign architect of life on Earth" (Rifkin 1999, 66). Whether regarded as mastery of a particular form of nature that has to this point remained relatively obdurate, or a final violation of the essence of nature itself, human beings would appear to be on the verge of an epochal shift in their relation to life. And while more sober commentators might silence God in their assessments, they place no less emphasis on the supposed disjuncture marked by biotechnology in the human-nature relation.

Now, while the invocation of the image of God, in particular, amongst proponents and opponents alike is likely to induce skepticism amongst social scientists, it is 
important to take this "rhetoric of the technological sublime" seriously. As Vincent Mosco (2004) points out with regard to information technology, such 'mythology' infuses technological change with meaning and is thus itself constitutive of this change. Where sociologists have tended to emphasize the continuities of biotechnology with technology more generally in their focus on issues of ownership, distribution, and regulation, the 'biotechnological sublime' of Silver and others suggests that there is a deeper disjuncture here. While the substance of this mythology itself is beyond our focus, we will take it seriously as reflective of a disjuncture marked by biotechnology in the meaning of nature. Thus, we arrive at our preliminary research question: how and to what degree does biotechnology constitute a disjuncture in the meaning of nature?

Yet, in posing the question in this way, we run the risk of silencing certain assumptions that should remain available for further interrogation. To this point we have allowed for the meaning of nature to vary, but tended to hold (bio)technology constant as that which explains changes in this meaning. The difficulty here is that the relation will prove more complex than this. As we will see, the meaning of biotechnology cannot be adequately grasped independently of the historical development of the human-nature relation; this is, biotechnology itself requires explanation with regard to nature. And this is to suggest more than that nature and biotechnology exist in a kind of reciprocal relation to one another with changes in one 'feeding back' to cause changes in the other; rather, it is to suggest that the two interpenetrate one another and, moreover, that the unique form of this interpenetration is in fact central to the disjuncture in the meaning of both.

This difficulty is compounded when we come to specify the particular perspective we are going to employ to assess this disjuncture - what we will, rather loosely, refer to 
as a Marxian 'labour process approach'. This is ultimately a misleading description of what will follow, not because the term 'labour process' fails to capture our approach, but because the term 'approach' fails to capture the complex role that the labour process will play in the analysis. A labour process approach has meant two kinds of things in similar contexts and we might use the 'labour process' in one or both of these ways. We might, on the one hand, begin with a theory of the labour process and proceed to analyze the relation between biotechnology and nature from the perspective of 'labour process theory'. On the other hand, we might take the labour process as an empirical site at which to investigate the relation between our two variables and thus locate ourselves in the rich tradition of 'labour process studies'. While these approaches are of course related to one another, one can employ one without the other, as the histories of both reveal. ${ }^{3}$

While the analysis here does indeed employ the labour process in both these senses - as theory and site of investigation - the labour process will also itself be allowed to vary along with nature and biotechnology. That is, rather than taking the meaning of the labour process as concept or site of investigation for granted, this meaning must itself remain a question, the answer to which changes as technology and nature change. As much as a focus on a particular 'labour process' centered on biotechnology will allow us to reveal a disjuncture in the meaning of nature and technology, this disjuncture in turn will reveal a disjuncture in the meaning of the labour process itself.

Thus, the three concepts central to the analysis - nature, biotechnology, and the labour process - rather that merely tools employed to understand the world, are themselves the objects of investigation. At various points one or more will be bracketed as the others are allowed to play off one another and their relationships as 'variables' will 
change depending on the specific claim being pursued. While there is a linear coherence to the argument as a whole, each chapter simultaneously constitutes a different 'cut' at the relation between these concepts as their various interpenetrations reveal the disjuncture in their meaning. Thus, the analysis is foundational insofar as it seeks to use recent developments in biotechnology to destabilize certain of the taken-for-granted assumptions and categories of social thought. As these categories are themselves in a state of flux, the approach must be one appropriate to grasping them as such.

The argument here is abstract, theoretical, and speculative, and unapologetically so on all three counts. On the one hand, it is an argument about ontological categories and their meaning and employs 'empirical' evidence only insofar as it is useful in troubling these categories. Noel Castree (2000) suggests that "debates on the Marx-nature question need...to become more rather than less abstract before they can carefully inform (and learn from) a grass-roots ecoMarxism" (7) and this challenge is taken seriously here in our approach to biotechnology and the meaning of nature. On the other hand, the argument is developed primarily through an engagement with various theoretical perspectives. This reflects more than simply a need to acknowledge the literature in the area; rather, in light of the fact that the argument concerns the role of biotechnology in destabilizing foundational conceptual categories, the inability of extant traditions in social theory to capture its significance in this regard is itself evidence for this claim.

And, while any analysis of biotechnology will tend to be somewhat speculative owing to the nascent development of the technology and fledgling state of the industry, this is particularly true of our analysis owing to our interest in 'living factories' in particular. As we will see, this technology, while certainly 'in use', is still largely in 
various stages of the development process, with relatively few products on the market. This will not pose too much of a difficulty, however, in light of the fact that our interest is in the ontological significance of these technologies rather than in their proliferation. We address the challenges posed to our 'labour process approach' by the uneven development of the technology and industry in chapter 2 .

In the first chapter we begin by bracketing biotechnology and outlining a 'labour process approach' to understanding the significance of technology more generally for the question of nature. Emphasizing the continuity in Marx's writings on the labour process with his conception of the 'first historical act' makes clear the degree to which, rather than something that happens to nature, the labour process is itself a movement and metamorphosis of materials and forces of nature infused with human purpose; the labour process is thus constitutive of nature as such. Moreover, Marx's analysis highlights the importance of machinery in transforming the labour process and the meaning of nature insofar as it harnesses the forces of nature as forces of production and possesses the kind of self-movement that is the unique capacity of 'nature' in pre-industrial modes of production. Thus, our labour process approach is decidedly dialectical insofar as nature, technology, and the labour process are internally related concepts whose meanings change as the labour process itself changes historically.

In the second chapter we bracket our labour process approach and questions of nature in order to conceptualize biotechnology as an 'object of investigation' only to find that it is precisely this bracketing that explains the limitations of extant concepts of 'biotechnology' and 'genetic engineering'. The concept of a transgenic labour process is developed in order to grasp the specificity of recent developments in the 
industrial application of molecular biology, central to which is a unique creation and employment of living nature as itself a technology. Thus, we arrive at a conceptualization of biotechnology, nature, and the labour process that reveals their interpenetration. Grasping the significance of 'biotechnology' for 'nature' requires locating both within the unique labour process that gives them their specific meaning.

In chapter 3 we highlight what is unique about our labour process approach through an engagement with three traditions in contemporary social theory whose concerns come closest to our own. Labour process theory, while concerned with technological change at the point of production, has tended to theorize labour in a way that obscures its materiality as a metamorphosis of human and non-human nature; it has thus tended to neglect more ontological questions concerning the significance of technological change for the meaning of nature. The artifactual constructivist tradition in science and technology studies emphasizes the materiality of the engagement of humans and non-humans, and is thus more sensitive to the ontological significance of (bio)technology, but the relation of this material engagement to the labour process remains unclear. The Marxian strand of environmental sociology goes some distance toward recovering the materiality of the labour process in a way that foregrounds more ontological questions concerning nature, but the role of (bio)technological change in transforming both the labour process and the meaning of nature has received little attention. Thus, the limitations of these perspectives lie precisely in a failure to grasp the interrelation of the labour process, (bio)technology, and nature.

Having developed our conceptual framework and positioned ourselves in relation to other extant perspectives, chapters 4-6 constitute the analytical centerpiece of the 
argument. We step 'inside' the transgenic labour process itself to investigate its disjuncture with past forms of the labour process. Chapter 4 reveals the degree to which the transgenic labour process constitutes an industrial form of the labour process distinct from past uses of life in production by virtue of its repositioning of living nature as an instrument of production. Chapter 5 reveals the disjuncture marked by these living technologies in the degree to which industrial instruments of production approximate a force of nature. And finally, chapter 6 focuses on the relation of living labour to the nonhuman components of the transgenic labour process and suggests that this relation has more in common with agricultural labour processes than with the 'instrumentaltransformative' labour associated with industry. Thus, the analysis of the transgenic labour process ends in a paradox: it is an 'industrial' form of the labour process central to which is a more 'agricultural' form of labour.

In chapter 7 we step back 'outside' the transgenic labour process to resolve this paradox. Marx provides the key to this resolution in his use of the term 'regulation' to distinguish both agricultural and industrial labour from pre-industrial handicraft and his use of biological metaphors to distinguish machinery from hand-tools. The inability of the dominant interpretations of Marx in environmental sociology to account for his argument here points us both back to our own 'labour process approach' developed in chapter 1 , as well as toward identifying the crucial disjuncture marked by biotechnology in the degree to which the labour process constitutes a force of nature infused with human purpose. Thus, the argument comes full-circle, with the disjuncture marked by biotechnology revealing the truth of the labour process approach that allowed us to identify this disjuncture in the first place. 
In the final chapter we introduce the concept of capitalism, having kept it relatively 'bracketed' throughout the analysis of the transgenic labour process. In addition to allowing us to identify the crucial disjuncture marked by biotechnology in the meaning of nature, this bracketing simultaneously allows us to reconceptualize the relation of capitalism to the question of nature and the disjuncture marked by a transgenic labour process in this regard. Thus, the transgenic labour process simultaneously reveals both a disjuncture in the meaning of nature as well as a disjuncture in the meaning of capitalism; or, better, the disjuncture in the meaning of nature marked by a transgenic labour process is a disjuncture in the meaning of capitalism. While the analysis of capitalism here must in the end remain unsatisfactory, leaving us with far more in the way of questions than answers, its value lies in reconceptualizing questions of political economy that makes clear their inherent interrelation with more ontological questions concerning technology and the meaning of nature.

The overarching claim here will seem odd, if not perverse, in light of the widespread public concern over biotechnology central to which is the notion that it is in some sense a violation of nature that should be stopped, or at least highly regulated. Implicit in such a biotechnological politics is the notion that technology is somehow other than nature and that biotechnology therefore constitutes a disjuncture insofar as this 'other' is now threatening to 'de-nature' life itself. However, a shift of perspective - one that emphasizes the role of biotechnology in the labour process understood as a material engagement of human and non-human nature - suggests that this disjuncture is better characterized as revealing the degree to which technology, and the labour process more generally, is a force of nature infused with human purpose, albeit one subordinated to the 
requirements of capital accumulation. Thus, rather than a politics of purity, wherein nature is protected from technology, biotechnology reveals like never before the degree to which the 'liberation of nature' requires a liberation of the forces of production from their form as fixed capital; indeed, it reveals the degree to which the liberation of the forces of production is the liberation of the forces of nature. 


\section{1 -Technology, the Labour Process and the Question of Nature}

In a self-reflective consideration of the ontological foundations of agro-food studies, David Goodman (2001) suggests that a privileging of the 'labour process' amongst Marxists is reflected in a series of 'modern' dualisms and a failure to adequately theorize new agricultural biotechnologies and the "transformations these technologies foreshadow in the relational materialities and socialities of ecologies and bodies" (183). The question of the ontological status of 'nature' looms large in Goodman's critique and he points to a lack of theoretical sophistication in this regard amongst political economists concerned with technological development. He joins a number of others in the Marxian tradition in suggesting the value of the constructivist tradition in contemporary social theory in addressing this and other supposed ontological limitations of the Marxian problematic.

This chapter takes up Goodman's challenge to develop a theoretical perspective on technology that, while sensitive to its development within the political economy of capitalism, refuses to assume a rigid ontological boundary around nature as a foundation of analysis. However the argument moves in a rather different direction than that proposed by Goodman; indeed, rather than decentering the labour process in favour of the actor-networks of constructivism, the labour process, as conceptualized by Marx, is made an indispensable entry point for addressing these more ontological questions concerning nature posed by technological change. While Marx's most systematic theorization of the capitalist labour process appears in Volume 1 of Capital, appreciating its ontological significance requires that we understand its relation to his earlier account of the role of technology in the process through which nature comes to be. We will thus begin where human beings themselves begin, with the first historical act. ${ }^{4}$ 


\section{The 'First Historical Act' and the Origin of Nature}

Despite the relatively widespread acceptance of the claim that capitalism is best understood as a specific set of social relations, it is the forces of production, and technology in particular, that are given primacy in Marx's own analysis of capitalism, and in his account of the movement of history more generally. ${ }^{5}$ For evidence of the importance that he attributed to the study of technology in this regard we need look no further than a footnote to his discussion of machinery in Volume 1 of Capital. “Technology," writes Marx, "reveals the active relation of man to nature, the direct process of the production of his life, and thereby it also lays bare the process of the production of the social relations of his life, and of the mental conceptions that flow from those relations" (1976: 493). Here we catch a glimpse of the centrality of technology to Marx's ontology as a whole, and to the question of nature in particular. Rather than rigidly defined in opposition to one another, humanity and nature are conceived of in an "active relation" to one another; moreover, it is an active relation that is "revealed" by technology itself.

The argument underlying this relatively bare assertion regarding technology and the human-nature relation in Capital is developed most clearly in the German Ideology, in Marx's account of the first historical act, where he takes as his point of departure the seemingly commonsensical premise that human beings "must be in a position to live in order to make history" (1970: 48). From this simple premise he develops an explanation of human history central to which is the productive activity through which human beings make themselves and their history, what he would later call the 'labour process'. The first 'moment' of this activity is the satisfaction of needs: "life involves before everything else 
eating and drinking, a habitation, clothing and many other things. The first historical act is thus the production of the means to satisfy these needs, the production of material life itself" (49). What is most significant here for our purposes is that while human beings are natural beings in the sense that they require a material exchange with the 'rest of nature', their needs are such that they are only satisfied through a purposeful transformation of nature, a transformation that is accomplished through the use of instruments. The relation of human beings to nature is always technologically mediated, then, insofar as without such mediation uniquely human needs would not be satisfied, and a uniquely human history impossible.

Still, while a transformation of nature to meet needs may be a necessary precondition of a specifically human history, it does not by itself explain the movement of this history. That is, it does not explain why human beings do not simply exist in a state of relative equilibrium with the rest of nature, albeit one that is technologically mediated; it may explain a uniquely human existence, but it does not explain a uniquely human history. The solution to this problem lies in Marx's identification of a second moment of the 'first historical act', that of the creation of new needs: "the satisfaction of the first need (the action of satisfying, and the instrument of satisfaction which has been acquired) leads to new needs; and this production of new needs is the first historical act" (49). The satisfaction and creation of needs are two analytically distinct aspects of all human productive activity and it is the dialectical interplay of needs and the production of the means to satisfy them that is the engine driving human history. As technology is central to the satisfaction of human needs, so is it central in determining the shape of new needs and the way in which these new needs will in turn be satisfied. As a primary 
component of all human productive activity technology is thus a crucial determinant of the shape of human history.

Implicit in this notion of the first historical act is a particular ontology of nature. In a word, nature comes to be for human beings through their labour. That there can be a relation between human beings and 'nature' at all implies that humanity has differentiated itself from the rest of nature, a differentiation that occurs through practical life-activity. Only when a unique set of needs emerge that require such activity do the possessors of those needs begin to distinguish themselves from 'nature'. Human beings, suggests Marx, "can be distinguished from animals by consciousness, by religion, or anything else you like. They themselves begin to distinguish themselves from animals as soon as they begin to produce their means of subsistence" (42). With the growth of productive forces and corresponding expansion and differentiation of needs, human beings increasingly come to distinguish themselves as possessors of needs from 'nature' as a set of non-human phenomena with which they must engage to satisfy those needs. Thus, human beings, while always part of nature conceived as an abstract unity, are a unique part insofar as their relation to the whole is mediated through their labour.

The 'question of nature' from this perspective is thus a very different kind of question than that addressed by the various currents of ecological thought. The question can never be reduced to one concerning the effects of humanity on nature, or even one concerning the interaction between humanity and nature; in the end, both of these assume an ontologically distinct nature as a foundation of analysis. However, that there is a 'nature' at all requires explanation, an explanation that of necessity begins with the practical activity through which human beings satisfy their needs because it is through 
this mediating activity that such categories are created in the first place. And as this activity has taken, and continues to take, different forms both geographically and historically, so to will the meaning of nature. ${ }^{6}$ The question of what nature is 'in-itself', or independent of human beings, is meaningless because nature can only ever have meaning for human beings who are always-already in the act of transforming it.

We can also begin to appreciate the ontological importance of technology for Marx. The study of technology can 'reveal' the relation of human beings to nature precisely because it is central to the practical activity through which this relation comes to be. As the primary means by which human beings mediate their relation with their world, technology is in the most literal sense an instrument through which nature is created as such; as technology changes, so to will the form of mediation and the 'active relation' of humanity to nature. Understanding what nature is at any given period in history or within any particular social formation thus requires close attention to the kinds of technology employed by human beings as they satisfy their needs through practical transformative activity. And, conversely, no analysis of technological change would be complete without attention to its significance for the human-nature relation. Questions of technology and nature are thus inseparable, despite the tendency in both the sociology of technology and various forms of ecological thought to treat them as such. ${ }^{7}$

The conclusion to be drawn is clear: if we are to answer our question regarding the significance of biotechnology for the meaning of nature, we must begin by locating the technology within the practical activities through which human beings are transforming nature to meet their needs. Of course to this point our characterization of these practices themselves has remained particularly vague, and this is reflective of the 
lack of specificity in Marx's own earlier writing in this regard. It is in Capital that Marx provides the details of this 'labour process' and the particular form it takes in a capitalist mode of production. Yet it is essential that we keep the 'first historical act' in mind if we are not to lose sight of Marx's ontology in the more 'political economic' analysis of Capital.

\section{The Labour Process as a Metamorphosis of Nature}

Consistent with his methodology throughout Capital, Marx begins, not with a concretespecific form of the labour process, but with the labour process in the abstract. He abstracts what is common to all forms of the labour process in order to get at what is particular to its specific form under capitalism. Marx's definition of the labour process in the abstract is worth quoting at length here as it reveals the continuity of his conception of the labour process with that of 'the first historical act':

Labour is, first of all, a process between man and nature, a process by which man, through his own actions, mediates, regulates, and controls the metabolism between himself and nature. He confronts the materials of nature as a force of nature. He sets in motion the natural forces which belong to his own body, his arms, legs, head and hands, in order to appropriate the materials of nature in a form adapted to his own needs. Through this movement he acts upon external nature and changes it, and in this way he simultaneously changes his own nature. He develops the potentialities slumbering within nature, and subjects the play of its forces to his own sovereign power. (283)

Here we have three important insights from the discussion of the 'first historical act'. First, human beings, rather than having their needs satisfied immediately, must "appropriate the materials of nature in a form adapted to [their] own needs." Second, this appropriation takes the form of practical activity, or 'labour', "a process by which man, 
through his own actions, mediates, regulates, and controls the metabolism between himself and nature." And finally, this mediation constitutes a dynamic relation between human beings and nature: "through this movement [they] act upon external nature and change it, and in this way [they] simultaneously change [their] own nature." Despite the shift of focus to the laws of motion of capitalism, there is thus an underlying continuity in Marx's ontology.

At the same time, however, there is here a much more complex understanding of nature and the process through which it is transformed than was present in the German Ideology. Where nature tended to be taken for granted in the earlier work as the relatively passive object transformed by human beings, here nature is conceived as a "force" with which human beings engage in order to develop its "potentialities". This subtle shift in emphasis avoids both what are often read as 'anthropocentric' tendencies in Marx's earlier work, as well as the ecological tendency to assume an ontologically distinct nature standing opposed to human beings. As a "force" with certain "potentialities" nature ceases to be a passive, infinitely malleable material in which humanity realizes itself. Adapting the materials of nature to human needs requires uncovering and developing these "potentialities slumbering within nature", which implies that there are always material 'limits' to this transformation. On the other hand, nature is conceived meaningfully as a 'force' only when considered in relation to human beings' engagement with it; thus, the 'limits' to the transformation of the forces of nature are only ever immanent in the process of transformation itself. Just as potentialities are only ever realized in this process of transformation so to are the limits to this transformation, limits that are in turn only meaningful insofar as they are potentially transcended. 
Marx's method of abstraction in Capital also enables him to identify in a much more systematic way the components of the labour process. There are three components common to all forms of the labour process. The first is "purposeful activity, that is work itself". The second is the "object on which that work is performed"; these can be "spontaneously provided by nature," but are increasingly "raw materials" that have been "filtered through previous labour" (284). The third component of the labour process identified by Marx is technology, or what he more commonly refers to as the "instruments of that work" or the "instruments of production". He defines an instrument of production as "a thing, or a complex of things, which the worker interposes between himself and the object of his labour and which serves as a conductor, directing his activity onto that object" (285). These non-human components, the object and instrument, are considered collectively as "means of production" as they are the means through which purposeful human labour becomes objectified in a product that meets human needs.

What is most important here for our purposes is that all of these components can be conceived of as materials and/or forces of nature. This is perhaps clearest in the case of the 'object of labour', or raw material, but it is no less true of technology and labour itself. In the case of technology the following passage is instructive:

Leaving out of consideration such ready-made means of subsistence as fruits, in gathering which a man's bodily organs alone serve as instruments of labour, the object the worker directly takes possession of is not the object of labour but its instrument. Thus nature becomes one of the organs of his activity, which he annexes to his own bodily organs... (285, emphasis added)

Human beings do not transform nature immediately, but only through harnessing and employing one form of nature, technology, as a "conductor, directing [their] activity" 
onto another form of nature, the object of labour. And this activity is itself a force of nature as human beings "set in motion the natural forces which belong to [their] own bodies, [their] arms, legs, head and hands..." (285, emphasis added). In short, the labour process, rather than a 'socio-technical' process through which human beings transform 'nature' can be, at this level of abstraction, conceived of as itself a metamorphosis of human and non-human materials and forces of nature, or what David Harvey calls a "form giving fire in which some natural processes work on others in order to produce things" (1995).

But there is a difficulty here: if the labour process is itself a metamorphosis of forces and materials of nature, how is this distinct from the 'nature' that is confronted by human beings as a "force" whose "potentialities lie slumbering" and must be developed? Alfred Schmidt's solution to this problem will suffice for the time being. As Schmidt points out, Marx tends to use 'nature' in two senses, as the underlying substance of everything that is, and as that which is not (yet?) subsumed within the labour process in a form adapted to human needs. Thus, while the labour process is indeed a metamorphosis of materials and forces of nature, it is a self-conscious transformation insofar as it is infused with human purpose and directed to the satisfaction of some determinate set of human needs; this contrasts with nature as such, whose metamorphoses are not selfconscious. And again, there is no question of the 'independence' of nature in this second sense for the notion of 'potentiality' is of course only meaningful in relation to that which might make it actual and this process of actualization is the labour process itself.

Moreover, this distinction between the labour process and nature as such is an historical one, rather than one that is ontologically rigid. There was, prior to the 
specifically human labour process, no distinction at all; rather, there 'was' only nature in its immediacy. It is the labour process itself, the mediation of human and non-human materials and forces through technology, that makes the concept of 'nature' meaningful as a field of potentialities distinct from its 'actualization' in the labour process. And the labour process is just this process of actualization insofar as it harnesses the materials and forces of nature to human needs, thereby infusing their movement with conscious purpose. In short, history is a process of subsuming that which is confronted as 'nature' within the movement of the labour process.

We can begin to see clearly now the degree to which this conceptualization of the labour process leads us to a very different approach to the question of nature than we are used to. There is a tendency amongst Marxists and non-Marxists alike to view the labour process as a kind of socio-technical mechanism where 'nature' enters one end as 'raw material' and comes out the other end as a product, but which remains essentially other than the labour process in this movement. In contrast to this view, we have here emphasized the degree to which, rather than a technical transformation of nature as other, the labour process is best understood as itself a metamorphosis of nature, the movement of materials and forces of nature harnessed to the satisfaction of human needs.

Thus, even at this level of abstraction, or perhaps especially at this level of abstraction, Goodman's argument regarding the ontological limitations of a focus on the labour process would appear to be off the mark. Indeed, it would seem that a labour process approach not only avoids 'modern' dualistic thinking with regard to the question of nature, but can provide just the kind of ontological sophistication he suggests is necessary for understanding the significance of new biotechnologies as shifts in the 
labour process, rather than distinct from 'nature', are themselves shifts in the human and non-human materials and forces of nature. However, as Goodman is no simple 'constructivist, but a political economist concerned with the specificity of biotechnology as an instrument of production in a capitalist mode of production, we must turn, with Marx, to a conceptualization of the labour process in its specifically capitalist form in order to make the value of our perspective clear.

\section{Capitalism and the Labour Process}

The capitalist mode of production is one in which the private accumulation of capital serves as the primary motivation for the production of commodities, products produced not merely for their use-value, but primarily for the exchange-value they yield when sold on the market. Capital is wealth whose purpose, rather than merely mediating the exchange of commodities, is to generate more of itself through a process of valorization; thus, capital can be understood as self-expanding value and capitalism as a system of production animated by the movement of capital through this process of self-expansion.

Now, in order for the valorization process to occur, it is clear that more value must be generated in production than is required for production to take place, and so capitalist production is always production for profit, profit that can in turn be accumulated as capital and reinvested in production so that it may itself be valorized, and so on. While neither the production of commodities nor the accumulation of capital are themselves unique to the capitalist mode of production, it is only with the ascendancy of capitalism that the accumulation process comes to be the primary animating principle of commodity production, and that in turn the production of commodities becomes the 
primary means through which the accumulation of capital takes place. Capitalism is thus a system of production in which the requirements of capital accumulation come to determine the shape of the production process, both what is produced and how it is produced. Of course like any mode of production capitalism produces use-values that satisfy determinate human needs, but it does so only insofar as these can be satisfied profitably; it is a system of commodity production in which the satisfaction of human needs is mediated by the requirements of capital accumulation.

That capital's self-expansion, rather than taking place in the realm of exchange, requires that it animate the production of commodities, implies that it is within the labour process itself that the value of the capital advanced is augmented, that a surplus-value is produced. Assuming that the components of the labour process (labour, instruments, raw materials) are all purchased at their value, the only way in which a surplus-value can be produced in production is if there is a commodity whose exchange-value is less than the value it contributes to the final product, that is, a commodity whose use-value is to create more value than is required for its reproduction. The only factor that possesses this unique quality is living labour, whose exchange-value as labour-power, expressed as wages, is less than the value in commodities it can create as active, concrete labour at the point of production. Capitalist commodity production thus rests on the application of living labour in production and, indeed, the exploitation of that labour insofar as the creation of surplus-value requires that labour be applied for longer than is required to create the value equivalent to the means of subsistence necessary for its own reproduction. 
But of course capital does not simply seek to expand itself, but to do so at the highest rate possible. The incessant drive to increase the rate of capital accumulation, rather than merely the mass of capital, explains the inherent tendency in a capitalist mode of production toward a reduction in the time required for labour to reproduce itself (necessary labour time) relative to the time during which labour is 'free' to produce surplus-value (surplus labour time). While an absolute surplus can be created through an extension of the working day, or intensification of work, toward the physical limitations of living labour - leaving the form of the labour process relatively intact - increasing the rate of relative surplus-value requires that capital transform the labour process itself so as to increase the productivity of labour (in the consumer goods sector), thus decreasing the necessary labour time during which living labour must work to produce value equal to the cost of reproducing its labour power. A capitalist mode of production is thus increasingly characterized by a real, as opposed to a merely formal, subsumption of the labour process within the circuit of capital; and capital becomes truly self-expanding only to the degree that such a real subsumption is achieved. It is thus only when the labour process is subordinated to the movement of capital - when it becomes merely a moment in capital's self-expansion - that capitalism, as an historically specific mode of production structured by the requirements of private capital accumulation, comes into its own.

What most distinguishes capitalism from previous modes of production then rather than a mere quantitative increase in commodity production, capital, or wage-labour - is a qualitatively distinct form of the labour process, one subsumed within the circuit of capital and subordinated to the requirements of capital accumulation. The simplest form of a capitalist labour process is one whose transformation by capital takes the form of 
refinements of the technical division of labour. While a social division of labour between producers of commodities is of course not unique to capitalism, a technical division of labour between producers of a single commodity becomes a significant structuring principle of production only in a system of capitalist manufacture under the compulsion experienced by individual capitalists as the need to compete - to improve the 'efficiency' of the labour process, cheapen the commodities produced, and increase profits. Eventually, however, the labour process takes a form more appropriate to capital's selfexpansion, a form whose transformation takes as its point of departure not the organization of labour, but the instruments of production themselves - thus the importance that Marx attributes to the coming of the machine.

The importance that Marx attributed to labour process transformations in the development of capitalism is evidenced by his discussion of machinery in both the Grundrisse and Volume 1 of Capital, discussions that are unsurpassed in both their analytical power and prescience. The coming of the machine, "a mechanism that, after being set in motion, performs with its tools the same operations as the worker formally did with similar tools," (495) marks a turning point in the development of capital insofar as its subsequent self-expansion increasingly comes to rest not on a transformation of living labour, its antithesis, but on a transformation of itself in 'fixed' form. The emergence of large-scale industrial production based on systems of machinery thus ushers in a period of relatively continuous technological change to satisfy human needs increasingly mediated by the requirements of capital accumulation.

The incorporation of instruments of production into an automatic system of machinery forever transforms the active relation between living labour and the other 
components of the labour process. Prior to the coming of the machine labour takes the form of 'handicraft' where the instruments of production are primarily hand-tools that serve to transmit living labour, limited for the most part to the mental and physical capacities of individuals, onto a raw material. Even in a system of manufacture, characterized as it was by an increasingly complex technical division of labour, the instruments of production remained hand-tools as productivity increases were achieved primarily through a transformation of the organization of labour. Prior to the machine and large-scale industry, living labour serves as the active, animating principle of the metamorphosis of nature that is the labour process, the guiding force of a transformation of nature to meet human needs.

With the machine, however, the instrument of production itself, now animated by the self-expansion of capital, guides this transformative process, labour being merely a "living accessory of this machinery" (1973: 693). As self-acting fixed capital, technology ceases to be merely a tool interposed between living labour and a raw material, and emerges as a force of production proper, that itself employs living labour in working up a raw material into a finished product. The technical division of labour, whose refinement was itself the starting point of labour process transformation in a system of manufacture, now has its structuring principle in the movement of the machine and is transformed 'objectively' to meet the requirements of the system. Living labour, while always a necessary component of capitalist commodity production, ceases to be the active 'subject' of the labour process employing a tool in the transformation of an 'object', and is instead relegated to monitoring and regulating the movement of self-acting machinery, a material embodiment of capital's self-expansion. Industrial capitalism thus witnesses 
the ascendancy of the 'general labourer' who, objectified in the form of machinery, harnesses the forces of nature to the satisfaction of human needs in a historically unique way and to an unprecedented degree.

That the system of machinery itself, fixed capital, can become the 'subject' and animating force of the labour process implies a fundamental transformation of the role of knowledge in the labour process, and, in particular, knowledge of the forces of nature. All forms of the labour process of course imply some knowledge of the forces of nature. Prior to the machine and large-scale industry, however, this knowledge arose relatively unsystematically within the process itself and was derived, for the most part, from the experiences of living labour. While there have no doubt always been advances in practical knowledge throughout human history, these have come relatively slowly and in a piecemeal fashion, and been accumulated primarily through tradition. Prior to the formal subsumption of the labour process under capital, there was little compulsion to transform the instruments of production, and there was certainly none amongst the direct producers, still in possession of these instruments to some degree, to increase the surplus product handed over to the appropriating classes.

However, once the instruments of production themselves form the starting point for labour process transformation under the compulsion to increase the productivity of labour there is a flourishing of systematic enquiries into the forces of nature and how they might be transformed into forces of production. The power of the forces of production as machinery, their unprecedented potential for increasing the productivity of labour, and their infinite capacity for improvement encourage the investigation and harnessing of the physical, chemical, and biological properties of nature to production like never before. 
And as it is the instruments of labour themselves that come to embody these forces of nature, knowledge of them can be produced, accumulated, and stored independently of living labour and applied 'objectively' in production. The production of knowledge, mental labour, becomes distinct like never before from the employment of that knowledge in production, manual labour. Knowledge and skill increasingly come to reside in the instruments themselves and living labour is directed, not by a selfconsciousness that is its own, but by a 'general intellect' that it confronts as a material force through the movement of an automatic system of machinery. Thus, with the development of the forces of nature as forces of production living labour, in both body and mind, is transformed.

\section{Large-Scale Industry and the Nature of Technology}

And what is the significance of large-scale industrial labour processes centered on machinery for the meaning of nature? As we have seen, this significance cannot lie in a violation of nature, or even particular kind of interaction with nature; both fail to capture the degree to which the labour process is nature adapted to human needs. The interpretation of Marx offered thus far leads to a radically different set of propositions regarding the significance of large-scale industry for the meaning of nature. These propositions will of necessity be somewhat speculative at this point and will find empirical grounding in the concrete analysis of biotechnology in later chapters. Indeed, it is a central claim of the thesis that what Marx saw in a relatively abstract way with the coming of the machine in this regard is in fact more recognizable with the mobilization of living nature as a productive force. 
To start, we can distinguish between two forms in which non-human nature is appropriated as part of the labour process and the form of appropriation required for each. On the one hand, nature can be regarded as the 'material' of the labour process, that of which the instrument and object of labour are made, and whose metamorphosis into a product can serve either as means of consumption or means of production in subsequent labour processes. The usefulness of these materials of nature lies in their capacity to be transformed into products that meet human needs. On the other hand, Marx often conceives of nature as a set of 'forces' that are not so much transformed in the labour process as much as harnessed and redeployed as a force of production. Water wheels and windmills, for example, do not effect a transformation of water and wind, as much as they harness and redeploy them as forces of production. Of course forces of nature are often harnessed and redeployed through the transformation of materials of nature - one thinks of the burning of wood or coal to fuel machinery or splitting the atom to harness the nuclear forces - but it is not the transformation of the material per se that is of significance as much as it is the force that is released and redeployed through this transformation.

Now, while all labour processes, in some sense, appropriate non-human nature as both material and force - indeed all of nature is simultaneously both - this conceptual distinction is useful in identifying a crucial difference between handicraft and industry in terms of the involvement of nature in each. Labour processes centered on handicraft work up the materials of nature into useful products, some of which are consumed and some of which enter into subsequent labour processes as means of production. Hand tools indeed transmit a force of nature onto the object of labour, but it is primarily a human force that 
is, and can certainly be conceived of as, 'other than' the natural materials employed as means of production.

This contrasts sharply with a labour process centered on machinery. Of course machines are also made of natural materials, but their unique productive force, rather than lying in characteristics of these materials per se, lies in their harnessing and redeployment of the physical and chemical forces of non-human nature. A machine is able to "perform with its tools the same operations as the worker formally did with similar tools," precisely because it harnesses physical (e.g. air and water pressure, gravity) and chemical (e.g. coal burned as fuel) forces of nature as a force of production. Environmental sociologist Raymond Murphy, in a sympathetic critique of Weber's suggestion that a machine is 'mind objectified', makes just this point, although without reference to Marx. "Both Weber and contemporary sociology," writes Murphy, "have deflected attention away from an important point: machines consist of the redeployment of the forces and materials of nature and hence embody those forces and materials" (2002: 80). While we will return to Murphy's argument in more detail later, we can begin to see the degree to which large-scale industry is unique in the degree to which it centers on the transformation of the materials of nature in such a way that they harness the forces of nature as forces of production. And this would explain Marx's emphasis on the unique “[s]ubjection of Nature's forces to man" $(1967,85)$ under industrial capitalism - labour processes centered on machinery mark a qualitative disjuncture in the degree to which the forces of nature are harnessed as forces of production.

Now, where this particular shift in the meaning of nature from material to force is relatively straightforward, the second is decidedly less so. In the Grundrisse Marx adds 
another layer of ontological complexity to our understanding of nature. He suggests that, with the development of large-scale industrial labour processes and their harnessing of the forces of nature as forces of production, "no longer does the worker insert a modified natural thing as middle link between the object and himself; rather, he inserts the process of nature, transformed into an industrial process, as a means between himself and inorganic nature, mastering it. He steps to this side of the production process instead of being its chief actor" $(1973,705)$. Now, on the one hand, the argument here is plain enough in its consistency with the conception of the labour process we have explicated above. We have seen that technology, rather than something independent of nature, is in fact a natural material adapted to human needs. And, we have also seen that industrial labour processes witness a shift in the role of living labour to that of regulation and monitoring. Yet, Marx appears to be making a distinction here between industrial and pre-industrial labour processes with regard to the meaning of nature that we have yet to consider. He suggests that where pre-industrial instruments are 'modified natural things', industrial instruments are a 'process of nature'; moreover, it is precisely to this difference in the 'nature' of technology that he attributes the shift of labour 'to the side' of the production process. Thus, it is not merely that the forces of nature are harnessed in a new way, but that technology itself, and the labour process as a whole, is transformed in the process, becoming 'natural' in a unique way.

Making sense of this distinction between pre-industrial and industrial labour processes requires that we recognize Marx's debt to Aristotle's conception of nature. ${ }^{8}$ While everything that is can be said to be 'natural' in the abstract, Aristotle saw that in order to be meaningful, the concept of 'nature' must denote a set of things, or some 
characteristic of things, that is other than that which is 'artificial', or produced by human beings. Now, what is unique to Aristotle is not so much his desire to make such a distinction, but that he defines nature positively, that is, not in terms of what it lacks transformation by human hands - but by what it possesses.

Among beings, some are formed by nature, some by other causes. Among those formed by nature, we may name animals and their parts, plants, and the simple bodies (earth, fire, air, and water); all of these, together with beings like them, we call 'formed by nature.' Observation discloses how they differ from things not constituted by nature: each of them has within itself a beginning of movement and rest, whether the movement [or specific type of behaviour] is a local motion, growth or decline, or a qualitative change. $(1961,23)$

Thus he defines 'nature' as that which has in-itself a principle of motion and distinguishes this from 'artifice' which, as a product of human hands, does not in-itself possess any such principle. Of course artifice is also in-motion, as it too 'moves' through a process of decay, but here it is the 'natural material' that is in motion, not the artifice per se. Aristotle uses the examples of beds and clothes which, while moving through a process of decay by virtue of being composed of natural materials, do not, as beds and clothes, move in any meaningful sense. A better example, for our purposes, would be the looms that he discusses in the Politics, whose movement as looms is provided externally by the human spinner.

This distinction between 'artifice' and 'nature' can help us understand Marx's identification of handicraft with 'modified natural things inserted between the worker and the object'. Pre-industrial hand-tools are artificial; they are materials of nature modified by human hands whose principle of motion, as tools, lies external to them in the body and mind of the worker. Pre-industrial technology is thus distinct from nature as such, which 
has its principle of motion 'in-itself'. The productive force of a hand-tool lies, in this sense, lies in its capacity to be moved by living labour in such a way as to transmit the skills of the worker onto the object, which is itself a natural material more or less modified by, or 'filtered through', previous labour. And in making this distinction between 'artifice' and 'nature' we are consistent with our conceptualization of instruments of production in our discussion of the labour process in the abstract: natural materials adapted to human needs.

But what do we make of this distinction in the case of industrial labour processes centered on machinery? Clearly machinery is composed of natural materials like any other instrument of production and in this sense marks only a quantitative increase in the amount of material required and the size of the instruments. Yet, Marx wants to suggest more than this, that machinery is 'natural' in a way that is qualitatively distinct from hand-tools, that it is a natural process rather than merely a modified natural thing. What appears paradoxical at first glance becomes less so in light of the nature/technology distinction discussed above, central to which is the self-movement of the former in contrast to the externally provided movment of the latter.

Now, Aristotle never takes the idea of self-moving products of art seriously and his distinction between artifice and nature is an ontologically rigid one; after all, it is the absurdity of 'self-spinning looms' that provides the central justification for slavery in the Politics. However, this distinction becomes decidedly destabilized with the ascendance of large-scale industrial labour processes. As we have seen in our discussion of the labour process and capitalism, there is an important sense in which machinery is self-acting in a way that hand-tools are not; indeed, this is central to the very meaning of machinery 
insofar as, again, it is a mechanism that "performs with its tools the same operations as the worker formally did with similar tools." While they must of course be 'set in motion' and thus only ever approximate 'nature' in this regard, there is an important sense in which, with the coming of the machine, artifice moves in a way that hand-tools, which must be continuously moved by human hand, do not.

In a word, with the coming of the machine the instruments of production themselves come to approximate a force of nature insofar as they possess that capacity for self-movement previously unique to 'nature' as distinct from 'artifice'. And it is in this sense that Marx suggests that, rather than merely 'modified natural things' standing between human beings and an object, industrial technologies are themselves a force of nature, a natural process transformed into an industrial process. They are 'natural', not simply in the sense that they are composed of natural materials, but in the sense that they possess a principle of motion as technologies that is absent in pre-industrial instruments. As this point will prove central to the analysis of biotechnology that follows, we need to make it clearer and we can do so through specifying 3 unique characteristics of machine systems.

The first and perhaps most obvious sense in which machine systems come to approximate a force of nature lies in their unique activity. Where hand-tools are passive and require human labour to animate them machines are active in a way that was previously the unique capacity of nature. Moreover, the historical development of machinery delineated by Marx is one where this activity becomes increasingly 'natural'. The first machines, while doing with their tools what workers formerly did with theirs, still depended largely on human being for their 'motive force'. Hence the significance 
that Marx attributes to the construction of prime movers (e.g. steam engines) lies precisely in their capacity to replace an external principle of motion with one internal to the machine itself. However, it is only with the linking of machines with transmission mechanisms into a 'machine system' that the instruments of production really take on a 'life' of their own. "Here we have, in place of the isolated machine," writes Marx, A mechanical monster whose body fills whole factories, and whose demonic power, at first hidden by the slow and measured motions of its gigantic members, finally bursts forth in the fast and feverish whirl of its countless working organs. $(1976,503)$

And while there has been much attention paid to the significance of this 'automation' for the process of value-creation, we have here identified its crucial significance for the meaning of nature as technology comes increasingly to possess the kind of activity characteristic of a force of nature.

The second sense in which machinery approximates a force of nature, thus destabilizing the nature/artifice distinction, lies in its unique relation to the raw material. We have seen that handicraft is characterized by tools that transmit the force of living labour onto a raw material; technology here mediates the relation between a subject and object that are relatively external to it and transmits a human force of nature onto a nonhuman material of nature. And, as we have seen, insofar as the mediating force of handtools is provided by living labour, it is distinct from nature as such. However, in the case of machinery the materials of nature, in addition to being transformed into a product, also serve as fuel, whose transformation harnesses the physical and chemical forces of nature as forces of production. Thus we have an important sense in which machinery is selfmediating; that is, it transforms natural materials as a requirement of its own activity, 
materials that are not 'external' to the machine, but transformed into energy as part of the movement of the machine as such. The machine, writes Marx, "is itself the virtuoso, with a soul of its own in the mechanical laws acting through it; and it consumes coal, oil, etc., just as the worker consumes food, to keep up its perpetual motion" $(1973,693)$. Thus, the self-movement of machinery presupposes that it consume materials of nature and, as such self-mediation was previously an exclusive capacity of nature as distinct from artifice, this is another dimension of industrial technology's approximation of a force of nature.

And finally, not only is machinery self-acting and self-mediating in a way that only 'nature' had been previously, but there is an important sense in which machine systems are self-reproducing. "Modern Industry," writes Marx, "had...to take in hand the machine, its characteristics instrument of production, and to construct machines by machines. It was not till it did this, that it built up for itself a fitting technical foundation, and stood on its own feet" (qtd. in Rosenberg 1981, 19). While, Nathan Rosenberg has pointed to the importance of machine making machines to the self-expansion of capital, we can also point to the significance of this shift for the degree to which technology approximates a force of nature. While the creation of any technology is at the same time the creation of the means for the production of more technologies, there is little sense in which hand-tools reproduce themselves. And insofar as the production of machinery first relied on handicraft techniques and tools, industry lacked this capacity also. However, once machinery, as a function of its self-activity, possesses the capacity for the production of more machinery, there is an unprecedented sense in which the instruments of production become self-reproducing. And again, insofar as such self-reproduction had previously been excluded from 'artifice' and been the unique characteristic of 'nature', 
large-scale industry marks a qualitative disjuncture in the degree to which industrial technology comes to increasingly approximate a force of nature, particularly when we understand this capacity in combination with those for movement and mediation. And what of the relation of living labour to these instruments qua forces of nature? As we have seen, the advent and development of machinery witnesses a decentering of living labour from the position of active subject of the labour process to a "living appendage" of the machine system. Workers, rather than the primary force of production animating hand-tools, become an 'objective' part of the labour process whose role and division is specified by the movement and refinement of the instruments of production themselves. Now, in light of our discussion of the meaning of nature here, we can see that this decentering of labour constitutes a shift in the relation of human and non-human nature. In a pre-industrial labour process living labour relates as subject to the materials of nature as object. Human and non-human nature stand, as it were, on opposite sides of the hand-tool - a mere modified natural thing - that transmits the purposeful activity of the former onto the latter. In an industrial labour process, on the other hand, the forces of nature are harnessed as forces of production and the instruments of production themselves come to approximate a force of nature. Thus, industrial labour, insofar as it monitors and regulates self-acting machine systems, becomes subsumed as an objective component of a labour process whose movement as a whole - as a metamorphosis of human and non-human materials and forces of nature - increasingly comes to approximate a force of nature.

Yet, there is a problem here in our conception of the labour process as a force of nature and the role of labour. On the one hand, we have seen in our discussion of the 
labour process in the abstract that, while all of the components of the labour process are 'natural', the labour process is distinct from nature as such insofar as it harnesses the materials and forces of nature to the satisfaction of human needs and thus constitutes a conscious metamorphosis of nature. On the other hand, we have just argued that central to the unique productive force of an industrial labour process is its approximation of a force of nature, implicit in which is the subsumption of labour as an objective component of the labour process whose role and division is specified by the movement of the instruments themselves. Thus we seem to be presented with a contradiction: the unique productive force of an industrial labour process is premised upon the elimination of the very 'consciousness' that we used to distinguish the labour process from the process of nature in the first place.

But this difficulty is resolved when we keep in mind Marx's concepts of 'social individual' and 'social intellect'. The development of industrial productive forces witnesses the relegation of living labour 'to the side' of the labour process, thus repositioning it as a force of nature whose role and division is determined by the movement of the labour process more generally. And this 'naturalization' of living labour, which is at the same time its 'objectification', is premised upon the shift of the conscious purpose, or subjectivity, of the labour process from living labour to the "social individual' in the form of the 'social intellect'. And by social intellect Marx means the capacity of 'humanity', largely through science, to harness the forces and materials of nature to the satisfaction of their needs, thus infusing these materials and forces with conscious purpose. Now, what is important here is that the unique productive force of industry, its approximation of a force of nature, implies the alienation of its conscious 
purpose from labour. Thus, to the degree that the labour process constitutes a force of nature infused with conscious purpose is the degree to which this purpose is that of 'humanity' conceived in abstraction from the living labour that is subsumed as a moment in this self-conscious movement of nature.

We can now see connection between Marx's 'mature' work on machinery and large-scale industry with his early writings on nature in the Paris Manuscripts, writings that are too often rejected, or embraced, because of a perceived 'romanticism' or 'humanism' that lacks the scientific rigour of the later 'political economic' works. Central to Marx's argument regarding nature here is the notion that history moves toward a resolution of the conflict between nature and humanity. Making explicit theoretical links between communism and the question of nature, he writes:

The natural existence of man has here become his human existence and nature itself has become human for him. Thus [communist] society is the accomplished union of man with nature, the veritable resurrection of nature, the realized naturalism of man and the realized humanism of nature (1963: 157).

Moreover, this resolution is, rather than an accomplishment of mind, or even of 'social transformation' in-itself, an historical-material realization: "the essence of man and of nature, man as a natural being and nature as a human reality...become evident in practical life"(166). The potential of industrial labour processes to engender such a realization could not be more profound for it is here that the 'humanization of nature' and 'naturalization of humanity' is accomplished; it is a 'union' of human and non-humans that moves as a force of nature infused with human purpose.

Now, there is a final puzzle here that must be addressed. If large-scale industrial labour processes constitute a force of nature infused with human purpose, and this 
humanization of nature is the mechanism by which the unity of human beings and nature is realized as a mediated-unity, then why the emphasis on communism as the resolution of the conflict between humanity and nature. The answer lies in recognizing that industrial labour processes are moments in the self-expansion of capital; they are thus not harnessed to the satisfaction of human needs in the abstract, but a determinate set of needs that are mediated by the requirement of capital accumulation. While it is true that the forces of nature increasingly come to confront human beings as forces of production harnessed to the satisfaction of human needs, they do so as capital, private property that stands in opposition to the living labour that is its anti-thesis. This is the key to understanding how Marx can make the paradoxical claim that the humanization of nature in industry is simultaneously the ultimate alienation from nature. Human beings come to know their unity with nature in a form that stands in opposition to them, as an achievement not of their self-conscious practical activity for-itself, but of this activity mediated by the requirements of capital accumulation.

This is a very different conception of 'alienation' than that embraced by various currents of ecological thought, and was central to Marx's own critique of romanticism. Human beings, for Marx, are not alienated from nature per se, but from nature infused with human purpose, a labour process that is itself an historical-material achievement of their labour; thus for Marx alienation from nature is simultaneously humanity's species alienation. Capitalist industry has paved the way for the resolution of the conflict between human beings and nature; however, the transcendence of the alienation from nature, the realization of the labour process as a force of nature harnessed to human needs 
unmediated by the requirements of capital accumulation, would require a transcendence of its existence in an alien form as capital.

We can now see clearly the degree to which the politics of technology and the politics of nature are inextricably linked. Moreover, we see that the goal of political struggle can never meaningfully be about defending 'nature' from technology; it can only ever be about liberating the forces of nature, as forces of production, from their estranged form. Thus, not only are technological and ecological politics linked, but they are inherently a politics of the most radical kind for it is only through the transcendence of capital that the unity of nature might be realized as an achievement of human beings and the forces of nature harnessed to the satisfaction of human needs unmediated by the requirements of capital accumulation.

Now, such a radical technological politics at this point remains rather vague, and this is reflective of the level of abstraction at which our labour process approach has to this point been pitched. Developing a politics of any specific technology requires attention to the concrete specific form of the labour process in which that technology is implicated. Only then can its significance for the human-nature relation be determined and meaningful political strategies developed. We must turn now to conceptualize biotechnology in a way that makes sense in light of the labour process perspective outlined here. 


\section{2 - Conceptualizing Living Technologies}

Despite a profusion of recent scholarly work ostensibly concerned with 'biotechnology', there is currently very little clarity regarding the meaning of the term; moreover, there is seldom any recognition that differing conceptualizations of recent developments in the industrial application of molecular biology are often at the root of divergent estimations of their significance. Use of the term 'biotechnology' by industry associations, for example, tends to highlight the continuities of recent developments with past innovations in agriculture. ${ }^{9}$ Since human beings have been 'biotechnological' in a broad sense at least since the Neolithic revolution, so the argument goes, there is nothing terribly new about 'new biotechnology' as an instrument of production. On the other hand, use of the term 'genetic engineering' by critics emphasizes the discontinuity marked by recombinant DNA techniques and their unique risks. ${ }^{10}$ The difficulty here is that 'biotechnology' and 'genetic engineering' have distinct meanings and little analytical attention is given to determining their relation to one another. ${ }^{11}$

The purpose of this chapter is to conceptualize biotechnology in a way that will prepare it for analysis with the labour process approach outlined in the previous chapter. In the first section I evaluate the concept of biotechnology and conclude that, while useful in distinguishing living from non-living instruments of production, it fails to capture what is surely unique about the living instruments created through techniques of recombinant DNA; namely, that they are transformed at the molecular genetic level in order to produce proteins that would otherwise be foreign to their species. In the second section I evaluate the concept of genetic engineering and conclude that, while effectively distinguishing the process through which these 'transgenic' organisms are produced, it 
obscures the role that these organisms actually play as instruments in the production of recombinant proteins. In the third section I propose the concept of transgenic labour process as an alternative to biotechnology and genetic engineering. I argue that a focus on a labour process centered around the creation and employment of transgenic organisms as instruments of production overcomes the limitations of both biotechnology and genetic engineering, while at the same time revealing their significance for the meaning of nature in a new way.

\section{Biotechnology}

While difficulties in defining biotechnology are widely acknowledged, the notion that it is distinct from other technologies in its involvement of life in the production process is common to most 'official' definitions. The Canadian Biotechnology Strategy (1998) defines biotechnology as "an umbrella term covering a broad spectrum of scientific applications used in many sectors. It involves the use of living organisms, or parts of living organisms, to provide new methods of production, make new products and find new ways to improve our quality of life" (2). A similar, but more concise definition is provided by the OECD: "the application of biological organisms, systems and processes to the production of goods and services" $(1998,15)$. These definitions are useful in distinguishing biotechnology from, on the one hand, those technologies not concerned with 'life' and, on the other, those recent developments in the biological sciences not directly concerned with production. 
However, when we turn to compare biotechnology with other kinds of technology, information technology for example, these definitions pose an immediate obstacle. The OECD defines information technology as follows:

technologies used in the collection, processing and transmission of information. It includes micro-electronic and opto-electronic based technologies incorporated in many products and processes and increasingly affecting the service sector. It covers, inter alia, computers, electronic office equipment, telecommunications, industrial robots and computer controlled machines, electronic components and software products. (1987)

Now, whatever the subtle adjustments that might be made to this fairly standard definition, its incommensurability with official definitions of biotechnology is clear. Where information technology is generally taken to refer, at the very least, to a set of tangible objects, biotechnology appears much more elusive, referring to the 'application of life' rather than to a specific set of things. This creates an immediate difficulty when it comes to comparing biotechnology with information technology, a comparison, ironically, that those employing this definition of biotechnology are often interested in drawing. While analyses of information technology have benefited from a focus on a relatively bounded, empirical object, biotechnology lacks any such specificity and those who deem biotechnology to be the successor to information technology are generally relying on analogy rather than any serious analytical comparison.

The need for greater specificity in defining biotechnology is all the more pressing in light of our labour process approach and the conception of technology it involves. Definitions of technology are of course wide ranging in the social sciences, ${ }^{12}$ but our approach is clear in its emphasis on the set of instruments with which human beings transform nature to meet their needs. While official definitions of information 
technology, with their emphasis on computers, fiber optic networks, robots, etc. appear to be compatible with such a conception of technology more generally, biotechnology requires further conceptual preparation if we are to grasp its meaning as an instrument of production.

Before attempting a concise definition of biotechnology as an instrument of production, it will prove useful to identify those phenomena that, while relevant to discussions of biotechnology, do not themselves constitute our object of investigation. First, we need to distinguish biotechnology as an instrument of production from research in the biosciences. There is a popular trend in science studies toward collapsing science and technology into a single phenomenon, often referred to as technoscience; the Human Genome Project, for example, is often regarded as a quintessential technoscientific endeavor. However, while clearly a response to important changes in the relation between science and technology in recent decades, this conceptual move threatens to obscure more than it illuminates. The knowledge of the living world produced through 'mapping' the human genome, while indeed requiring the employment of technology, and perhaps infusing the development of new technologies, does not itself constitute a technology. The relation between knowledge and instruments is a complex one, but it is a relation that is highly variable and one that requires explanation. To assume from the outset that science and technology are 'imploded', to use Donna Haraway's (1997) term, merely explains the relationship away with a rhetorical flourish. While some attention to 'bioscience' will be required, and attention to the relation between the two certainly needed, the analysis that follows will be focused squarely on 'biotechnology'. 
We also need to distinguish biotechnology as a set of instruments from its various applications in production. Explanations of biotechnology in government and industry literature often centre on descriptions of a wide range of sectors that are considered biotechnological. ${ }^{13}$ The significance of biotechnology is then measured by the quantitative expansion of research and development, investment, and product lines within these industries. Agricultural, pharmaceutical, and environmental biotechnologies, among others, are thus often dealt with as distinct objects of investigation. A primary difficulty with this approach, however, is that it reduces biotechnology to the various forms of its application, rather than attempting to grasp its significance as an instrument of production in and of itself. Again, the parallel with information technology is instructive here insofar as grasping the specificity of the computer as an instrument of production would hardly be furthered by making an a priori distinction between, say, automotive and textiles computers. While the applications of computers in each of these sectors do indeed vary, grasping the specificity of information technology itself requires that we abstract it from these various applications. A distinction will be maintained throughout this analysis, then, between biotechnology as a set of instruments and the various firms and industries that may employ these instruments.

Finally, if we are to grasp the specificity of biotechnology as a technology we need to distinguish it from the various products it is used to produce. Much of the critical discourse, both popular and scholarly, surrounding biotechnology is focused on the containment, release, and implications of genetically modified organisms (GMOs). The environmental, ethical, and trade concerns that have arisen in response to these new forms of life have served to galvanize an oppositional movement that has at times 
achieved significant political victories. ${ }^{14}$ Yet, while it is important not to lose sight of these issues in any critical discussion of biotechnology, it is also important to make clear from the outset that GMOs are not biotechnologies. Biotechnology is clearly the means through which such organisms are produced, and GMOs can themselves be employed as instruments in the production of other products, but genetically modified 'Frankenfood' is not in and of itself a technology any more than 'organic' food is. ${ }^{15}$ Again, technology is distinguished from the rest of the world by virtue of its role as an instrument of production; it is thereby necessarily analytically distinct from that which it produces. A distinction will thus be maintained throughout this analysis between biotechnology and the bio-products it is used to produce.

While the tendency to confuse biotechnology with bioscience, the 'life industries', and GMOs has tended to obfuscate the meaning of biotechnology as technology, what such conceptualizations do effectively highlight is the centrality of life to the meaning of biotechnology. The term biotechnology must specify a subset of instruments of production that is distinct by virtue of its involvement of living organisms. Now, a technology can involve living organisms in two kinds of ways: it can be employed in the transformation of living things, or it can itself be a living thing. Industry Canada employs the first criterion in its consideration of biotechnology as distinct in its "manipulation of living things to produce goods and services. ${ }^{16}$ We must of course reject this definition because it fails to distinguish biotechnology as a set of instruments from the hand-tools, machines, and information technologies that have been, and continue to be, employed in the transformation of living nature since the beginning of human history. And so, by default, we arrive at our working definition of biotechnology: the set of living things 
employed by human beings as instruments in the transformation of nature (living or otherwise) to meet their needs.

Such a definition is valuable insofar as it allows us to distinguish biotechnologies from non-living instruments of production; there is thus a clear difference here between biotechnology on the one hand, and hand-tools, machinery, or computers on the other insofar as the latter are non-living. Perhaps the most significant implication of this definition, however, is that it excludes much of the agricultural production that is the focus of many ostensibly interested in biotechnology. Agricultural production is primarily centered on the transformation of living nature to meet human needs rather than the employment of living nature as an instrument of production. Agriculture may employ living things as instruments - as Marx points out, a cow may be used as a material in the production of meat or an instrument in the production of manure - but the transformation of plants and animals into food and other materials of use to human beings is not in-itself a biotechnological process; and the fact that GMOs increasingly constitute the raw material (seed) and product (food) of this transformative process does nothing to alter this. Indeed, the more recent history of agriculture might be viewed as a shift away from biotechnology insofar as living instruments, drought animals for example, become replaced through mechanization and automation. Again, biotechnology, in order to be a useful concept, must refer to living instruments rather than merely living materials that may or may not require the employment of biotechnology in their transformation.

The approach here has much in common with that of Robert Bud (1993) who identifies three stages of biotechnological development. The first is marked by the employment of yeast in ancient practices of brewing; the second, by the characterization 
and employment of microbial life in fermentation processes yielding pharmaceuticals and industrial chemicals from the late $19^{\text {th }}$ century; and the third by the revolution in molecular biology over the past few decades that has allowed for the employment of living things as bioreactors for the production of proteins that they would not otherwise produce in their 'found' form. While Bud's history of biotechnology tends to focus on the employment of micro-organisms at the expense of appreciating the ways in which animals, in particular, have been employed as technologies, his approach is nevertheless valuable in conceptualizing biotechnology as technology and in highlighting the historical continuity of biotechnological development. And, indeed, we can go further than Bud in this regard and locate the origin of biotechnology in the Neolithic revolution and the domestication and employment of animals as instrument of production.

Still, while there may be nothing new about the use of life as an instrument of production per se, even a cursory glance at some of the latest instruments themselves is enough to raise some doubt as to their continuity with past biotechnologies. Is a bacteria engineered to produce human insulin even relatively continuous with those used in traditional fermentation processes? What about goats that produce spider silk in their milk or chickens that produce human growth hormone in their egg whites? Are these merely more advanced forms of animal husbandry? Such examples seem to provide at least enough prima facie evidence to suggest that there is more going on here than Bud's history of biotechnology would suggest; and indeed, they point to a weakness of the concept of biotechnology in grasping what is unique about the contemporary use of life as an instrument of production. For what the concept of biotechnology neglects is the process through which these living instruments are themselves produced. These examples 
suggest a possible disjuncture in the ability of human beings to design living technologies and our interest in understanding the meaning of these instruments for the meaning of nature must thus enquire into their creation.

\section{Genetic Engineering}

Amongst those wanting to emphasize the unique threat posed by recent developments in biotechnology, the term 'genetic engineering' has become popular. Even those in government and industry who wish to stress the continuity of biotechnological development are willing to acknowledge a distinction between the more 'traditional' techniques of brewing from more 'modern' techniques that are concerned with altering the genetic structure of living things at the molecular level. ${ }^{17}$ The roots of the latter are generally traced to the advent of recombinant DNA (rDNA) in the early 1970s, and while other techniques have emerged as important, most agree that the splicing together of the genetic material of dissimilar species was the crucial breakthrough marking a new phase in the albeit long and relatively continuous history of biotechnology. Moreover, rDNA is widely considered to be the cornerstone technique of a new kind of production process without which the industrial application of molecular biology would have remained relatively marginal.

While the development of genetics as a science can be traced to the rediscovery at the turn of the century of Gregor Mendel's work on heredity, the identification of the structure of DNA in the early 1950s marked the beginning of a revolution in the field. Mendel, in experiments involving pea plants, had discovered in 1864 that certain characteristics are passed along from generation to generation in a systematic way. His 
work was largely ignored, however, and was revived only in light of the identification of chromosomes as the location of the hereditary units, or 'genes'. In the late 1940s the chemical composition of the genes was identified as deoxyribonucleic acid (DNA) and their role in guiding protein synthesis was elucidated. Still, genetics to this point remained a largely descriptive science. While great advances were being made in understanding the role that DNA plays in protein synthesis, and cellular reproduction more generally, very little was known about the mechanism whereby the information contained in genes (genotype) becomes expressed in the observable features of an organism (phenotype). With Watson and Crick's identification of the precise structure of DNA in the early 1950s, however, geneticists were in a position to explain in everincreasing detail the reproductive capacities of organisms at the molecular level.

The revolutionary potential of Watson and Crick's model lay in both its simplicity and universality. While the chemical components of DNA had been identified some years before, it was unclear how something with so simple a structure could direct the synthesis of the many proteins that make up complex higher organisms. DNA is composed of nucleotides each of which consists of the sugar deoxyribose, a phosphate, and one of four bases - cytosine (C), thymine (T), guanine $(\mathrm{G})$ or adenine $(\mathrm{A})$. The structure of DNA deduced by Watson and Crick is that of a 'double helix' - two intertwined strands of nucleotides whose protruding bases face one another, pair up in a systematic way (A - T, $\mathrm{C}-\mathrm{G})$, and are held together by weak hydrogen bonds. Each grouping of three nucleotides, a codon, contains a portion of the information needed to synthesize one of twenty amino acids which combine to form the polypeptide chains that make up proteins. A gene, then, is a section of DNA that 'codes' for the synthesis of a particular protein. 
During cellular reproduction, the two strands of the double helix separate and each matches up with a new strand according to the sequence of bases so that two identical copies are formed. The simplicity of the model is striking; the genetic codes for all life on the planet can be represented with only four letters corresponding to the four bases $(\mathrm{A}, \mathrm{T}$, $\mathrm{C}, \mathrm{G})$. And it was the reducibility of life to this common genetic code that facilitated the rapid advances in molecular biology during the following decades.

The most significant of these advances was the development of rDNA in the early 1970s. It did not take long for molecular biologists to realize that if protein synthesis in all organisms was determined by some variation of a common four letter code, manipulation of this code could induce cells to produce 'foreign' proteins, that is, proteins not normally coded for in the cell's DNA. Herbert Boyer and Stanley Cohen first achieved this feat through rDNA, what Jeremy Rifkin describes as "a kind of biological sewing machine that can be used to stitch together the genetic fabric of unrelated organisms" (1998: 12). The technique involves splicing together pieces of DNA from two dissimilar organisms and 'persuading' a host cell to 'express' the trait coded for by the new recombined DNA. First, the desired gene or set of genes is isolated using a restriction enzyme - a pair of molecular 'scissors' that cuts DNA at a specific location. This leaves 'sticky ends' on the desired fragment that can then be joined to the 'sticky ends' of a piece of DNA from a host cell. The host DNA is then used as a 'vector' to insert the foreign DNA back into the host cell which proceeds to reproduce itself with the 'cloned' DNA in each copy. Thus, while identifying the structure of DNA enabled biologists to explain the reproductive capacities of living things at the molecular level, rDNA first enabled them to manipulate these capacities to meet human needs. 
Despite having certain similarities with past techniques employed by plant biotechnologists and industrial microbiologists, and hinging upon advances in molecular biology throughout the $20^{\text {th }}$ century, it would seem clear that the genetic engineering facilitated by rDNA constitutes a significant discontinuity in the human capacity to transform nature to meet their needs. Species boundaries have by no means been historically inviolable; plant biotechnologists have been developing hybrid varieties since the early $20^{\text {th }}$ century and, as evolutionary biologists point out, such boundary crossing also occurs 'naturally' without human intervention. Nor did the technique of rDNA itself emerge from the lab ex nihlo; molecular biologists and industrial microbiologists have understood and employed the reproductive capacities of micro-organisms in production for years, albeit in their relatively 'found' form. However, the technique of rDNA constitutes a qualitative shift in both instances. Genetic information is now itself manipulated at the molecular level allowing for a potentially unrestricted crossing of all species of plants, animals, and micro-organisms with each other. The speed and relative accuracy with which this can be done allows for the design of life at a most basic level through rearranging its molecular genetic building blocks.

Having described recombinant DNA technology we are now in a position to better grasp the conceptual relation between genetic engineering and biotechnology. As we have seen, biotechnology refers to any living instrument employed by human beings in the transformation of nature to meet their needs. Biotechnologies range from draft animals, used as the motive force driving agricultural technologies, to the bioreactors currently used to produce pharmaceuticals and industrial chemicals. Until recently, living things have been employed as instruments by virtue of their found characteristics. 
Genetic engineering is novel, then, insofar as it produces transgenic organisms, new organisms with combinations of genes that would not otherwise exist. Transgenic organisms are specific biotechnologies - transgenic biotechnologies - created through techniques of genetic engineering. The concept of genetic engineering thus shifts analytical focus away from the biotechnologies themselves to the process of their creation.

Such a conceptual move also points us in the direction of a specific labour process by avoiding the considerable confusion that exists in attempts to identify a 'biotechnology industry', confusion that is nowhere more evident than in Industry Canada's on-line 'biotechnology sector profile'. Here we have the 'industry' divided into 8 sectors: therapeutics, diagnostics, agriculture, food processing, environment, natural resources, bioinformatics, and aquaculture. Now, there is nothing new about the identification of an industry with a technology. Industry Canada also distinguishes an 'information and communication technology' industry whose sectors (or subsectors) are differentiated according to the role of firms in the production and marketing of the technology and the provision of related services (manufacturing, software, cable). However, the 'biotechnology industry' is rather different, distinguished as it is not by the production of a particular technology, but by the 'application of life in production'. The sectors, then, are not differentiated according to their role in the production of biotechnology, but by the kind of product they produce through the 'application of life', irrespective of whether or not the product is living, or even a technology.

Thus Monsanto is considered a biotechnology firm because it 'applies life in production', despite the fact that it produces seed, which is an agricultural raw material 
rather than a technology per se, ${ }^{18}$ and herbicide, which, even if it were considered a technology, is not living. Compare this with the inclusion of Lilly, the producer of human insulin, a therapeutic that is neither living nor a technology. While this may seem an innocuous enough contrast, the problem becomes clearer when we imagine trying to assess the significance of IT if the industry and its sectors were organized in the same way. IBM, Microsoft, GM and McDonalds could all be considered part of the IT industry by virtue of their 'application of information in production', and assigned to the 'microelectronics', 'software', 'automotive' and 'food' sectors respectively. While some have responded to this difficulty with the suggestion that biotechnology does not constitute an industry as such, but is rather an enabling technology used across a whole range of sectors, this would seem to err in the other direction, neglecting the emergence of a whole range of new firms whose emergence can be clearly traced to the innovations sparked by the advent of rDNA since the early 1970s.

The concept of 'genetic engineering', on the other hand, allows us to both appreciate the relevance of biotechnology, whether transgenic or not, across a wide range of 'traditional' sectors (e.g. agriculture, therapeutics), and at the same time identify a unique industrial sector concerned with the specific task of transforming the reproductive capacities of living things at the molecular level. Genentech, whose co-founder, Herbert Boyer, was also the 'co-inventor' of rDNA, is the earliest example of a 'biotechnology firm' in this narrower, and more meaningful, sense of the term. Genentech first created a transgenic microbe using rDNA that would produce human insulin. Genentech can thus be considered a pioneering biotechnology firm in the same sense that IBM and Apple were pioneers in information technology; where the latter produce computers, Genentech 
produces transgenic organisms. The significant growth in the number of such firms over the past three decades indicates the emergence of a genuinely unique sector that should be distinguished from those 'traditional' sectors that employ life (transgenic or otherwise) in the production of otherwise dissimilar products. The concept of genetic engineering developed here allows us to make such a distinction and provides a clearer site of investigation for assessing what is new about 'new' biotechnology.

Yet, despite the value of this conceptual shift, it would at the same time lead us astray somewhat from our purpose, which is, after all, to assess the significance of biotechnology, as an instrument of production, for the human-nature relation by looking at its role in the labour process. We have identified 'transgenic organisms' as the specific biotechnology in question and found that a focus on the process of their creation, genetic engineering, is central in distinguishing them from other biotechnologies and providing a specific site of investigation. However, the difficulty with the concept of genetic engineering is that it does not capture what is surely as important as the creation of transgenic organisms; namely, their employment as bioreactors in the production of recombinant proteins. On the other hand, we do not want to merely dissolve the creation and employment of transgenic organisms into a vague concept of 'biotechnology', which as we have seen does more to obscure than illuminate. Maintaining an analytical distinction between the two processes is particularly important in light of the very different role that life plays in the two processes; in the case of 'genetic engineering' life is the primary raw material that is transformed into a transgenic product, whereas in the case of the bioreactor, it is the organism itself that is the instrument of production, a transgenic biotechnology. 
Of course this is not a limitation in itself, for all technologies are characterized by the same product/instrument duality and the Marxian distinction between departments 1 (the production of means of production) and 2 (the production of consumer goods) helps make sense of this. In the case of IT the distinction is relatively clear: ITs are both the product of IBM's production process (department 1) and instruments in General Motor's production of cars (department 2). It might be enough, then, to merely make a distinction between those firms for whom living organisms are the raw material transformed through genetic engineering into transgenic organisms (department 1), and those for whom transgenic organisms serve as instruments of production (department 2). The former could then be considered part of the transgenic biotechnology industry proper, just as IBM is a cornerstone of the information technology industry; the latter would be considered part of an industrial sector that employs biotechnology, but is not itself part of the biotechnology industry, just as GM is not considered an 'information technology firm' in this sense of the term.

However, there is a further complication in the case of biotechnology that makes such a distinction, and the parallel with IT upon which it is based, problematic. While the creation of transgenic organisms and their employment as living factories may be analytically distinct processes, they would also seem to involve one another in a unique way. Unlike the computer, whose significance derives from its employment in multifarious industries, transgenic organisms are designed for the production of specific proteins. In this sense, those firms engaged in genetic engineering are more akin to Microsoft than IBM insofar as they 'program' an organism for a specific purpose, rather than building one whose use is largely determined by those who employ it as a 
technology. On the other hand, genetic 'information' is not distinct from an organism in the same way that software is distinct from hardware and so this analogy is also inadequate. Genetic 'information' is not so much 'processed' by the organism as it is the molecular building blocks of the organism without which it ceases to be. Transgenic organisms are thus 'dedicated machines' in a way that computers are not.

And rather than a mere academic point, this unique aspect of transgenic biotechnologies is reflected in the structure of the firms engaged in their creation and employment. Where those firms that produce IT (the IT industry proper) can be distinguished in a relatively straightforward way from those who merely employ these technologies in the production of other products, the production and employment of transgenic biotechnologies takes place in the same firm, or at least within the same partnership of firms.

Sembiosys of Calgary, for example, both genetically engineers safflower seeds and employs these seeds in the production of biopharmaceuticals and feed additives, or at least enters into partnerships with firms who possess the required manufacturing and other necessary capabilities. The firm thus produces and claims proprietary rights to both the biotechnology, the Stratosome Biologics System ${ }^{\mathrm{TM}}$, as well as the products it is used to produce - for example, Immunosphere ${ }^{\mathrm{TM}}$, a feed additive that protects against viral disease in shrimp. Similarly, Nexia of Montreal both creates transgenic goats and employs them in the production of 'spider' silk that can be woven into a replacement for steel, again claiming proprietary rights to both the Bele Goats $\otimes^{\text {and the BioSteel }}{ }^{\mathrm{TM}} .^{19}$ This is a unique characteristic of these 'biotechnology' firms and is reflective of the 
'dedicated' nature of transgenic biotechnology. In short, transgenic biotechnology destabilizes the distinction between departments 1 and 2 .

Thus, the obstacles we face in attempting to specify an empirical object appropriate to grasping the significance of recent developments in biotechnology, rather than merely conceptual, arise out of biotechnological development itself. With developments in molecular biology since the early 1970 s and the creation and employment of transgenic organisms as living factories, our traditional distinctions between material, technology, product, and industry become decidedly 'destabilized'. Perhaps the problem is not, then, one of defining biotechnology, or of distinguishing genetic engineering from more 'traditional biotechnology', but one of developing alternative ways of thinking about recent developments in the industrial application of molecular biology that capture its uniqueness as an object of investigation.

\section{The Transgenic Labour Process}

Rather than merely try to operate within the confines of existing conceptions of biotechnology and genetic engineering, this section proposes the concept of a transgenic labour process in response to the unique empirical challenges discussed in the preceding sections. While the term 'transgenic production' is appearing with increased frequency in industry literature, it can be expanded in two ways. First, while the term is most commonly used to refer to the industrial employment of transgenic animals, there appears little reason to distinguish between animals and other forms of life in this regard. Second, while the term is often used to refer to only the 'employment' of transgenic organisms in production, I will explicitly include not only the industrial employment of transgenic life, 
but also the creation of transgenic life through techniques of genetic engineering. Thus, we arrive at a preliminary definition of the transgenic labour process that incorporates our definitions of both biotechnology and genetic engineering; it is a labour process centered on the genetic engineering of organisms and their employment as transgenic biotechnologies in the production of useful substances.

The concept of a transgenic labour process focuses our immediate attention on the unity of the process through which living things are being designed at the molecular level and harnessed as biotechnologies. The process begins with life in its relatively 'found' form and ends with a useful substance. Harnessing living things to the labour process in this way is achieved through altering their genetic structure at the molecular level so that they might be persuaded to produce substances that they would not otherwise produce. Considered as a whole, then, a transgenic labour process transforms living nature at the molecular genetic level so that it might serve as an instrument for the production of substances that satisfy human needs.

On the other hand, the concept of a transgenic labour process allows us to clearly differentiate between the two analytically distinct phases of the process: 1) the creation of transgenic organisms; and 2) their employment as transgenic biotechnologies. In the creation phase of the process living organisms and their parts are the objects of labour that are worked-up with the technologies and techniques of genetic engineering. A new, transgenic organism emerges from the creation phase whose genetic design reflects a need for a specific substance. In the employment phase of the process transgenic life is 'scaled-up' in order that it might produce commercially viable quantities of the substance. While in the creation phase the living organism is the object of labour, in the 
employment phase it serves as the instrument itself insofar as it is employed as a bioreactor to produce useful substances. The concept of a transgenic labour process thus enables us to begin to capture the changing role of life in the production process that has emerged with the advent of the novel tools and techniques of genetic engineering: life is at once raw material, technology, and product of the transgenic labour process.

Taking the transgenic labour process as our object of investigation avoids the difficulties we encountered with the concepts of biotechnology and genetic engineering. On the one hand, our focus on transgenic organisms and the practices through which they are created avoids the tendency of the concept of biotechnology to obscure what is clearly unique about these biotechnologies in particular. On the other hand, our subsumption of genetic engineering as a phase of the transgenic labour process enables us to avoid a tendency amongst those interested in transgenic organisms to neglect the ways in which these organisms are actually employed as biotechnologies. And as we have seen, the need to grasp both the creation and employment of transgenic organisms is necessitated by the 'dedicated' nature of transgenic biotechnologies themselves.

However, despite all of its conceptual advantages, we find ourselves confronted with a rather abstract object of investigation, the analysis of which requires that we generate more concrete descriptions of exactly how transgenic life is being created and employed as an instrument of production. In order to generate such descriptions we need to establish criteria for distinguishing types, or modalities, of the transgenic labour process. There are two kinds of criteria commonly used to distinguish forms of 'biotechnology'. 
First, as we have seen, industry associations and governments tend to differentiate the 'biotechnology industry' into various sectors according to their product lines and generate descriptions through 'case studies' of specific firms. While the creation and employment of transgenic life as an instrument of production does indeed take place in different industrial sectors (e.g. pharmaceuticals, fine chemicals, food additives, new materials), the differences between such sectors would seem irrelevant to our purpose. As we are interested in what is distinctive about the creation and employment of living technologies, we need to differentiate our labour process in a way that foregrounds the differences in the way these processes take place, differences that are obscured by a focus on product lines.

More promising is the practice, common in both the more technical literature as well as in more popularized accounts, of differentiating genetic engineering/ biotechnology according to the specific organism created and/or employed. Many edited collections written for a 'scientific' audience are thus divided into sections devoted to 'microbial', 'plant', and 'animal' genetic engineering/ biotechnology, and individual contributions often focus on specific organisms (e.g. e coli, corn, goats). The advantage of this method of differentiation is that it attends to the characteristics of the organisms themselves, rather than the product they are used to produce, thus highlighting what is specific to the creation and employment of living technology. The limitation here, however, is a general tendency to regard microbial, plant, and animal genetic/engineering as sui generis, which obscures the underlying logic of the process through which lifeitself is being harnessed as a productive force. 
Given these limitations of a focus on either particular industries or life-forms for our purposes, our transgenic labour process will in many ways remain abstracted from both. While descriptions of the process rely on industry and firm literature, this will be used to construct the 'transgenic labour process' in abstraction from its existence in any particular industry or firm. This will prove necessary to get at the essential characteristics of the process, which is particularly important if we are to get at the degree to which it is qualitatively distinct from other forms of the labour process. And, again, while the technical literature will be an important source for our descriptions, we want to first abstract from the differences in forms of life in order to get at the essence of the process as a whole; this will enable us to see the degree to which what is significant about the transgenic labour process is its harnessing of 'life-itself' to human needs, rather than any particular form of life. The transgenic labour process is thus best understood here as a conceptual construction intended to trouble certain ontological assumptions regarding the meaning of nature.

Constructing this labour process requires recognition of its uneven development and a willingness to include in this construction much that is still emerging. While the employment of transgenic microbes in the commercial production of pharmaceuticals is well established, their use in the production of plastics, for example, is still in its nascent stages. On the other hand, the use of transgenic plants as delivery systems for human pharmaceuticals has been stalled by regulatory concerns over contamination of the food supply, while their development for use in the production of non-human therapeutics and plastics is relatively more developed. Interestingly, allusions to Frankenstein's monster amongst opponents notwithstanding, the employment of transgenic animals has been 
relatively more successful than that of plants, with the recent regulatory approval of GTC's ATryn in Europe - a biopharmaceutical produced in transgenic goats -likely marking a turning point for the industry (Pollack 2007).

Thus, the industry must be regarded as largely emergent, with most transgenic production platforms still in the research and development stage and in various stages of clinical trials. Nevertheless, transgenic microbes, plants, and animals are all in use as biotechnologies and there is little to suggest that their slow movement to commercial application is anything more than a reflection of the complexity of biological processes and the relatively strict regulatory guidelines covering the engineering and employment of living things, particularly in the production of biopharmaceuticals. Indeed, part of the attraction of this particular application of transgenic life is that it seems to be immune from the kind of public concern that generally attends the genetic engineering of food. Thus, despite the emergent and uneven development of the technology, there should prove to be enough bits and pieces of the technology far enough along in their development to be able to confidently construct our transgenic labour process at a relatively high level of abstraction.

Still, our interest in what is unique about living technology would seem to suggest the importance of attending more concretely to differences between transgenic labour processes centered on microbes, plants, and animals. As we shall see, while there is a common logic underlying the transgenic labour process as a whole, whether the organism created and employed is a microbe, plant, or animal, has important implications for the more concrete form this process takes. Accordingly, we will distinguish between microbial, plant, and animal modalities of the transgenic labour process. While the details 
of these modalities will be discussed in chapters $4-6$, a broad outline of them here should prove useful in providing some concrete footing for an analysis that will tend to be conducted at a relatively high level of abstraction.

The creation and employment of transgenic microbes as 'tiny factories' for the production of useful substances has the longest history of any of our modalities and remains by far the most common in terms of commercial production. The process of genetic engineering, as we have seen, transforms individual cells, and so the use of relatively simple single-celled organisms, and bacteria in particular, has proven an efficient method of working-up life so that it issues in a useful substance that it would not otherwise produce. ${ }^{20}$ The employment of microbes as transgenic biotechnology centers on the fermentation tank that is used to monitor and regulate the life-process of the microbial population as it grows, thereby producing the substance in greater quantities.

The most well documented example of a transgenic microbial labour process is Eli Lilly's creation and employment of transgenic $E$. coli in the production of Humulin® Other pharmaceutical giants employing transgenic technology in the production of a wide range of products include Aventis, GlaxoSmithKline, Bayer, and Novartis. Smaller firms whose origins lie specifically in techniques of rDNA - or, biotechnology start-ups (Kenney 1986, 1997) - include Genentech, the leader in transgenic biotechnology by most accounts, Genzyme, Biogen, and Amgen, all producers of therapeutic proteins via transgenic microbes. Metabolix is a leader in the employment of transgenic microbial systems in the production of a wide range of polymers, or 'nature's plastics' as they are referred to in their promotional material (http://www.metabolix.com). The Biotechnology Industry Organization provides a comprehensive list of companies employing microbial 
systems that highlights those employing transgenic biotechnology

(http://bio.org/speeches/pubs/er/approveddrugs.asp).

While transgenic plant production remains the least developed of our modalities, an increasing number of firms and governments are exploring and developing techniques for the creation and employment of transgenic plants as biotechnologies for the production of a wide range of useful substances. While the creation of rDNA molecules is consistent across the modalities, plant genetic engineering requires that transformed plant cells be grown into mature plants and cross bred with one another to produce a 'pure' transgenic species, a process that relies on practices with a long history in plant breeding. The seeds of the transgenic plant are then planted and employed as instruments for the production of useful substances, which of course relies on agricultural practices with an even longer history than those of plant breeding.

While a transgenic plant-based pharmaceutical has yet to be commercialized, Calgary-based SemBioSys Genetics Inc. has achieved commercially viable levels in its transgenic safflower seeds and is entering the clinical trial stage in the production of insulin. Further along in clinical trials are transgenic safflower systems for the production of non-pharmaceutical topical ingredients and animal health products. Quebec-based Medicago is currently in pre-clinical trials with their treatment for avian influenza produced in transgenic alfalfa and others engaged in the development of transgenic plant systems for pharmaceutical production include Planet Biotechnology, Large-Scale Biology and Agracetus, a 'campus' of Monsanto specializing in the development transgenic plant technology. And, in addition to its transgenic microbial system, 
Metabolix is also developing transgenic tobacco and alfalfa systems for the production of its 'natural plastic'.

And finally, if there is a cutting edge to all this, it must be the creation and employment of transgenic animals as bioreactors for the production of useful substances. The creation of a transgenic animal, in addition to requiring techniques of rDNA, requires that embryos be made transgenic and brought to term in a mother's womb. Once born, these transgenic animals can be bred to produce a founder herd whose offspring will serve as transgenic bioreactors. The employment of animals in this way centers on the 'barnyard' and requires practices of animal husbandry, which, along with agricultural practices, have their origins in the Neolithic revolution.

We have already encountered the example of Nexia's Bele Goats, and the lactation capacities of mammals more generally makes them ideal 'factories' for the production of large quantities of pharmaceuticals at relatively low cost; although chickens and even insects are receiving increased attention. GTC Biotherapeutics, with the recent regulatory approval of its ATryn produced in transgenic goats, is the first to bring a pharmaceutical produced in a transgenic animal to the commercialization stage. Pharming is developing transgenic rabbit and cow technologies. And, in addition to Tranxenogen, whose development of transgenic chicken systems has stalled, Avigenics' chickens produce pharmaceuticals intended to treat cancer and organ dysfunction and are in various stages of clinical trials.

Now, the unevenness and emergent nature of the industry, and, indeed, the failure of many of the firms, requires that we address how these specific examples of microbial, plants, and animal technology will figure in the analysis that follows. Again, the 
argument here does not concern the proliferation of transgenic biotechnology, nor the relative success of the firms in question, or of the industry as a whole. The purpose here is to construct a 'transgenic labour process' in order that we may use it to trouble conceptual categories and theoretical assumptions concerning the meaning of nature. The value of these examples lies not, then, in their success, or indeed whether their products have or will reach the market at all, but in degree to which they allow us to construct a labour process centered on the creation and employment of transgenic life in the production of useful substances. These firms are thus useful places to pick up the bits and pieces with which we will construct our labour process. Thus, we are not interested in the firms themselves and will make little reference to their specific activities.

The main exception to this will be our use of the promotional material provided on the websites of these firms, a use that requires some justification in light of our interest in the transgenic labour process at a relatively high level of abstraction. Not only are these websites valuable as a source of information conveyed in a relatively userfriendly and non-technical way, but, more importantly, they provide an interesting site at which to explore the repositioning of life as an industrial force of production. Of course there is 'spin' here, but our purpose is not to offer this information as an 'objective description' of the firm's activities and progress. Our purpose, rather, is to explore this 'spin' as itself a discursive constituent of a qualitative disjuncture in the meaning of nature. We thus take for granted that the technology is being spun and are more interested in the unique way that it is being spun. Our choice of websites reflects this purpose, with special attention being paid to those who provide the best spin, rather than those produced by the most successful companies. Thus, the promotional material of Nexia and 
Tranxenogen will figure prominently in the analysis despite its lack of commercial success. After all, who could resist Nexia's spidergoats and a proud creator who once suggested that "we're changing the world from a tiny low-rent sugar farm, and our only machinery is a goat" (qtd. in Osborne 2002). The fact that Nexia has found no commercial application for these goats is less interesting here than what this statement reveals about the repositioning of life as technology.

Having sorted out at least some of the methodological difficulties our interest in transgenic biotechnology presents, we can, by way of conclusion, suggest the power of this conception of a transgenic labour process in enabling us to start moving beyond the facile continuity/discontinuity debate that so often characterizes discussions of the significance of recent developments in biotechnology. On the one hand, it employs living things as instruments in the satisfaction of human needs and is thus continuous with biotechnological development throughout human history. At the same time, in emphasizing the novelty of the process through which transgenic organisms are created, our transgenic labour process is also effective in grasping the significant discontinuity represented by 'genetic engineering'. While human beings have employed life as technology since the Neolithic revolution, techniques of recombinant DNA mark a disjuncture in this regard insofar as they allow for unprecedented speed and accuracy in the manipulation of the molecular genetic reproductive capacities of living things. The resulting transgenic organisms are hybrids that have not been accomplished in the whole span of human history, but are now created in days. Thus, while locating 'genetic engineering' within the relatively continuous human engagement with nature, the concept of a transgenic labour process is also sensitive to its novelty in this regard and so grasps 
the truth of the critic's claim that there is something very different about 'new biotechnology'.

Indeed, when 'genetic engineering' is subsumed as a phase within our broader labour process the discontinuity represented by 'new biotechnology' becomes even more significant than critics suggest. The novelty of 'new biotechnology' is not that it is used to transform living nature, for clearly there has always been biotechnology in this sense, nor does its novelty lie necessarily in any specific technical characteristic at all. What is significant about recent developments in the industrial application of molecular biology is the way in which life is implicated in a unique production process, first as transgenic product designed at the molecular level, and then as living factory employed in the production of recombinant substances. While neither the working up and production of living things as products, nor their employment as instruments of production are unique developments in themselves, transgenic production unifies these previously distinct uses of life in a unique and unprecedented way. All of living nature can now be designed at the molecular level for the express purpose of serving as an instrument of production to satisfy human needs. Understanding the significance of any individual biotechnology requires that we understand it in relation to this overarching process of transgenic production.

Delineating this labour process and assessing its significance will be the focus of the analysis that follows. However, having outlined our theoretical approach and identified our object of investigation, we must first situate ourselves in relation to those whose concerns come closest to our own. 


\section{3 - Putting the 'Material' back into Historical Materialism}

It is odd that the tradition of Marxian 'labour process theory' has made so little a contribution to current debates over the meaning of nature in general, and the significance of technological change for the question of nature in particular. As we saw in chapter 1 , the labour process is at the center of Marx's ontology and the concept of nature figures prominently both in his more abstract discussions of labour, as well as in his more concrete analysis of machinery and large-scale industry. Nevertheless, the significance of technology for the meaning of nature remains relatively unexplored in labour process theory and has been left largely to a variety of traditions in cotemporary social theory with little interest in Marx, let alone an interest in labour. ${ }^{21}$ Our concept of a 'transgenic labour process' in chapter 2, however, brings questions of technology, the labour process, and nature together in a way that destabilizes any such boundaries between "political economy' and 'social theory' and is thus a useful site at which to bring together various perspectives between which there has been little in the way of cross fertilization.

In this chapter we proceed through a critical engagement with labour process theory and the artifactual constructivism of Bruno Latour and Donna Haraway in order to position ourselves amongst the 'environmental sociologists' whose approach comes closest to our own. We address the limitations of extant labour process theory for approaching questions of technology and nature in the first section and argue that these arise largely out of a strangely amaterial conception of the labour process and a case study approach that tends to eschew more ontological questions. We next turn to artifactual constructivism to retrieve a focus on the 'material' practices through which 'worlds are made' and the ontological significance of biotechnological change, albeit a 
focus that tends to abstract these practices and their significance from the labour process. In the final section we find kinship amongst the Marxists working in the tradition of 'environmental sociology', a kinship that will nevertheless prove an often difficult one in the analysis of the transgenic labour process that follows.

\section{The Ontological Blind spots of Labour Process Studies}

Our claim to a 'labour process approach' to the study of technology and the question of nature demands that we engage with Braverman's seminal work in the labour process tradition, especially since technological change has figured so prominently in this literature. For Braverman ([1974] 1998), the capitalist labour process is the site at which labour power must be transformed into labour and reflects the struggles and contradictions of capitalism more generally. Rather than merely a question of efficiency, technological change is conceived in class terms, as the embodiment of capital's need to both increase relative surplus value and maintain or increase control over process and product design. The process of deskilling that attends technological change in this context is thus, for Braverman, both a question of value creation and, perhaps more importantly, a question of control insofar as the separation of execution and planning (Taylorism) concentrates power in the hands capital. The 'degradation' of work identified by Braverman is inherent in a labour process formally subordinated to capital. While we will deal with Braverman's substantive arguments regarding the division of labour and automation in chapter 6 , we are interested here in assessing the value of his general analytical method to understanding technological change and the question of nature. 
While seldom recognized, there is a tension in Braverman's conceptualization of technology. On the one hand technology is an instrument of control, an embodiment of the class struggle and thus inherently degrading. In refuting 'technological determinism' Braverman argues that "the 'mode of production' we see around us, the manner in which labour processes are organized and carried out, is the 'product' of the social relations known as capitalist" ([1974] 1998, 15). Here we see Braverman pioneering a constructivist perspective in the sociology of technology where technology, rather than a purely technical question, possesses certain 'social' imperatives that reflect its origins and development. ${ }^{22}$ On the other hand, in his more concrete analysis of machinery, Braverman argues that "it is not the productive strength of machinery that weakens the human race, but the manner in which it is employed in capitalist social relations" (158). Here we have technology not as a 'product' of social relations per se, but more a 'technical' accomplishment, conceived as 'productive capacity' whose specific 'employment' is attributed to capitalist society. Rather than a constructivist perspective, Braverman here comes closer to embracing what the philosopher of technology Andrew Feenberg (1991) calls an 'instrumental' perspective that views technology itself as relatively neutral. What is important here for our purposes, however, is the degree to which this tension has shaped the development of labour process studies in a way that has tended to obscure the 'materiality' of the labour process as an engagement of human and non-human nature.

The constructivist impulse in Braverman's work is reflected in a strain of labour process studies whose focus is on the design and implementation of technology and the degree to which these embody and reinforce specific sets of power relations. David 
Noble's (1984) study of the design and development of numerically controlled machines is exemplary in this regard. Cynthia Cockburn's $(1985,1993)$ work, among others, expanded the conception of 'social relations' to include gender, and more recent work in the tradition of Canadian political economy has focused on the class and gender impact of computer-based technologies in the auto and airline industries (Lewchuk and Robertson 2006; Shalla 2006). This work is consistent with Braverman in regarding technological change as reflective of the broader power structures of a society characterized by capitalism and patriarchy and thus offers a powerful critique of a technological determinism that would see technology as developing autonomously and imposing certain imperatives by virtue of its purely technical characteristics.

However, despite the value of this work in dispelling a simple technological determinism, the conception of technology here poses certain limitations to understanding its significance for the meaning of nature. In a word, where technology is regarded primarily as an instrument of exploitation and control, its role as an instrument of production, as a means of engagement between human and non-human nature in the labour process, recedes into the background. The question of technology becomes a question of the social relations of which it is a reflection and more ontological questions concerning the meaning of nature, and changes in this meaning engendered by new technologies, are generally absent from these labour process studies. Thus, in a recent, and otherwise valuable, collection of work in this tradition (Shalla and Clement 2007), despite a number of studies that emphasize the importance of technological change, there is not a single reference to 'nature', or even any systematic attention to the 'raw material' characteristic of the 'new world of work'. 
And where technology tends to be reduced to 'social relations' in this first strain of labour process studies, it tends to be neglected all together as an object of investigation in the second. As we saw, there is tendency in Braverman's work to distinguish between the 'technical' and 'social' aspects of the labour process and to attribute the degradation of labour to the latter. While in Braverman this dualism exists in a, largely creative, tension with his more constructivist impulses regarding technology, labour process studies that have followed in the wake of Burawoy's seminal work $(1979,1985)$ have tended to embrace this dualism and focused solely on what Burawoy calls the 'social relations in production' (1985, 51-54). Taking as his point of departure Braverman's (intentional) neglect of the 'subjective' element of the labour process, the transformation of labour power into labour becomes for Burawoy a 'game' where overcoming worker resistance, rather than merely an objective process of deskilling, requires strategies to 'manufacture the consent' of workers. Related to Burawoy's work is a strain of 'poststructuralist' work that centres more explicitly on processes of subjectivity and identity formation within the labour process (Knights and Willmott 1989; Miller and Rose 1995).

Now, whatever the value of this perspective in addressing the limitations of Braverman's work, the lack of attention to the 'materiality' of the labour process here is troubling. If the 'problem' of the labour process is reduced to the question of transforming labour power into labour, and this process is itself explained in terms of power struggles inherent in the 'social relations in production', then technology becomes taken for granted as the 'technical' component of the labour process or, at most, acknowledged as part of the changing context in which these power struggles are played out. But technological change itself, and its meaning for the material engagement of 
human and non-human nature, are nowhere considered in any systematic way, as is evidenced in a more recent collection of labour process studies edited by Burawoy that addresses the labour process in the context of globalization (2000). None of these studies addresses in any systematic way the role of the non-human components of the labour process, and even when 'information technology' does enter the picture it does so merely as one more 'workplace' - a software design firm - in which to investigate the 'games' between labour and management.

In light of these limitations of the dominant strains of labour process studies, it is worth noting the unique contribution of Wallace Clement in the tradition of Canadian political economy. While not concerned with the question of nature per se, Clement's analyses of extractive industries, and his study of mining in particular (1981), highlights the materiality of the labour process in a way that analyses of the manufacturing and service sectors have not. Critically engaged with the 'staples' tradition - whose emphasis on the importance of the material characteristics of particular raw materials in determining the shape of Canadian political economic development is too often merely dismissed as 'technological determinism" ${ }^{, 23}$ - Clement provides a dialectical model where the material engagement of labour and 'staple', via increasingly complex machinery, at the point of production and capitalist social relations interpenetrate one another. Clement's relatively unique focus on extractive industries reveals the degree to which labour processes, while in some sense 'shaped' by capitalist social relations, are nevertheless 'material processes', whose specific characteristics pose certain limitations to capital accumulation. There is an interesting, and as yet unexplored, intersection here with the work of Ted Benton $(1989,1993)$ whose contribution to environmental 
sociology will figure prominently in the analysis that follows here. At this point we can suggest that such an engagement would benefit both environmental sociology and, perhaps more importantly, a tradition of Canadian political economy in which such questions have been largely absent.

Despite these differences in emphasis, what is common to all three of these labour process perspectives is the use of the 'case study', a methodology that has become synonymous with post-Bravermanian labour process studies. The use of a case study approach is generally justified in three kinds of ways. First, it can provide detailed accounts of what it is like to work in specific industries or firms, a valuable goal in itself considering the centrality of work to social life more generally and its historical absence as a site of social scientific research. Second, it provides a concrete site at which to investigate the larger forces and consequences of capitalism, the analysis of which can otherwise tend to remain overly abstract. And finally, a case study approach is useful in tracing in detail the transformations engendered by technological change in particular industries. While the tendency in the labour process tradition toward 'plant particularism', to use Paul Thomson's phrase (1989), has much to do with the case study methodology, is has nevertheless provided a wealth of empirical detail.

Central to the case study methodology is the use of (often participant) observation and interviews, strategies that have two kinds of justifications. First, because the labour process tradition tends to understand 'labour' as a particular category of people (i.e. direct producers or shop-floor workers), the experiences and interpretations of these workers are themselves viewed as important and constitutive aspects of labour process transformations. Second, because the purpose of the case study is to provide a detailed 
description of the labour process in a particular firm, observations and interviews are both an efficient and effective way of revealing aspects of the labour process that might by ignored or obscured by the more 'official' accounts provided by firms or industry organizations.

While a case study approach is no doubt valuable for all of these reasons, our interest in the significance of transgenic production for the meaning of nature would seem to point away from such a method for a number of reasons. First, we are interested in the labour process only insofar as it holds the key to grasping the significance of a specific technology for the meaning of nature. We thus want to avoid detailed descriptions of the labour processes within specific firms for their own sake as these would only distract us from our more abstract, ontological concerns. Second, we are not so much tracking the impact of technological change on a particular form of the labour process as we are delineating a new form of the labour process centered on transgenic life. Since we are primarily interested in 'inter-process' rather than 'intra-process' differences, a case study approach would be less effective than in traditional labour process studies. Finally, our theorization of the labour process as a metamorphosis of materials and forces of human and non-human nature involves a certain decentering of shop-floor workers insofar as living labour is conceptualized as only one among the many 'natural processes' involved in this metamorphosis. Our ontological focus, empirical object, and theorization of the labour process thus all point to the need for a more abstract methodology than the case study.

Our use of the concept 'labour process' here has much in common with those interested in explaining the role of technological change in generating broader structural 
transformations in the political economy of capitalism. ${ }^{24}$ While much of this 'postFordist' literature has tended to abstract technological change from the specificity of capitalism as a mode of production, there is a Marxian strain of work in this area that locates the engine of capitalist development in the labour process (Palloix 1976; Aglietta 1979; Blackburn, Coombs, and Green 1985; Mandel 1995; Teeple 2000). Rather than an empirical site at which to investigate the consequences of capitalist development, the labour process is here conceptualized as the "real heart of the economy" (Palloix 1976), where technological change is a central force in the production of capitalist social relations. The emphasis is thus on the qualitative disjuncture in capitalist development marked by labour process transformations, rather than on the degree to which these transformations 'reflect' the broader continuities of capitalism conceived in terms of the capital-labour relation. This approach aims at understanding broader changes in the form of the labour process and is consistent with Marx in his contrast between 'manufacture' and 'large-scale industry' in this regard - subsequent forms being variously defined as Fordist, neo-Fordist, advanced Fordist, informational, post-industrial and so on. Here the case study in eschewed in favour of a more abstract approach that draws broad distinctions between forms of the labour process and their broader significance

On the other hand, this 'broader significance' has not to this point included questions of nature. Despite Marx's emphasis on the role of labour process transformations in producing both new social relations and new human-nature relations, the latter have remained absent in Marxian analyses of the labour process. While Manuel Castells has engaged with these questions within a broadly 'post-Fordist' paradigm, his notion of 'mode of development', while having something in common with the Marxian 
notion of the 'labour process', emphasizes the materiality of production at the expense of understanding the specific form this takes in a capitalist mode of production. While we will return to Castell's argument a number of times in later chapters, we will turn now to a rather different approach in an attempt to revive the ontological significance of the labour process for questions of nature.

\section{Technoscience and the Construction of Nature}

While a focus on the labour process clearly locates the present work in the Marxian tradition of political economy, our interest in biotechnology and the meaning of nature requires that we engage with science and technology studies and, in particular, the constructivist perspective in this tradition of scholarship. The purpose of this section is to locate our approach to biotechnology and the meaning of nature in relation to this tradition and, in particular, to clarify the conceptual relation between the labour process and technoscience. Developments in biotechnology demand that political economists and constructivists begin to take each other seriously and bringing the labour process and technsocience into contact with one another reveals some surprising similarities.

Central to contemporary science and technology studies (Sismondo 2004) is the notion that 'nature', in one way or another, is a construction (Demeritt 1998). Drawing on the sociology of knowledge tradition, and the social construction of reality thesis of Berger and Luckman (1966) in particular, David Bloor (1976) argued early on for a 'strong programme' in the sociology of science in which the content of scientific knowledge would itself be open to 'social' explanation. Where Berger and Luckman had focused on the more 'everyday' social processes through which taken-for-granted 
ontological categories are constructed, proponents of the strong programme focus specifically on science as a set of practices through which 'nature' becomes constructed as an object of knowledge. Central questions have concerned the way in which these practices are 'shaped' by the broader social context and, in particular, the power relations characteristic of modern industrial societies (Barnes, Bloor, and Henry 1996; Collins and Pinch 1993).

Constructivism has opened up the content of the natural sciences to sociological investigation as well as provided a valuable critique of realist ontology more generally. And there is clearly something similar here to our own approach to the question of nature, at least insofar as they are both a critique of naïve realism. As we have seen, for Marx, nature is only ever meaningful in relation to the activity of human beings. The 'reality' of nature, its ontological status, must thus be explained with reference to this activity. Indeed, there is a sense in which Bloor was merely making more systematic and explicit a constructivist impulse that had always characterized the neo-Marxist critical theory of Lukacs and the Frankfurt school (influenced as it was by Heidegger) for whom nature is always, more or less, a social category.

Nevertheless, our approach to the question of nature differs from this social constructivist perspective in at least three important respects. First, there are neo-Kantian assumptions underlying the strong programme that are at odds with Marx's historicalmaterialism. For Kant, the 'reality' of the world is accessible to human beings only through categories of mind. Where for Kant these categories are transcendant, they become the objects of sociological explanation in the strong programme. Still, the question of 'nature' is here reduced to an epistemological question concerning the social 
construction of the concept of nature. For Marx, on the other hand, nature is the material whole of which human beings constitute a unique part by virtue of their capacity for purposive labour. In regulating their metabolism with nature human beings come to distinguish themselves from 'the rest of nature' and thus always confront nature as a differentiated unity. Of course human beings always possess a 'conception' of nature, but these conceptions are not somehow distinct from nature; rather, they are immanent in the materiality of nature itself. As we saw in chapter one, human beings are best conceived here as self-conscious nature

Thus, the second important difference, implicit in the first, lies in the way the process of 'construction' itself is conceptualized. If the question of nature is reduced to an epistemological question then the 'construction' of nature refers to a conceptual activity and the primary site of sociological investigation is the social construction of knowledge and, in particular, the social construction of scientific knowledge. However, for Marx, conceptions of nature are immanent in humanity's differentiation of itself from the rest of nature. The labour process is the primary site of this differentiation and so the meaning of nature must be sought in the materiality of this process. And again, a focus on the materiality of the labour process does not somehow negate the 'meaningfulness' of nature. Indeed, for Marx, it is only through its purposeful transformation that nature comes to have any meaning at all. Thus, it is not in spite of its materiality that human beings attribute meaning to nature, but precisely because of this materiality.

And finally, we must take a closer look at the conception of the 'social' that does the constructing of nature in the strong programme. Clearly, if nature is regarded as an epistemological category, and science is central in the construction of this category, then 
science is regarded as itself a social activity, or at least one that is 'shaped' by a broader social context. The difficulty here is that 'society' tends to be reified as the independent variable that explains 'nature', but one whose origin and development do not themselves require explanation. As Collins and Pinch suggest, "the truth about the natural world is what the powerful believe to be the truth about the natural world" (qtd. in Mermin 1996, 11). Now, despite the fact that many neo-Marxists have themselves embraced a kind of 'social shaping' perspective on science and technology, Marx is himself relatively clear in his emphasis on the labour process as a material transformation of nature, implicit in which is a particular division of labour and attendant property and class relations. Indeed, attributing primacy to the materiality of the labour process is the only way that changes in these 'social relations' can be effectively explained. While we will return to this point in greater detail in chapter 8, we can emphasize here that Marx does not explain 'nature' with reference to 'society', but explains both with reference to the labour process.

While this list of differences is by no means exhaustive, what is most interesting here is that the dominant perspective in more recent science and technology studies actor-network theory - distinguishes itself from the strong programme for similar reasons (Latour 1991; Law and Hassard 1999). Central to actor-network theory is a critique of the strong programme on the grounds that it takes 'society' as foundational in its explanation of the construction of scientific knowledge and, by extension, nature. While the strong programme called for 'symmetry' in looking for social explanations for both 'true' and 'false' scientific claims, Bruno Latour advances a 'second principle of symmetry' which requires that 'society' itself be explained with reference to the same kinds of constructive activities. Thus, there is a shift of analytical focus here from the 'social determinants' of 
scientific knowledge to the practice of science itself. And there has been a corresponding methodological shift away from social institutions to the 'lab' as the primary site at which the construction of nature, and society, takes place. At least at a relatively high level of abstraction, this perspective seems to have something in common with our own and so the remainder of this section will be devoted to a critical engagement with actor-network theory.

At the root of actor-network theory is a materialist ontology, central to which is the notion that nature requires explanation with reference to what Latour calls the 'practices of mediation' (1991). There are two important ways in which this approach differs from the strong programme that are worth emphasizing. First, rather than assuming an ontological distinction between society and nature and explaining the latter as an effect of the former, actor-network theory focuses on practices of 'translation', whereby networks of humans and non-humans are mobilized in the construction of hybrids, or quasi-objects, and practices of 'purification', whereby some characteristics of this hybrid world are categorized as 'natural' and others as 'social'. The second important difference is that, rather than the conceptual construction of nature as a mere 'category', actor-network theory emphasizes the degree to which 'nature' is both fact and artifact or, rather, the degree to which nature is constructed through mediating practices that are always simultaneously material and conceptual. Thus, rather than a perspective on science per se, ANT is a more general social theory with a distinct ontology and epistemology, and one that provides a valuable critique of currents of 'modern' social theory that have tended to take nature or society, or both, for granted. 
While ANT has been applied in the study of various sites at which the construction of nature takes place, it has of course been particularly useful in the study of the mediating practices of science, or what is generally referred to as technoscience in ANT. The concept of technoscience is used to destabilize a number of distinctions that are viewed as obscuring the mediating practices of translation. Most important for Latour in this regard is the distinction between science and society. Rather than attempting to discern the relation between 'society' and 'science', he uses the term technoscience to "describe all the elements tied to the scientific contents no matter how dirty, unexpected or foreign they seem" $(1987,174)$. Included in these dirty, unexpected, and foreign elements are "supporters, allies, employers, helping hands, believers, patrons, and consumers" (175) and rather than viewing these 'social actors' as merely shaping the direction of science, technoscience is intended to capture the degree to which these networks of actors constitute the practice of science itself. Rather than a set of pure relations between humans, 'society' is in this view made and remade through the practices of technoscience as networks of humans and non-humans are translated into a hybrid world of facts and artifacts.

The second kind of distinction that the concept of technoscience destabilizes is that between science and technology, and it does so in three senses. First, it highlights the degree to which science, rather than a disinterested pursuit of truth, constructs knowledge with an eye to its usefulness. While there is some ambiguity regarding whether this has always been the case, or whether it is now especially the case, ANT is generally critical of the notion that science is about 'discovery' while technology is about the practical use of these discoveries. Second, the concept of technoscience captures the role played by 
non-human artifacts in the construction of knowledge. Science, rather than merely a conceptual activity, is thus itself technological insofar as it must employ various instruments (microscopes, computers, research animals, etc.) in order to construct the facts. And finally, the notion of technoscience is intended to capture the degree to which the design of 'artifacts', or 'machines', is open to the same kind of constructivist perspective. Thus, the work of 'engineering' is similarly regarded as a translation of networks into hybrids. Indeed, we might regard the image of the engineer, rather than that of the scientist, as most compatible with ANT's notion of technoscience insofar as engineers have always been explicitly concerned with the construction, rather than merely the discovery, of worlds.

In light of this concept of technoscience, it is no coincidence that biotechnology and its attendant blurring of the boundaries between life science, engineering, and technology has received so much attention in science studies influenced by ANT. Drawing on the work of Latour and influenced by feminism and Marxism, Donna Haraway (1997) has analyzed biotechnology in a way that brings science and technology studies closest to our own perspective. Thus, while acknowledging a variety of valuable studies of biotechnology in this tradition, we will focus on her argument in particular.

Haraway considers biotechnology the quntiessential technoscience; indeed, she often uses it as a 'metonym' for technoscience as a whole insofar as it reveals more than ever before the processes through which contemporary worlds are made. First, biotechnology involves the construction of complex actor networks across a wide range of spheres that were previously considered relatively autonomous. Foremost in this regard is the unprecedented 'implosion' of the biological sciences and their instrumental 
application in the production of goods and services. Second, biotechnology 'translates' these actor networks into artifacts that constitute an unprecedented 'mixing' of human and non-human elements. And finally, the hybrid artifacts created through biotechnology are mixed to such a degree that they defy 'modern' ontological classifications and attempts at purification and therefore demand new ways of thinking about the relation between nature and society.

Haraway employs oncomouse as a 'trope' that can be 'read' to assess the significance of biotechnology as technoscience. Oncomouse is genetically engineered to develop cancer so that it can serve as a research tool for medical researchers. The creation of oncomouse has involved the construction of a complex network of actors including university administrators, scientists, business leaders, government officials, labs and lab equipment, and, of course, the mice themselves. The translation of this network into the artifact 'oncomouse' requires a mixing of these diverse actors at the molecular genetic level, and so constitutes a 'hybridization' in the most profound sense, challenging 'modern' distinctions between science and technology, universities and industry, and nature and society. In the face of this challenge, there have emerged numerous struggles to redefine the boundaries between these spheres and purify the world of the oncomouse. Emerging struggles over the commercialization of science, the corporatization of universities, and the patenting of life-forms can all be read as ontological struggles over boundary construction in a world where previous, taken-for-granted dualisms have become thoroughly destabilized.

Now, returning to the question of the relation of our labour process approach to ANT, we can suggest that ANT's 'materialist' critique of 'modern' ontology does not 
apply to Marx's historical-materialism. Nowhere does Marx assume an a priori distinction between 'society' and 'nature' and then seek to identify the impact of one upon the other. As we have seen, labour is Marx's central ontological category and the relations of human beings to non-human nature and each other must be explained with reference to this process. In fact, the conceptual role of technoscience in artifactual constructivism is strikingly similar to that of the labour process in Marx's historical materialism. Both reject foundational ontologies and shift analytical attention to material practices, processes and relationships. Both view nature in particular as only meaningful in relation to human activity. Both attribute primacy to the engagement of human and non-human components and avoid assuming an active human 'subject' standing opposed to a passive non-human set of 'objects'. In short, both constitute materialist critiques of 'modern' ontology and focus on the practices of mediation, rather than on the interaction between the mediated. Haraway refers to herself as "something of an unreconstructed and dogged Marxist" $(1997,8)$ and it is a great strength of her work that she recognizes a kinship between studies of technoscience and Marxian political economy.

On the other hand, while playing a similar conceptual role in a more general social theoretical perspective, the practices of technoscience are clearly different than those generally associated with the labour process. With Heidegger, ANT locates the origin of the 'modern' conception of nature in the production of scientific knowledge and the design of technology. The scientist and engineer are viewed as mobilizing a wide variety of humans and non-humans in order to construct 'nature' in a way that is consistent with 'modern' goals of control and domination. In the end, the construction of nature here refers to the process through which these and other modern values become 
embedded in, and in turn are bolstered by, the facts and artifacts created by scientists and engineers. Question of the employment of technology as industrial instruments of production, their relation to capitalism as a mode of production, and their role in revealing the 'active relation of human beings to nature', are relatively absent.

And, coversely, we must admit that our labour process perspective, while emphasizing technology as industrial instruments of production, has left the practices of the scientist and engineer rather undertheorized. We did see in Marx the importance of science to the development of industrial capitalism insofar as the machine encourages the 'search' for the 'laws of nature' in order to develop the forces or production now liberated from the limitation of human physical capacities. However, this tells us little about the practices of science and engineering and, in particular, the way in which these practices are themselves implicated in changes in the meaning of nature. Our focus has thus been decidedly been on the employment of technology in the production of things rather than on the production of knowledge and design of things. This has been, however, less a 'modern' oversight than simply a reflection of our interest in a rather different set of mediating practices.

Now, there is a sense in which our object of investigation itself has led us toward the industrial production of things. In an attempt to clear up some of the confusion in definitions of biotechnology we found that the creation and employment of transgenic life as itself a technology for the production of useful substances gave more precise meaning to the term and suggested a genuine disjuncture in the relation human beings to living nature. We distinguished this 'transgenic biotechnology' from 'bioscience' because, while the latter is focused on the construction of life as an object of knowledge, we are 
interested in the significance of living technologies. Thus, while not necessarily denying the importance of bioscience and the production of knowledge to the development of biotechnology and changes in the meaning of nature, we began with a specific object of investigation that seems to point in the direction of industrial labour processes.

Yet, the distinction we are making is not as clear cut as it first seemed. We have seen in the work of Haraway the importance of oncomouse to bioscience and, to this point, we have assumed that oncomouse is best understood as a product of genetic engineering whose role is that of an object of knowledge rather than a technology per se, what Rheinberger calls an 'epistemic object' rather than a 'technical product' $(1997,31$ 32). Yet, might we not regard oncomouse also as a technology insofar as it is employed as an instrument, or technical product, in the production of bioscientific knowledge? And, if so, would we not need to include in our definition of transgenic biotechnology oncomouse and apply our labour process perspective to bioscience as well? Could not the role of transgenic biotechnology in the production of knowledge mark as significant a disjuncture in the human-nature relation as that marked by its role in the industrial production of things?

There are three ways in which we might address these questions, none of which are entirely adequate, all of which raise more questions. First, we might simply avoid the questions altogether and simply make a qualitative distinction between the use of life in the production of scientific knowledge and its employment in the industrial production of things. We might then accept a division of labour between actor-network theory, or science and technology studies more generally, and labour process theory, with the latter being specifically appropriate to the study of industrial biotechnology and its significance 
for the meaning of nature. And such an approach would not be as perfunctory as it might first seem; indeed, the absence of a concern with the industrial employment of technology in ANT would seem to suggest such a qualitative distinction and division of labour. Thus, where understanding oncomouse might require Heidegger, Foucault, actor-networks, ethnographies, and modernity, understanding 'living factories' requires Marx, Braverman, means of production and labour, case studies, and capitalism. The difficulty with such an approach, however, is that it does not explain the relationship between science and industry and, in particular, how the production of knowledge and the production of things became distinct in the 'modern' period in the first place, only to be reintegrated in the 'post-modern', or 'amodern', period.

Alternatively, then, we might suggest that science and the production of knowledge, rather than a set of mediating practices sui generis, is in fact better understood as part of a broader labour process who primary purpose is the production of things. While admitting of the relatively unique practices of 'technoscience', and granting the value of actor-network theory in understanding it, we might thus enquire more deeply into its relation to the industrial capitalist system of commodity production. Yoxen suggested early on that the 'molecular vision of life' was particularly compatible with harnessing living nature as a force of industrial production (1983; see also Kay 1998). Others have pointed to the compatibility of reducing life to 'genetic information' with a shift to informational capitalism more generally (Kenney 1986; Schiller 1994). This work emphasizes the degree to which the construction of living nature through science does not occur in the abstact, but always in a form that facilitiates, or is at least compatible with, its industrial transformation into useful things. Thus, it is to transformations of 
capitalism, and the labour process in particular, that we would look to explain "the implosion of science and technology" (Haraway 1997, 50) characteristic of biotechnology, just as the advent of a labour process centered around machinery explains the increased importance of science in production and the emergence of engineering (Noble 1977).

Finally, a more radical approach would be to deny that there is any conceptual difference at all between the production of knowledge and the production of things and to apply a labour process approach to bioscience itself. Robert Young argued again and again in the 1970s that science is a labour process. Scentists and engineers would in this case be regarded as becoming increasingly proletarianized and the instruments (or nonhumans) employed in the lab would be means to the transformation of a raw material which in this case would be knowledge itself - into scientific knowledge, knowledge that itself increasingly takes the commodity form. Oncomouse would thus constitute a transgenic biotechnology like any other, a means of production in a labour process subordinated to generalized commodity production and the self-expansion of capital. The great advantage of this perspective would be that it would require that a Marxian political economy take seriously bioscience as a set of material practices, while emphasizing the historical-material specificity of these practices in a capitalist mode of production. It would thus bring Marx into confrontation with ANT, a valuable exercise in itself and one that, with a few notable exceptions (e.g Sunder Rajan 2006), has received little attention. Nevertheless, the role of transgenic life in the biosciences, and the significance of this construction of life as an epistemic object and technical product for the meaning of nature, will remain largely beyond the scope of the analysis here. We must remain 
satisfied with acknowledging questions concerning science and the construction of knowledge, and admitting the limits of the argument here, which will focus specifically on the creation and employment of transgenic life as a technology in the industrial production of things. This is not to suggest that a labour process perspective is incapable of analyzing bioscience, only that such an analysis raises questions the complexity of which demand sustained attention in their own right. We can, however, before turning to our analysis of the transgenic labour process, assess work in environmental sociology, where the employment of the labour process as a site at which to investigate questions concerning nature provides fertile ground for the cross fertilization of Marxian political economy and constructivist science and technology studies.

\section{The Fertile Ground of Environmental Sociology}

Existing on the border between sociology and social geography, environmental sociology has emerged as the sub-discipline most concerned with theorizing nature in a way that avoids the Scylla and Charybdis of social constructivism and naïve realism. Its origins in a rejection of a perceived 'human exceptionalism' in the sociological canon, early environmental sociology tended to embrace ecological thought and all of the difficulties that accompany an attempt to come to terms with nature in abstraction from its specific forms in relation to human labour, social relations, and ideologies (Dunlap, et al.). More recently, however, attention has shifted toward recovering the concept of nature from the classics, a move which has served to bolster the sociological critique of ecology, as well as stimulate amongst sociologists an interest in questions of nature that had largely been lost in the $20^{\text {th }}$ century. 
The most fruitful strain of environmental sociology has proven to be that focused on recovering the concept of nature in Marx's work. And, most importantly for our purposes, much of the debate has revolved around differing conceptions of the labour process. Reiner Grundmann (1991) conceives of technology, and the labour process more generally, in decidedly 'Promethean terms', as a mastery, or domination, of nature. John Bellamy Foster (2000), on the other hand, makes much of the notion that capitalist industrial labour processes constitute a 'metabolic rift' in the 'society-nature' relation, threatening the existence of both. For social geographer Noel Castree (2000), capitalist labour processes are best conceived in terms of a 'production of nature as a commodity' and Ted Benton (1989) suggests the need for an ecological reconstruction of historical materialism that focuses on reconceptualizing the labour process. Despite their disagreements, common to all is the recognition that addressing the question of nature requires a focus on the material engagement of humans and non-humans in the labour process; it requires putting the 'material' back in historical materialism.

While we will return to the substance of their disagreements in a later chapter, we can see in this tradition as a whole a conceptualization of the labour process that comes closest to our own. Rather than interesting for its own sake, or as a site at which to investigate the consequences of capitalist development, the labour process is attributed theoretical primacy for ontological reasons; that is, for its role as a set of mediating practices through which the human-nature relation is constituted and articulated (in some way) with the broader logic, relations and structures of capitalism. The labour process is thus not 'read off' capitalist social relations, nor regarded as an uncomfortable meeting of 'technical' and 'social' concerns, but as the site at which the world is made, and it is to 
the particular forms of this making that analytical attention must be directed if we are to assess the significance of a specific technology for the question of nature.

In addition to conceptualizing the labour process in a way that makes it invaluable for understanding the meaning of nature, work in this tradition also employs a methodology that will prove useful for our purposes. Marxian environmental sociologists are often interested in comparing different kinds of labour processes in order to bring into relief the important points of disjuncture. A contrast between 'agricultural' and 'industrial' labour processes lies at the foundation of most analyses, a distinction that becomes increasingly important when considering the significance of biotechnology. This comparative approach, one that distinguishes the broader contours of forms of the labour process rather than focusing on the site specific details of what goes on in transgenic firms, will be central to our delineation of the transgenic labour process in chapters 4-6.

The work of environmental sociologist Ted Benton (1989) exemplifies the usefulness of this kind of comparative approach to the labour process at a relatively high level of abstraction. Benton's argument for an ecological reconstruction of historical materialism rests on his identification and comparison of (at least) 3 distinct types of labour processes each of which constitutes a qualitatively distinct human-nature relation: instrumental-transformative, eco-regulatory, and extractive. While the details of his argument will be discussed in later chapters, what is important here is the level of abstraction at which Benton carries out the analysis, recognizing, with others, that posing questions concerning the meaning of nature requires stepping back from specific casestudies and reassessing the concept of the labour process itself. Also, as mentioned, Benton's 'extractive' type finds interesting parallels in the work of Wallace Clement on 
fishing and mining, and indeed suggest the possibility of a reevaluation of the staples tradition in Canadian political economy and its usefulness for addressing questions of nature. There are also parallels with work in rural studies, and in particular the work of David Goodman (Goodman, Sorj and Wilkinson, 1987; Goodman and Redclift, 1991; Goodman, 2001), who is interested in drawing a broad distinction between industrial and agricultural labour processes, central to which is the different role played by 'nature' in each.

And so, with our return to Goodman, we have come full circle to where we began in chapter 1 , with the need to reconceptualize the labour process in a way that enables us to grasp the significance of biotechnology for the meaning of nature and, in particular, the degree to which it constitutes a disjuncture in this meaning. However, we now have before us a much clearer sense of the 'labour process' and 'biotechnology' in question, and where we sit in relation to other approaches. It is now time to bring our labour process approach and object of investigation together in a more concrete analysis of the transgenic labour process. This analysis will be the substance of chapters 4-6, and its broader ontological significance for nature and capitalism will be addressed in chapters 7 and 8. 


\section{4 - Harnessing Life as a Force of Production}

Edward Yoxen argued in 1983 that the significance of molecular biology, and its 'reductionist' conception of life, lay in the degree to which it would facilitate the emergence of 'life as a force of production'. What Yoxen meant by this, and what others have meant who have subsequently made similar kinds of arguments, is that developments in molecular biology, and rDNA in particular, allow for a repositioning of the biosciences in relation to industry so that they might play the kind of research and development role assumed by the physical and chemical sciences beginning in the $19^{\text {th }}$ century. What such analyses have paid much less attention to, however, is whether life itself - the actual living organisms - might be repositioned as instruments of industrial production and the degree to which this harnessing of the forces of living nature as a force of production constitutes a disjuncture with past uses of life to meet human needs. Our conception of a transgenic labour process centered on the creation and employment of transgenic life as an instrument of production brings just this question to the fore.

This chapter assesses whether the transgenic labour process constitutes an industrial form of the labour process - and transgenic biotechnology an industrial instrument of production - and the degree to which this constitutes a disjuncture with past uses of life as a means of production. In the first section I argue that, despite a tendency amongst many to exclude 'life' from definitions of industry, a transgenic labour process is indeed best regarded as an industrial form of the labour process that works up living materials into instruments of production whose unique productive force derives from a harnessing of the synthetic capacities of life-itself as forces of production. In the following sections I distinguish the three modalities of transgenic production from past 
uses of microbes, plants, and animals, in industrial microbiology, agriculture, and animal husbandry respectively. I argue that, while characterized by diverse practices with long histories in brewing, agriculture, and animal husbandry, the transgenic labour process constitutes a disjuncture in the degree to which living nature is harnessed as a force of industrial production and is thus best understood as a distinct form of industrial labour process whose modalities derive their specificity from the unique characteristics, capacities, and requirements of the organism transformed and employed.

\section{The Industrial Logic of Transgenic Production}

Traditional distinctions between agriculture and industry pose an immediate obstacle to understanding life as a means of industrial production. "Industrialism," argues environmental historian Colin Duncan, "is most usefully conceptualized as a series of transformations performed on lifeless matter comprising both inherently nonliving matter (e.g., minerals) and long-dead matter (e.g., fossil fuels)" (1996, 29; emphasis added). He contrasts this with agricultural production, central to which is the transformation of 'living matter', and is consistent with the tradition of rural sociology more generally in doing so. The notion that organisms might themselves be forces of industrial production would thus seem problematic in these terms insofar as what is distinct about industry is precisely its exclusion of life.

Leaving aside, for the moment, the question of the relation between agriculture and industry, the definition of industry above is inadequate even on its own terms because it fails to distinguish between production centered around hand-tools from that centered around machinery, a distinction that, as we have seen, is crucial to 
understanding the significance of industrialization for the meaning of nature. This difficulty arises from an attempt to distinguish industry by the raw material that is transformed, rather than by the unique logic underlying this transformation. As we saw in our discussion of Marx in Chapter 1, this logic is one whereby materials of nature are transformed into instruments of production that harness the forces of non-human nature as forces of production. This definition is useful in distinguishing industry from labour processes centered around hand-tools insofar as the latter is characterized by the transmission of a force of human nature through a 'modified natural thing' onto a 'natural object'. Its crucial significance for our purpose here, however, is that this definition of industry does not necessarily exclude the transformation and employment of living systems as instruments of production.

Of course we must remain sensitive to what is unique about living nature if we are to avoid regarding it as merely one more industrial input. Unlike non-living matter, an organism is a form of nature whose existence as such requires that it engage in an active exchange with a specific environment. All organisms 'take in' from their environment particular amounts and kinds of nutrients, heat, and light - what we will call their 'system requirements'. The life-process of the organism is the transformation of these requirements into the various materials necessary for its growth and development, a most important of which are proteins. As part of this life-process all organisms in turn give back to the environment in the form of heat and waste. Insofar as the organism's DNA determines the structure of these proteins, it is best understood as a set of molecular instructions that guide the life-process of the organism and the functioning of the living system as a whole as it transforms its system requirements into materials, some of which 
are required for growth and development (e.g. structural proteins), others of which are 'released' into its environment.

The transgenic labour process transforms these living systems at the molecular genetic level so that they will issue in substances that they would not otherwise produce. We can distinguish 3 kinds of practices characteristic of this transformative process. First, the organism is filtered out of its found environment. This purification of the found organism ensures that it is relatively free of contaminants that might interfere with the efficient creation of a transgenic organism. Second, the gene of interest and vector must be 'cut and pasted' together through the process of recombination. The result is a recombinant DNA molecule containing the gene of interest and vector DNA. Finally, the rDNA molecule must be inserted into the purified organism so that it may be expressed and the desired substance produced. This transformation results in a transgenic biotechnology, an organism that, as part of its life-process, produces a 'foreign' substance that meets some determinate human need.

Now, in order that a transgenic system might issue in a commercially viable quantity of the substance, a population of transgenic organisms must be 'scaled-up', a process central to which are 4 kinds of analytically distinct practices: media prep, inoculation, and monitoring/regulation and retrieval. First, an environment, or media, containing the system requirements of the transgenic organism must be constructed at increasing scales. All organisms require certain amounts and kinds of nutrients, heat, light, and air and these are generally provided at lab, small batch, and production scales. Second, at each scale the environments must be populated, or inoculated, with transgenic organisms in order that they may grow, develop, and produce protein in increasing 
quantities. Third, the efficient functioning of the living system at each scale requires practices of monitoring/ regulation designed to ensure the growth and development of transgenic organisms within specific parameters. And finally, once the system has reached optimum growth the substance must be retrieved from the living system. Retrieval of the substance from the living system generally means the 'disruption' of the life-process of the transgenic organism by chemical or physical means. The goal of scaleup is a living production system, the 'engine' of which is the life-process of a population of transgenic organisms.

While the practices outlined here are unique insofar as they are centered on the transformation and scale-up of living nature, what is striking here, at this level of abstraction, is the degree to which the transgenic labour process corresponds to the logic of industrial production. The process begins with the modification of the DNA of an organism so that it produces a protein that it would not otherwise produce. Here we have the transformation of a natural material (an organism) into an instrument of production (a transgenic organism). This instrument is then employed in the production of protein on an industrial scale, thus harnessing a force of nature (the capacity of life to synthesize proteins) as a force of production. While we have yet to assess what is distinct about transgenic production in this regard, we can define the transgenic labour process as the harnessing of living nature as an industrial force of production and the transgenic organisms themselves as industrial technologies. We can thus already see here the degree to which a transgenic labour process problematizes traditional distinctions between agriculture and industry insofar as it harnesses living nature as an industrial productive force. 
Now, our interest in assessing the disjuncture marked by a transgenic labour process requires that we ask if there is anything terribly new here. Traditional distinctions notwithstanding, there would seem to be at least two precedents for this kind of border crossing between agriculture and industry. First, there are the industrial microbiological labour processes that are the focus of Bud's history, which have long employed microbial life in the production of useful substances. Second, there is the "industrialization of agriculture', or 'factory farming', that is so often the object of investigation amongst rural sociologists and seems to imply the use of plant and animal life as means of industrial production. Comparing our transgenic labour processes to these will enable us to both thicken our description of the transgenic labour process and specify in a more concrete way the lines of continuity and disjuncture marked by the creation and employment of transgenic life as an industrial force of production.

\section{The Factories are Alive: Transgenic Microbial Production}

Even a cursory glance at the history of industrial microbiology reveals the inadequacy of distinguishing industry by virtue of its exclusion of life as a means of production. As Robert Bud (1993) demonstrates, this history dates to the late $19^{\text {th }}$ century with the greater understanding of the life-process of micro-organisms (fermentation) that emerged out of the work of Pasteur and others. Where they had been little understood and their use limited to brewing, they were now increasingly used in pharmaceutical, fine chemical, and food production. For Bud, this history suggest that there in nothing terribly new about 'new biotechnology' and that, despite the importance of genetic engineering, there is more continuity than disjuncture in the industrial use of life. Bringing Bud's argument 
to bear on transgenic microbial production in some detail will demonstrate that, despite the important continuities highlighted by Bud, transgenic microbial production constitutes a significant disjuncture in the industrial employment of microbial life.

Bud's claim regarding the continuity of biotechnological development rests on two strands of interrelated argumentation. First, he locates the origin of many of the instruments and techniques of 'new' biotechnology in the late $19^{\text {th }}$ century and traces their development to the present. Central amongst these is the development of fermentation technology. While the term 'fermentation' technically refers to the lifeprocess of any organism as it transforms its system requirements into protein, it has come to be specifically associated with the employment of microbes (e.g. yeast) to transform 'feedstock' (e.g. starch) into a useful substance (e.g. alcohol). While such fermentation is carried out by micro-organisms in their 'found' environments, the harnessing of this process as a force of production has required that it be contained in a 'fermentation tank' which allows for the manipulation of the system requirements of the microbes, the monitoring and regulation of their growth and development, and the extraction of the product of their life-process. Bud emphasizes the role of biochemical engineers in both the development of fermentation technology and its industrial employment and argues that the continuing importance of these traditional technologies and forms of labour suggest that there is far more continuity in biotechnological development than a focus on the techniques of genetic engineering would suggest.

The second strand of Bud's argument traces the discourse surrounding the development of industrial microbiology, a discourse that has both reflected the technical developments, and itself served to shape this development. It is no mere coincidence that 
the term biotechnology emerges alongside the increased understanding of the life-process of micro-organisms. On the one hand, the term gives meaning to a use of life in production that, while common in brewing since the ancient Egyptians, had been little understood. On the other hand, the term - in its discursive implosion of life and the practices of engineering - helps to reposition living nature as an instrument to be employed by human beings in the satisfaction of their needs. As Bud and others (Yoxen 1983; Kay 1998) suggest, such a shift in the meaning of life has been crucial in the mobilization of financial support for research in the biological sciences. Thus, both the technology and the discourse of biotechnology demonstrate, for Bud, more continuity than disjuncture.

We have already seen the value of Bud's work in focusing our attention on the use of life as an instrument of production and there is much to recommend in his argument regarding continuity more generally. The employment of transgenic microbes in the production of useful substances does in fact look very much like any other industrial microbiological labour process. ${ }^{25}$ Transgenic microbial production centers on the fermentation tank that provides the system requirements for the population of microbes. The microbes take in these requirements and synthesize the desired protein as part of their life process, a process that is attended to by biochemical engineers who both design and create the production facility, as well as monitor and regulate the production process itself via the fermentation tank. As Bud argues, there would appear to be a great deal of continuity here in terms of the technology and labour required for the employment of microbial life as an industrial force, and whether the microbes in question are transgenic or not would seem less significant than these lines of continuity. 
Yet, there may be something more to the fact that the microbes are transgenic than is captured in Bud's history. Martin Kenney (1986), in his own seminal contribution to the subject, provides a definition of biotechnology that suggests a greater rupture in this regard. While acknowledging the long-history of the "use of biological systems for the fulfillment of human needs", Kenney argues that this use "has always, until recently, involved naturally occurring organisms whose internal metabolism was not understood" (1). He distinguishes between this 'old' biotechnology and the 'new' biotechnology made possible with the advent of rDNA in the early 1970s that makes "living cells into tiny factories for the production of items satisfying human needs" (2). While there is some confusion in Kenney's definition of 'biotechnology', the notion that what is new is the degree to which life is made, rather than 'found', is what is crucial. Understanding the practices through which this making takes place alerts us to the very different position of life in a labour process whose goal is the transformation of living organisms into tiny factories.

Where the microbes characteristic of the history of the 'old' biotechnology are found, relatively ready-made for participation in fermentation processes, the microbes of transgenic production are worked-up into instruments of production and thus enter the transgenic labour process first as an object of labour. Microbes are 'found' in complex environments - characterized by non-target species as well as other 'undesirable' materials - from which they must be purified in order to be further processed. ${ }^{26} \mathrm{~A}$ sample material known to contain the target species of microbe is added to a 'selective medium' specifically designed to fulfill the system requirements of the target species. The incubation of this 'enrichment culture' results in the growth of the target species at the 
expense of non-target species of cells and other contaminants. Once the medium has become saturated with cells, a sample of the culture is taken and a fresh selective medium is inoculated. Incubation of this culture results in an even greater population of the target species. This continues until a 'pure culture' is achieved, which can then be 'plated out' to facilitate the isolation and selection of individual 'purified' cells. Once a species of microbe has been purified in this way, it can be stored, reproduced and supplied to genetic engineers as a raw material - an object of labour that has been, to use Marx's phrase, "filtered through previous labour" (1976: 284).

Working up this microbial raw material into a transgenic biotechnology requires that it be transformed through the insertion of a rDNA molecule containing the 'target DNA' and a vector. The evolution of a living world characterized by relatively distinct species is premised upon the ability of one species to maintain the integrity of their DNA. As a threat to this integrity, the insertion of foreign DNA into the genome of a cell, by a virus for example, is met with resistance on the part of the cell. Overcoming this is the purpose of transformation, which can be generally divided into physical and chemical techniques. ${ }^{27}$ Physical techniques of transformation aim at destabilizing the cell membrane through electric shock (electroporation) so that rDNA molecules can pass through. Chemical techniques involve the mixing of cells with rDNA in a chemical solution that renders the cell membrane porous to the rDNA molecules. Regardless of the technique, there is a relatively low probability that a microbe will 'take up' foreign DNA. Nevertheless, the aim of transformation is to produce at least some transgenic cells that have incorporated the gene construct into their genome. These cells can then be separated out from those that, for a variety of reasons, did not 'take-up' the foreign DNA and again 
immobilized until they are required for employment. The end result is a microbial transgenic biotechnology, materials of living nature worked-up into instruments of production and infused with human purpose.

We can now begin to see an important disjuncture that is obscured by Bud's long history of biotechnology. We saw in our definition of industry that it involves a specific logic of transforming and harnessing materials and forces of nature. Transgenic microbes can in this sense be regarded as industrial technologies in that they are a product of labour whose productive force lies in their harnessing of the synthetic capacities of living nature to the production of useful substances. However, as Kenney points out, prior to the advent of rDNA these microbial capacities, while indeed harnessed, were not transformed in any meaningful sense. Thus, there is an important sense in which a found microorganism is not an industrial technology per se since it is simply separated from its environment. Now, while we may not want to make such a sharp distinction - after all, even 'found' organisms go through some processing - a look at the practices of creation reveals the degree to which microbial biotechnology comes to be only with the capacity to transform living materials in a way that harnesses their capacities to the production of useful substances. Thus, while the term biotechnology may have been employed, rather loosely, in the past, its pervasiveness with the advent of rDNA, rather than a mere rhetorical shift, reflects an important qualitative disjuncture in the degree to which life is a technology.

But might we still not be able to accept the novelty of genetic engineering while locating it within a broader continuity of industrial microbiology? After all, Bud himself is willing to admit the novelty of rDNA, but, again, views this as relatively continuous 
with the long history of biotechnology insofar as the employment of these organisms takes place in the same way. And indeed, as we shall see shortly, practices of fermentation have not required any fundamental transformation to accommodate transgenic life. Bud's focus on industrial microbiology, then, does appear to support the notion that rDNA (or genetic engineering more generally) is best understood as a new technique within the overall continuity of biotechnological development.

But perhaps this is precisely the problem - that a focus on the use of a particular form of life in a particular productive sector tends to obscure the broader significance of transgenic biotechnology. Bud's work is useful in defining biotechnology as the use of life in industry and thus avoiding the confusion that often attends definitions in work concerned with agriculture. Yet, in focusing exclusively on the use of microbial life, his analysis obscures the degree to which genetic engineering is repositioning life-itself as an instrument of production, the employment of transgenic microbes in fermentation tanks being only one modality of this more general harnessing of life to an industrial labour process. Thus, rather than a form of labour process sui generis, practices of fermentation might in this case be better regarded as a modality of a transgenic labour process whose unique characteristics reflect the specific system requirements of microbial life.

While all organisms need to live in a specific environment in order to meet their nutritional requirements, microbes are unique in that they require immersion in a liquid media, called a broth, in order to grow, develop, and reproduce. A central task of the biochemical engineer is to design and prepare a broth with a specific chemical composition that will ensure that the microbial system produces the required protein. ${ }^{28}$ The broth thus contains the 'raw material', or feedstock, that is transformed by the 
microbial population into a specific recombinant protein. As the population of cells grows, subtle adjustments must be made to the composition of the broth in order that the cells might function as efficient producers of the recombinant protein. The broth is contained in fermentation tanks that are generally constructed at lab, pilot, and production scales to accommodate the growth of the cell population. At each scale the requirements of the population changes, changes to which fermentation tanks are designed to respond. $^{29}$

Employing the transgenic microbe in the transformation of this raw material requires that the broth be inoculated with the living technologies, a set of practices that begins with the removal of a small population of the microbes from a cell bank constructed to ensure the maintenance of the transgenic population in near perpetuity. ${ }^{30}$ The sample is injected into the broth contained in the lab-scale fermentation tank. The cell population grows until the media is saturated and the population reaches a 'lag phase' at which point a sample is removed and used to inoculate a pilot-scale fermentation tank. The production run commences once the broth in a production-scale fermentation tank is inoculated with a sample of the transgenic microbial cell population. For the most part, the run ends once the production-scale population has reached its lag phase, at which time the process begins again. While this 'batch run' method is the norm in transgenic labour processes, there are in some cases continuous methods being developed whereby the protein can be extracted from the broth in-process and production can continue without going through the inoculation process again. ${ }^{31}$ In any case, what you have here is a kind of 'living factory' at the centre of which is a transgenic microbe that works-up the feedstock into a useful product. 
Regulation and monitoring of transgenic microbial systems strives to ensure that growth and development of the population proceeds within set parameters once it is 'set in motion'. Monitoring can take place either on-line with the use of sensors built into fermentation tanks, or through the drawing and testing of a sample of the broth containing the cell population. In the event that the growth and development of the population deviates from the set parameters, fermentation tanks enable alterations to the system requirements. The goal is to ensure an efficient production run that concludes when the cell population is deemed to have produced all of the recombinant protein it can during its life-process. At this point the protein can be retrieved from the transgenic system.

Once the production run is complete the substance must be retrieved from the transgenic microbial system. While these practices are generally the same for all transgenic microbial production, two variables are important in determining how the substance is purified from the living system. First, where extra-cellular production requires merely the separation of the substance from the media into which it is 'released' by the microbial population, intra-cellular production requires the 'disruption' of the lifeprocess of the cells (through either exposing the cells to a 'denaturing' chemical or physically rupturing them, often through forcing them through a narrow tube) in order that the protein can be released into the media and retrieved. Second, where 'batch' production requires that the living system be constructed anew once the protein is retrieved, continuous production involves the retrieval of a quantity of the (extra-cellular) protein from a transgenic living system that remains in operation. These variables are 
determined by the species of cell used, the recombinant protein produced, and the 'state of the art' in fermentation and other technology, as well as marketplace considerations.

There are thus clear lines of continuity here with the 'industrial microbiology' that is the focus of Bud's work; and indeed, industrial microbiology might be regarded as the model to which all transgenic production aspires as its location in a 'factory' setting, rather than the field or barnyard, constitutes the clearest harnessing of life as an industrial productive force. However, our analysis of transgenic microbial production reveals an important disjuncture in the degree to which transgenic organisms are made, rather than found, and the significance of this for the meaning of life in production. Life is a technology here in an unprecedented sense insofar as the synthetic capacities of living nature itself are transformed and harnessed to industrial production. Transgenic microbial production, rather than a labour process sui generis as has been the case with industrial microbiology, is better regarded as a modality of transgenic production more generally, whose specificity derives from the unique life-process of microbes. In order to make this specificity clear, we must turn to the other two modalities for comparison.

\section{The Machine is the Garden: Transgenic Plant Production}

Where Bud's history of industrial microbiology challenges the conceptual distinction between agriculture and industry through highlighting the use of microbes in a factory setting, rural sociologists have long pointed to a rather different boundary crossing: the industrialization of agriculture. The work of Goodman, Sorj and Wilkinson (1987) is seminal in this regard and provides the theoretical framework within which many in this tradition continue to work. Central to their argument is the notion that 
agriculture is unique in its reliance on the 'natural production process', by which they mean the "biological transformation of solar energy into food" (1). Because there has been no way of reproducing this process of living nature as an industrial labour process, the industrialization of agriculture has taken a unique path. Where labour processes centered on handicraft can be fully subsumed under industrial capital, the industrialization of agriculture has had to take place in a piecemeal and more indirect way.

According to Goodman, Sorj, and Wilkinson industrial capitals have employed two distinct strategies in their efforts to subsume the agricultural labour process. First, they have sought to appropriate the agricultural labour process through the industrial production of inputs. Where the industrial production of machinery and chemical inputs (fertilizers and pesticides) characterized the $19^{\text {th }}$ and early $20^{\text {th }}$ century, increasing attention has been paid throughout the $20^{\text {th }}$ century to the production of hybrid and high yield varieties of seed. The second strategy is one whereby industrial labour processes are substituted for those dependant on the natural production process. Particularly important here are the chemical industries that emerged in the late $19^{\text {th }}$ century and their ability to create 'synthetic' fibers and food additives. This strategy constitutes a more fundamental challenge to agriculture as it removes production entirely from the land. Both, however, point to a slow, but inevitable, industrialization of food and fiber production and, insofar as substitution could become generalized, the end of agriculture all together.

The significance of biotechnology for Goodman, Sorj, and Wilkinson lies in furthering these relatively continuous processes of appropriation and substitution and here their work is prescient. In terms of appropriation, genetic engineering of seed has 
allowed for greater control of the primary input of agricultural production to be concentrated in the hands of large chemical producers. Monsanto is exemplary here. Originally a chemical producer, Monsanto has more recently shifted its productive resources to 'biotechnology' in the form of transgenic seed genetically engineered to be resistant to its fertilizers and pesticides. And in terms of substitution, the ability to create transgenic microbes suggests the possibility for a much greater variety of food and fiber production off-farm. A recurring theme in this approach is the notion that biotechnology constitutes a kind of final blow to the autonomy of agriculture, but the emphasis remains squarely on the lines of continuity in this industrialization of agriculture.

Now, it is important to note here the degree to which this emphasis on continuity is premised upon the particular position of plant life in the agricultural labour process. As we saw in our conceptualization of biotechnology in Chapter 2, plant life constitutes the raw material that is 'worked-up', from seed to mature plant, into a useful product. The instruments of agricultural production are best understood here as those required for this working-up of living material into food and fiber. And insofar as this working-up is accomplished by elements of the biosphere (sun, rain, soil, etc.) agriculture rests upon a 'natural production process' and, indeed, Goodman, Sorj, and Wilkinson refer to the soil as the 'factory' of agriculture.

This conceptualization of plant life as the raw material of agricultural labour processes is reflected in the two trajectories of biotechnological development identified by Goodman, Sorj, and Wilkinson. Biotechnological development is limited to either the creation of this raw material in the form of transgenic seed - what we are calling 'genetic engineering' - or the creation and employment of microbes as instruments in the 
production of synthetic food and fiber. In both cases, however, the 'natural production' process, the growth and development of plant life itself, remains outside the process of industrialization. The industrialization of agriculture, in this sense, takes place through a kind of subversion of 'nature' insofar as 'industry' is equated with off-farm production of inputs (appropriation) or final products (substitution). Thus, industry does not overcome the natural limitations to the labour process but simply sidesteps them, spelling not so much the 'industrialization of agriculture' as much as the end of agriculture all together.

But how would we understand Sembiosys within this theoretical framework, or Medicago, a company whose Proficia protein technology "harnesses the unique properties of alfalfa to produce therapeutic proteins"? Like Monsanto, they genetically engineer plant life, but the plant, rather than a raw material in the production of food and fiber, is instead an instrument in the production of pharmaceuticals and other substances. Genetic engineering is in these cases not the appropriation of an agricultural input, but the working-up of plant life into a technology. Now, Goodman, Sorj, and Wilkinson are willing to admit of the significance of transgenic microbial technologies as an industrial 'substitution' for the 'natural production process' on the farm, but the significance of transgenic plants in this regard is unclear. Our focus on transgenic plant production as a modality of transgenic production more generally, however, can make clear the degree to which the capacity to create transgenic plants marks a disjuncture in the role of plant life in the labour process.

Just as is the case with the genetic engineering of microbes, plant genetic engineering works up living materials which, in this case, are plants cells; however, there 
is an important difference here. ${ }^{32}$ Since a microbe is unicellular, the purification of the microbe itself from its found environment is enough to prepare it for transformation with rDNA. A mature plant, on the other hand, contains many differentiated cells and therefore cannot be made transgenic through the transformation of a single cell. Plant molecular biologists must thus first isolate undifferentiated plant cells from the mature plant, cells that can be grown in vitro as 'callus' and transformed with recombinant DNA prior to their differentiation into the various tissue that make up a mature plant. Despite these differences, however, transgenic plant production is consistent with microbial production insofar as it treats cellular life as a raw material that is worked up into a transgenic biotechnology.

The working-up of plant cells requires transformation with rDNA so that their synthetic capacities can be harnessed to the production of useful substances, and here the durability of the plant cell wall and the absence of plasmids demand unique methods of transformation. ${ }^{33}$ One common method is a 'biolistic', or 'shot-gun', method where gold or tungsten pellets are coated with rDNA and, literally, shot through the cell wall at high velocity. ${ }^{34}$ The pellets pass through the cell in the hopes that the foreign DNA will be washed off by plant cellular fluid and incorporated into its genome producing a transgenic cell

A more sophisticated technique for transforming plant cells is similar in its logic to the vector-mediated transformation used to create transgenic microbial cells. Here a virus or agrobacterium is first transformed with rDNA and then employed as vector, or what is often referred to as a 'natural genetic engineer', to insert the rDNA at a specific location in the plant's genome. The most commonly discussed 'engineer' is the 
agrobacterium tumefaciens (A. tum), notorious for its infection of crops with gall crown tumor. A. tum infects plants by inserting a plasmid into the genome of the plant thereby altering its DNA. Two steps are required to harness this normally 'destructive' force to the creation of transgenic plants. First, the microbe is transformed so that it will transfer the desired transgene to the plant cell, but will not alter the plants genome in its normally destructive way. This is achieved through the practices of recombination and transformation described above. Second, the transgenic microbe is then introduced into a culture of callus where it will infect the plant cells and insert the target gene into the plants genome. Thus, rather than using a 'gun' as in the biolistic method, the durability of the plant cell wall is here overcome through the use of the found capacities of a microbe to carry the DNA through the wall to produce undifferentiated transgenic plant cells.

Now, unlike transgenic microbial production, where the transformed cells themselves act as the transgenic factories, the employment of plants in this way requires that, once transformed, the transgenic undifferentiated callus grow and develop into a mature transgenic plant. Plant molecular biologists are aided here by a unique characteristic of many plant cells called totipotency, the capacity to, under the right conditions, grow and develop into a whole plant. ${ }^{35}$ This is often referred to as a process of 'redifferentiation' in the sense that undifferentiated callus that has been isolated from a mature plant comprised of differentiated cells and tissue, is then cultivated in such a way that it dedifferentiates into the mature plant again, only this time the plant is transgenic. This redifferentiation is achieved by incubating the transgenic callus in a nutrient rich medium infused with specific growth promoting hormones. Eventually a sapling will 
develop that can be transferred from the lab to the greenhouse where it can grow into a mature plant.

At this point in the creation process, however, another obstacle is encountered that is absent in transgenic microbial production. The multi-cellular nature of plants means that only a percentage of a mature plant's cells will express the transgene and so the result of redifferentiation is always a less than 'pure' transgenic plant. At this point traditional cross-breeding techniques are employed to produce transgenic plants with the highest percentage of transgenic cells possible. ${ }^{36}$ Generally the process is one where successive generations of transgenic plants are crossed with one another with the result that each generation will have a higher percentage of cells that express the transgene. Once the generation is deemed 'pure', transgenic seed can be harvested and processed for scale-up in the field, seeds that are the central force of transgenic production, living factories in germ form that, as part of their life process, will issue in useful substances.

Thus, where for Goodman, et al. the significance of plant genetic engineering lies in the industrial appropriation of a raw material, here we see that it can also be understood as a modality of the working-up of life into an instrument of production whose productive force lies in its harnessing of the capacity of life to synthesize useful substances. In this case it is better understood as a variation on the genetic engineering of microbes, whose unique methods derive from the specific characteristics of plants as forms of life - totipotency, a durable cell wall, limited mobility, etc. While many of these methods have a long-history in plant breeding more generally, they have new significance here in that they are mobilized in the creation of transgenic biotechnology, instruments of production in a new form of the labour process. Thus, plant genetic 
engineering, rather than merely the appropriation of an agricultural input constitutes a repositioning of plant life in the labour process as an industrial instrument of production.

And so we can begin to see the 'industrialization of agriculture' in a rather different light. Where Goodman sees the 'natural production process' through which plant life is worked-up as raw material as distinct from the 'industrialization' facilitated by biotechnology, we can see here the degree to which the genetic engineering of plant life as transgenic biotechnology enables the harnessing of the natural production process itself as an industrial labour process. "Based on alfalfa plants grown in hi-tech greenhouses" suggests Medicago,

Proficia offers the flexibility and high volume potential of plant-based technology together with the safety and control of confined environment production. This advanced bioprocess is like a perfectly natural and renewable bioreactor ready to produce the medicines that will improve lives tomorrow. (http://www2.medicago.com/en/tech_platform/proficia/)

In this sense, rather than a labour process sui generis, agricultural practices can nevertheless be conceived anew as a modality of transgenic production.

Like all living organisms, transgenic plants require nutrients, heat and light that must be provided at increasing scales if plant systems are to produce their recombinant protein in vast enough quantities. The agricultural practices of soil cultivation, fertilization, and irrigation can thus be understood as practices of media preparation required to satisfy the system requirements of transgenic plants. The size, complexity and relative immobility of plants in comparison to microbes means that their nutritional requirements are most efficiently met on large tracts of land whose soil composition is appropriate for the plant's particular needs. Techniques of soil cultivation and irrigation 
ensure that plants take root in the media and receive adequate nutrition through their vascular system.

Not only is the media unique, but the practices of inoculation are also different because of the unique growth and reproductive characteristics of plants as forms of life. Owing to its single-celled nature, the capacity of a microbe to produce useful proteins is one with its existence as such and in this sense a microbe is always already a production facility. A mature plant, however, is the result of a process of cell differentiation, a process of growth and development through qualitatively distinct stages. Rather than being inoculated with functioning transgenic factories that merely require multiplication, soil is thus inoculated with seed, an embryonic form of the plant that over time will grow into a transgenic factory.

The unique reproductive behaviour of plants is also reflected in the unique practices of inoculation. Microbes produce through binary fission, a process which results in an exact copy of the microbe, which means that microbes not only produce proteins, but produce new production facilities as part of their life-process. This is a great strength of microbial production because a sample population inoculated into a fermentation tank will rapidly expand to fill the broth with tiny factories. The productive and reproductive capacities of microbes thus form part of the same process of production harnessed as a productive force. However, while plants also reproduce themselves as part of their life process, they do so in the form of seed which must itself be harvested, inoculated in a new media, and grown into a new generation of production facilities. A field, then, rather than inoculated with a sample must be inoculated with the whole population of organisms and larger tracts of land require more organisms, i.e. seed. In short, a production run does 
not employ the reproductive capacities of the plant as itself a productive force in the same way.

Thus, while all transgenic production requires the monitoring and regulation of living instruments, the specific life activity being monitored and regulated is unique. In the case of microbes, it is the relatively short-term and rapid quantitative increase of the cell population that is monitored. Owing to the size of microbes this is done in fermentation tanks which can be monitored on-line and the conditions adjusted. Here it is the reproductive activity of the microbial population that constitutes a primary force of production and is thus closely monitored and regulated to achieve maximum efficiency. In the case of plants, however, the reproductive activity is secondary and it is the qualitative growth of the individual organisms from seed to mature plant that is of interest. It is the growth and development of the plant, the natural production process, that is the primary productive force and is what is monitored and regulated. And owing to their size and specific system requirements, this is done through an engagement with the relatively found characteristics of the biosphere. While greenhouse technology suggests a further disjuncture here, we will return to this issue in detail later.

Finally, the purification of the protein in the case of plant production differs from that of transgenic microbial production owing to the unique life-process of plants. Where protein expression in cellular production takes place in a fluid, whether intra or extracellular, protein expression in plants takes place in the 'body' of the plant. On the one hand, because this 'body' is often a food product, substances that are physically consumed (i.e. pharmaceuticals) need not be purified from the plant system at all; rather, the transgenic plant itself can serve as a 'delivery system' for the substance, as in the case 
of the highly controversial "edible vaccines" (Norris 2005, 5). Where the substance is not 'consumed' in this sense, the plant, or parts of the plant, must be further processed so as to purify the substance from the body of the plant; or, as one journalist puts it, "shredded or ground up, a process that induces the plant to kick out protein molecules" (Zehr 1999). When only a part of the plant is harvested, there is an important sense in which the production run is continuous insofar as a new population of transgenic seed need not be planted to set the living production system in motion again. Medicago emphasizes the value of their specific transgenic plant in this regard:

Alfalfa is a highly-efficient protein production system. It is a perennial that does not die after harvesting but grows back to maturity in five weeks, without flowering, sexual crossing, or producing seeds. (http://www2.medicago.com/en/tech_platform/alfalfa)

Understanding the agricultural labour process in this way thus allows us to get at a much more profound sense in which the industrialization of agriculture is taking place Where for Goodman this takes place through a shift away from the agricultural labour process, reflecting the inherent obduracy of the natural production process, we see here the degree to which plant genetic engineering has allowed for the repositioning of the agricultural labour process as an industrial labour process through the repositioning of the natural production process as an industrial force of production. Aziz Elbehri of the US Department of Agriculture puts it succinctly:

Genetically engineered crops grown to produce PMPs [plant made pharmaceuticals] have little in common with traditional agriculture. These pharmaceutical crops do not represent a new wave of value-added agriculture. Rather, these crops represent open-air bioreactor farming, a component of pharmaceutical and industrial enzyme manufacturing process. $(2005,8)$ 
Agricultural practices, rather than working-up plant life as raw material, are consistent with an industrial logic of scaling-up an industrial instrument of production. The disjuncture here, again, lies in a crucial shift in the meaning of living nature in the labour process. We can thus see here the degree to which a labour process centered on the creation and employment of transgenic plants as biotechnologies constitutes a modality of the industrial logic of transgenic production more generally whose specificity derives from unique life-process of plants. To make the point here even clearer, we will now move on to compare microbial and plant production with our third modality: a labour process centered the creation and employment of transgenic animals as industrial productive forces.

\section{Brave New Barnyard}

Given the current interest in biotechnological development, it is odd that the role of animals in the labour process remains so undertheorized. On the one hand, we might certainly subsume animals within the logic of Goodman's analysis and regard them as raw materials worked-up into food and other products. Regarded as raw material inputs into the agricultural labour process, animals can be genetically engineered and provided to farmers in embryo in a way similar to Monsanto's appropriation of seed production. And, insofar as microbial life can be used to produce substances previously provided by animals, there will be a further substitution of microbiological labour processes for those agricultural labour processes centered around animals as well, the best know example of which is the production of human insulin with transgenic microbes, rather than harvesting it from slaughtered pigs and cows. Indeed, Ted Benton, virtually alone in his concern 
with animals in the labour process (1993), has suggested the value of Goodman's work in understanding the history of animals as means of production.

On the other hand, merely subsuming animals in this way risks neglecting the more diverse roles played by animals in agricultural labour processes. In addition to playing the part of raw material in the production of food, animals have a long history serving as instruments of production from the early use of dogs in hunting to the harnessing of draft animals to non-living instruments of agricultural production (Hyams 1972). And, as Marx suggests, animals have acted as raw materials and instruments simultaneously as is evident in his example of the cow that is both raw material in the production of meat and instrument in the production of manure. We might also want to distinguish the capacity for milk production as a kind of hybrid function insofar as milk is indeed food, but, like manure, is relatively distinct from the body of the cow. While we will come to see the limitations of conceptualizing life in this way, the lines of biotechnological continuity are in fact the clearest in the case of animals as they have for millennia been 'worked-up' through practices of breeding and employed as 'instruments' in the production of useful substances through practices of animal husbandry more generally.

However, while the continuities in the use of life as technology is perhaps most evident in the case of animals, a focus on the transgenic labour process, and the modality of transgenic animal production in particular, reveals an important disjuncture insofar as genetic engineering has allowed for the harnessing of animals as industrial productive forces. Where the use of animals as instruments has relied on the found capacities of particular animal species - selective breeding being a selection of certain of these 
capacities (Russell 1986) - transgenic animals are the products of a working-up of living raw materials in a much more profound sense. This working-up corresponds broadly to the industrial logic of transgenic production more generally, but a closer look reveals important differences that derive from the unique life-process of animals themselves.

Like plants, animals are eukaryotes that develop from a single cell into a complex organism with differentiated tissues. And like transgenic plant production, the creation of a transgenic animal is achieved through the transformation of cells with recombinant DNA and the 'growing' of a transgenic organism from these cells. However, there are two important differences between plants and animals in this regard. First, unlike plant cells, the cells of a mature animal do not possess totipotency, i.e. the capacity to develop into a whole plant; rather, the generation of a new animal can only be achieved through the combination of haploid germ cells (sperm and egg cells that possess only $1 / 2$ the genetic material required for the generation of an offspring) of the male and female of a given species: sexual reproduction. Creating a transgenic animal requires that the resulting diploid cells be transformed at some point between fertilization and the differentiation of cells that constitutes animal growth and development.

Second, while animals, like plants, develop through qualitatively distinct stages, the system requirements of animals during the early stages are much more complex and are most efficiently provided in utero as part of the life process of the parent. In microbes and plants these requirements are provided 'outside' the body of the 'parent', as it were. Thus where microbes and plants can be created in relative isolation from one another in vitro, the creation of a transgenic animal requires an engagement not only with the animal as raw material, but the animal as instrument employed in the creative process in order 
that transformed cells might develop into a mature production facility. While incorporating the practices of recombination common to all transgenic production, the practices of purification and transformation are unique to transgenic animal production and can be understood as a response to these unique characteristics of animals as forms of life. The two most common methods of creation are 'pronuclear injection' and the 'embryonic stem cell method'. ${ }^{37}$

Pronuclear injection aims to transform a freshly fertilized cell prior to its division. In addition to the components of the rDNA molecule that is used to transform the fertilized cell, two other materials must be purified in order to produce a transgenic animal by this method: the freshly fertilized eggs themselves and a 'foster mother' that will carry the transgenic animal to term. The eggs can be obtained from a recently impregnated female of the species, or 'artificially' fertilized, and a foster mother is a female that has been made 'pseudo-pregnant' through mating with a sterile male. A recombinant DNA molecule is physically inserted into the sperm head inside the fertilized egg just prior to its development into a pronucleus in the hopes that when cell division occurs each and every cell will be transgenic. Once transformed, the transgenic egg is implanted in the uterus of the foster mother who provides the in utero system requirements of the developing animal until birth. While there is currently research aimed at developing 'artificial wombs', which would remove the 'foster mother' from this scenario, a living environment remains the most efficient means of providing the system requirements for the developing transgenic factory. In any case, the offspring emerge from the womb and those that test heterozygous for the transgene, where the gene may or may not be expressed in the life-process of the organism, are mated with one another to 
produce a homozygous transgenic strain in which the transgene (as a component of the genotype) will be expressed in the life-process (phenotype) of the organism.

The other common method of creating a transgenic animal is the embryonic stem cell method. While similar in aiming at transforming cells at some point between fertilization and differentiation, this method aims at cells further along in their development than freshly fertilized eggs. Embryonic stem cells result from early cell division after fertilization and possess the same kind of totipotency that we saw in plants; that is, they possess the ability to become the multiplicity of cells required for different tissue, etc. These cells are extracted from a blastocyst, an embryo that has yet to become implanted in the uterus of the female. The cells are made transgenic through methods of recombination and transformation that we have already specified and are then injected back into the blastocyst. The blastocyst is then implanted in the uterus of a 'foster mother' made pseudopregnant and the creative process proceeds in the same way as in the case of pronuclear injection. The main difference between the two is the stage at which transformation occurs: in the egg prior to any division, or in the stem cells after initial division, but before differentiation. In both cases, however, the 'foster mother' is required to satisfy the system requirements of the embryo until it comes to term and is ready to be scaled-up and employed as a transgenic biotechnology.

So, just as was the case with transgenic plants, we have here revealed a disjuncture in the role of animals in the labour process. The crucial significance of genetic engineering lies in a repositioning of life as an instrument of production in the labour process, a transgenic biotechnology harnessed to an industrial logic of production. "By utilizing molecular biology technology," claims GTC BioTherapeutics, 
We can design DNA constructs that reliably express high levels of therapeutic proteins in the milk of the [goats] that carry the transgene. We take advantage of the normal mammalian protein processing mechanisms to synthesize properly folded and assembled complex proteins...By utilizing the milk specific promoters to express the heavy and light chains, the cellular machinery is capable of secreting high levels of properly folded antibody. (http://www.transgenics.com/science/questions.html)

Rather than a mere appropriation of an agricultural raw material, we have here an industrialization of the life-process of animals themselves. And again, just as was the case with agricultural practices in the case of transgenic plant production, the practices of animal husbandry, which of course have long history in human history, take on new significance in their mobilization and harnessing to an industrial labour process.

On the one hand, practices of animal husbandry can be understood as analogous to the practices of industrial microbiology and agriculture involved in the scale-up of microbial and plant life respectively. Where the system requirements of microbes are provided by fermentation tanks, and those of plants by the soil, the barn and barnyard constitute the environment constructed at increasing scales in order to provide the system requirements of larger populations of transgenic animals. This environment must be 'inoculated' with transgenic animals so that they may grow and develop into mature living production facilities and their life process must be monitored and regulated to ensure the efficient production of a recombinant protein that can then be extracted from them. In this sense the employment of transgenic animals is consistent with the employment of transgenic life as a production facility more generally.

However, the unique characteristics of animals as forms of life present certain challenges, and offer certain advantages, to which the practices of employment are a response. First, while the complexity of the system requirements of animal life is more 
akin to that of plants, animals, like microbes, are highly mobile in seeking out their system requirements. Second, like plants, animal growth and development takes place through a series of relatively long and qualitatively distinct stages to maturity. Third, animals reproduce sexually, but require physical contact to do so. And finally, animals can express proteins in bodily secretions that can be purified in a way that leaves the living system relatively in tact. The practices through which transgenic animals are employed as living production facilities are uniquely suited to take advantage of these found characteristics of animal life.

The size and complexity of animals means that their system requirements, like those of plants, are most efficiently provided on relatively large tracts of land that, while prepared to accommodate animal scale-up, nevertheless exist in a relatively found form as part of the biosphere more generally. The employment of transgenic animals, like that of plants, is therefore geographically sensitive in a way that microbial production is not insofar as the provision of the system requirements (heat, light, nutrients) is, at least in part, provided by the land and sun, elements of the 'found' environment whose 'artificial' construction is impractical.

However, there are two important differences here that distinguish the 'barnyard' from the 'garden'. First, the environment is constructed in such a way as to accommodate animal mobility. Unlike plants, which are rooted in their media, animals move throughout their environment seeking out food, shelter, and other animals. The environment must thus be constructed in a way that, on the one hand allows such movement, but on the other restricts it in a way compatible with their employment as production systems. Thus the use of fences, the barn itself, as well as divisions within the barn serve to structure the 
movement of animal systems in a way that is unnecessary with plants. Second, the environment must be constructed in a way conducive to regulating the reproductive activity of animals. That animals require physical contact to reproduce means the threat of cross contamination is less prevalent and dealt with through physical separation that is much more problematic in the case of plants.

Now, there is nothing new about the construction of the barnyard per se; animal husbandry has always required that animals be 'housed' in a way compatible with their species characteristics. However, these environments are given new significance as 'manufacturing facilities' with the advent of transgenic biotechnology. GTC describes its "production facility" in this way:

.... a state-of-the-art goat farm and dairy facilities in Massachusetts...for the transgenic production of therapeutic proteins. This site houses a clinic and barns for the production of transgenic animals as well as separate buildings for general animal housing, kid rearing and milk collection. There are 7,200 square feet of dairy operations including dairy and processing facilities, with dedicated single-product milking parlors and processing areas. (http://www.transgenics.com/science/production.html)

Tranxenogen makes clear both the continuity of its "controlled environment" with the animal husbandry of the past as well as its new significance:

Transgenic chickens have the advantage over other transgenic animals that they can be housed in a contained/barrier facility from the moment they hatch from their shell. Chickens have been reared and housed this way for the egg production industry for decades. Tranxenogen can add the element of controlled, filtered air flow to its chicken production facility to provide a barrier to adventitious agents which could contaminate the production flock. The result is a totally enclosed, contained, and controlled environment. (http://www.tranxenogen.com/NewFiles/hotbuttons.html)

The practices through which the barnyard is inoculated with transgenic animal production systems also reflect the unique found capacities of animals. Like plants, but 
unlike microbes, animals develop through qualitatively distinct stages during their lifeprocess and reach their full productive capacity as adults. The barnyard is thus inoculated with the young of a species that are then worked-up into mature producers of recombinant protein just as fields are planted with seed that is worked-up into mature plants. However, productive and reproductive activities are united in the life-process of animals in a way that is unique. Like microbes, animals reproduce themselves at the same time as they are producing recombinant protein; indeed, it is this reproductive activity that is central to the scale-up of the transgenic animal population. Things are more complex, however, because animals not only make more of themselves, but interact with one another as part of their reproductive activity. Scale-up, rather than merely increasing the size of the environment (as in the case of microbes), or increasing the amount of organisms (as in the case of plants), involves mobilizing the mating and nurturing activities of the organisms. Thus, a production herd, rather than merely a group of individuals whose scale-up is merely quantitative, is a group whose members interact in ways that must are harnessed to production.

And this means that the monitoring and regulation of transgenic animal systems has certain unique characteristics. Like microbes and plants there is an emphasis on the system requirements of food, temperature, etc.; however, two differences are worth highlighting. First, the size, complexity, and mobility unique to animals means a unique emphasis on the health of individual biotechnologies. The US Food and Drug Administration, in its 'Points to Consider in the Manufacturing and Testing of Therapeutic Products for Human Use Derived from Transgenic Animals', emphasizes importance of "monitoring the health transgenic animals": 
Monitoring plans are important both for maintaining the health of the animals and for preventing product contamination with adventitious agents, pesticides, and animal medications. Health records should contain the complete history from birth to death of all animals used in production, including the drugs and vaccines used. Disease episodes should be definitively diagnosed to the extent possible. Sick animals should be removed from production. (http://www.fda.gov/cber/gdlns/ptc_tga.txt)

Thus, where the health of microbial and plant populations is understood in group terms, animal health is monitored, and care provided through specialized veterinary care, on a much more individual basis.

A second important difference is that monitoring and regulatory activities, in the case of a labour process centered on transgenic animals, are uniquely concerned with the 'well-being' of the technologies beyond their 'physical health'. The Canadian Council on Animal Care suggests that "in the interest of well-being, a social environment is desired for each animal which will allow basic social contacts and positive social relations" $(1993,8)$. Ted Benton suggests that this unique 'sociality' of animals has shaped labour processes centered on the transformation of animal life into food. And Nexia concurs with respect to its spider-goat hybrids:

Goats are naturally playful and social animals; therefore Nexia uses group housing for its herds. We encourage their playfulness by providing them with toys that stimulate them both mentally and physically. These measures help keep the goats happy. Since happy, healthy goats are more productive and produce more milk, the environmental enrichment program is highly beneficial from both an ethical and economic perspective. (http://www.nexiabiotech.com/en/01_tech/06.php)

In short, a good social life makes for a happy transgenic biotechnology; and a happy transgenic biotechnology is a productive transgenic biotechnology. There is perhaps no greater indication of unique blurring of the boundary between life and technology than 
this emphasis on the sociality, playfulness, happiness, and well-being of animal production systems.

And finally, the unique way in which animals express the desired substance means that the practices of retrieval in a labour process centered around transgenic animals are relatively unique. A great advantage of employing mammals and chickens as production systems is that they can be engineered to secrete the recombinant substance in their milk and eggs. The animal system does not need to be 'disrupted' or 'de-natured' (as in the case of microbial production) or 'shredded and ground up' (as in the case of plant production); rather, the animal can simply be milked, or relieved of its eggs, and carry on its life-process relatively intact. This gives a labour process centered on transgenic animal biotechnologies a degree of continuity absent in either microbial or plant production insofar as milk and egg production are carried on throughout the lifespan of an animal. This continuous production of recombinant protein, coupled with their capacity to reproduce themselves, endows transgenic animal biotechnologies with the kind of perpetual motion long the dream of engineers, genetic and otherwise.

Thus, our analysis of a labour process centered on the creation and employment of animals as instruments of production gives new meaning to the term 'factory farming'. This term is often used to refer to the use of industrial methods to transform animal life into food, the case of chickens being the most notorious example. Here, however, we have not merely the use of industrial methods to transform animal life as raw material, but the harnessing of animal life itself as an industrial productive force. "This system," says GTC of its transgenic goats:

provides high level expression combined with modifications unique to mammalian production systems. This method permits flexible scale-up of 
protein manufacturing to meet increasing production needs throughout the product development process. Scale-up is as simple as breeding more transgenic animals. (http://www.transgenics.com/science/questions.html)

Transgenic animal production is thus best understood as a final modality of the transgenic labour process whose specificity derives from the unique capacities of animals as living nature.

\section{Conclusion}

To summarize the significance of these somewhat technical developments for our underlying argument, we can point to three important points. First, a transgenic labour process is best conceived as an industrial labour process unique in its harnessing of living nature as a productive force. Second, while characterized by practices with a long history in brewing, agriculture, and animal husbandry, the transgenic labour process constitutes a significant disjuncture in the use of life in production insofar as genetic engineering has allowed for a repositioning of life-itself as an instruments of production. Third, the various modalities of the transgenic labour process derive their specificity from the unique characteristics and system requirements of the transgenic biotechnologies themselves. So, now that we have a good sense of these modalities and their principle of differentiation, we can turn to look more closely at the role of transgenic biotechnology itself in the transgenic labour process and assess the degree to which it marks a disjuncture with non-living instruments of industrial production. 


\section{5 - Transgenic Biotechnology as a Force of Nature}

Despite a tendency amongst Marxists and non-Marxists alike to draw a rigid boundary between 'nature', as the object worked-up through the labour process, and 'technology', as the set of instruments that act upon the natural object, we have seen that in Marx matters are more nuanced. While all instruments of production are composed of 'natural materials', machinery is unique in the degree to which it harnesses the forces of nature as forces of production, and in turn possesses capacities for movement, consumption and reproduction, that previously distinguished 'nature' from 'artifice'. Having now seen the degree to which transgenic biotechnology constitutes an industrial instrument of production whose unique productive force derives from harnessing the synthetic capacities of living nature as a force of production, we are in a position to determine the degree to which transgenic biotechnology constitutes a disjuncture in the degree to which industrial instruments of production themselves come to approximate a force of nature.

The first section of the chapter problematizes the common tendency to regard transgenic biotechnologies as 'living machines' and suggest that such metaphors may do more to obscure than clarify their significance. In the following three sections we assess the degree of disjuncture in the development of industrial instruments of production marked by biotechnology using the capacities of movement, consumption, and reproduction as our 'yardsticks'. Central to the analysis will be a comparison with computer integrated machine systems that, in an unprecedented way, approximate a force of nature, a notion that has been central to the development of cybernetics. I argue that, while the development of machine systems has indeed been characterized by an 
increasingly approximation of a force of nature, transgenic biotechnology nevertheless constitutes a qualitative disjuncture in this regard.

\section{Breaking the Machine Metaphor}

While the traffic in metaphors between engineering and the life sciences has a long history, the capacity to construct an organism in a way that harnesses its synthetic capacities to human purpose has given new meaning to the notion of life as machine. Molecular biologist Jonathan King refers to transgenic organisms as "self-replicating factories" for the production of commodities (1997). A headline in the Globe and Mail (Zehr 1999) reads: "Power Plants: In the World of Molecular Farming, Plants are Living Factories that Produce Cheap Drugs, Plastics, even Human Blood Protein." An article in the Biotechnology Annual Review examines how "a number of valuable therapeutic proteins have been produced in the milk of transgenic bioreactors, ranging from rabbits to dairy cattle" (Janne, et al. 1998, 55). Such machine metaphors are commonly used by those trying to grasp the significance of repositioning life as an instrument of industrial production.

And such metaphors are common on both sides of the public debate over biotechnology, as making organisms into factories can constitute either a kind of victory over a form of nature that has heretofore proved resistant to the process of industrialization, or an unholy mixing of those symbols of technology and nature: the machine and life. Indeed, as Bud (1993) points out, it is just this implosion of technology and nature that has always given the term biotechnology its discursive power in both mobilizing support and instigating resistance, a power that derives in large part from 
locating biotechnology within the continuity of industrial production more generally. In this sense, organisms are one more instrument of industrial production whose status as 'life' is less important than their subordination to an industrial logic.

And it must be admitted that, to this point, we have embraced this machine thinking in our description of the transgenic labour process. In our description of the transgenic labour process in general we conceptualized the organism as kind of machine created through the working-up of raw materials into an instrument that is in turn employed to work up its system requirements into useful substances. And our modalities of the transgenic labour process were distinguished by the form of life created and employed as an industrial instrument of production. While the notion of life as machine has proven useful thus far in distinguishing a transgenic labour process from previous uses of life in industrial microbiology and agriculture, it has perhaps given the impression of too much continuity with industrial production centered around non-living instruments of production. Our interest in the disjuncture in the meaning of nature marked by transgenic biotechnology as an industrial productive force requires that we now trouble these assumptions insofar as they rest on a failure to appreciate the unique characteristics of living nature.

While a number of 'science studies' have interrogated the role of metaphor in giving meaning to life (Kay 2000; Oyama 2000; Keller 2002; Fujimura 2005), attention has tended to remain on the use of 'informational' metaphors in the life sciences, and in molecular biology in particular. The thrust of this work in general is to challenge the value of these metaphors in capturing what is unique about living organisms both inthemselves, and as objects of inquiry and manipulation in the lab. While appreciating the 
value of this work, the focus here is on the role of life as technology in the labour process in order to determine its degree of continuity with non-living instruments of production. We will use those characteristics of machines that Marx saw as so crucial to their approximation of a force of nature: activity, consumption, and reproduction.

Of course we must at this point acknowledge that 'machinery' has not remained static since Marx's analysis of large-scale industry. Subsequent to the period of 'largescale industry' identified by Marx, we can see, from the late $19^{\text {th }}$ century the importance of new forms of power in the form of internal combustion and electricity and their significance for the size and speed of machines. From the 1920s on innovations in 'transmission' mechanisms become increasingly important with the Fordist assembly line, realizing the notion of a 'machine system' that remained largely speculative in Marx. The post-war period witnesses the importance of new materials and increased automation with early innovations in microelectronics to what has been referred to as an 'advanced Fordist' (Teeple 2000) or 'neo-Fordist' (Palloix 1974) form of labour process. And finally, the advent of the microprocessor in the early 1970s is generally regarded as ushering in something of a qualitative shift in capitalist development. While the precise periodization of capitalism is the subject of debate, the important point is that capitalist development has been characterized by significant transformations of the industrial labour process, central to which are innovations in the instruments of production. ${ }^{38}$ What is seldom recognized in such accounts of capitalist development are the implications of these labour process transformations for the meaning of nature. To be sure, there are analyses of the ontological implications of 'information technology', and we will have occasion to engage with this work; however, as we will see, it tends to 
abstract technological change from transformations of the capitalist labour process and often subsumes biotechnology as an information technology. The result is a tendency, on the one hand, to overestimate the ontological disjuncture marked by microelectronics and related information technologies insofar as their continuity with industrial instruments of production more generally is obscured. On the other hand, in subsuming 'biotechnology' as an 'information technology', there is a tendency to understate the disjuncture marked by biotechnology, which, understood as part of a transgenic labour process, marks a qualitative disjuncture with non-living instruments of industrial production.

\section{Transgenic Biotechnology as Self-Acting Instrument of Production}

As we saw in our discussion of Marx in chapter 1, the harnessing of the chemical and physical forces of nature by machinery facilitates the kind of activity in the instruments of production suggestive of a natural process. Machinery is unique in the degree to which its movement is driven by non-human chemical and physical forces of nature thus blurring the distinction between nature as self-movement and technology as artifice infused with human purpose. In this light, we can understand the history of mechanization as a progressive destabilization of the technology/ nature distinction as self-acting technology increasingly approximates a force of nature. Drawing on Daniel Bell's periodization, Blackburn, Coombs, and Green (1985) distinguish historical forms of the labour process in a way that makes clear the increasing self-activity of machine systems from processes of 'transformation' (the direct action of machines on the object of labour), to 'transfer' (the movement of the object from one machine to another), to 'control' (the coordination of the machine system as a whole). In this section we assess 
the degree to which transgenic biotechnology constitutes a disjuncture in development of industrial instruments of production toward increasing self-activity.

The notion that the self-activity of machines is akin to that found in 'nature', and/or vice versa, has been central to the development of what Lily Kay (2000) refers to collectively as the cybersciences. Originally concerned with the transmission of messages, largely for military purposes, cybernetics came increasingly to inform an ontology of nature in its entirety where information processing and feedback become the central mechanisms by which evolutionary processes are driven. Machines can be regarded as approximating nature, then, insofar as their self-activity is made possible through reading instructions and correcting their activity in response to feedback from their environment. An often used example of a simple cybernetic system is the role of a thermostat in a heating system whose role is to interpret information from the environment (temperature) and adjust the activity of the furnace accordingly. Such a system is self-active insofar as, once 'programmed' with the desired temperature, a heating system ensures a constant temperature without intervention from outside the system.

It is clear that the pioneers of cybernetics always had the self-activity of living nature in mind in their analyses of machine systems, and this blurring of the distinction between life and machine soon found its way into the thinking and practice of the life sciences themselves. Lily Kay traces the development of cybernetic thinking and its relation to the life sciences in a way that makes clear the degree to which the notion of organisms as 'information processing machines' came to characterize molecular biology, first as metaphor, then increasingly as a literal description of the way organisms 'work'. 
The history is a complex one, with machines being characterized in organic terms and organisms in turn being characterized in machine terms, but the important point is that, with the increasing self-activity of machinery moving alongside developments in molecular biology, the life/non-life distinction becomes, throughout the $20^{\text {th }}$ century, increasingly incidental as organisms are viewed as one more information processing machine.

While cyberscience has its origins in a still largely analogue world, the ideal of a self-acting machine system would seem to have been realized to an unprecedented degree with the advent of the microprocessor and the digital information technologies of the past few decades. The notion that computers are 'thinking machines' is useful insofar as it points to the important disjuncture marked by Marcian Hoff's success in putting the entire central processing unit of a computer on a 'chip'. This was a tremendous breakthrough," suggests Tom Forrester (1987),

because by adding two memory chips - one to move data in and out of the CPU, the other to provide the program to drive the CPU - Hoff now had in his hand a rudimentary general purpose computer that could do far more than run a hand-held calculator: it could be used to control a set of traffic lights, an oven or washing machine, an elevator, or even a factory production line - the commercial potential was enormous. (21)

The crucial difference here is that where the integrated circuits of early computers were constructed to 'process' information in a specific way, and were in this sense 'dedicated' to a particular, relatively simple task, the programmability of computers, their flexibility in the way they process information, allows for their use in monitoring and regulating machine systems of all kinds. 
And with developments in sensor technology, with which the computer, the 'mind' of the machine, takes in 'information' and can alter the functioning of the machine system in response to 'feedback', there is an important sense in which machines have indeed become self-acting. The increasing number of what futurist Andy Hines calls "dark areas" - "whole sections of a factory with no people and therefore no lighting or other features needed by human workers" (1994: 11) is a rather ominous result of these developments. One is reminded of Canadian poet Archibald Lampman's 'City of the End of Things' where "moving at unheard commands,/ The abysses and vast fires between,/ Flit figures that with clanking hands/ Obey a hideous routine" $(1900,180)$. More optimistically, Wired magazine's Kevin Kelly (1994) sees advances in artificial intelligence infusing 'nature' with a kind of meta-consciousness - the computer as the central nervous system and brain of the world as it were.

'Post-human' presentiments aside, what is important here for our purposes is the degree to which the advent of digital information technologies bolstered the cybernetic view of life. Where the 'information' processed by a thermostat is only meaningfully conceived in terms of the activity of the thermostat in its interaction with a specific environment, there is an important sense in which digitized information exists independently of any particular machine in the form of 'data' on the one hand, and 'software' on the other. Important here is the degree to which the machine itself (hardware) becomes the relatively passive 'vessel' within which the processing of information (data) by information (software) occurs. Employing such metaphors, molecular biologists would come to regard 'genetic information' as independent of the 
organism, which, like the computer, became the relatively passive vessel within which this information (DNA) was processed by other information (RNA).

Such informational metaphors underpin claims that biotechnology is an information technology, a conceptual move that can mean two kinds of things. In its 'weak' version it suggests that 'genetic information', like any other information, can be stored, retrieved, and processed by the 'engineer' in a form independent of the organism itself. Thus, Heather Menzies suggests of biotechnology: "partly the biological twin of information technology, it breaks the natural genetic codes of organisms, and uses software and computers to rewrite them to meet a man-made priority" $(1989,155)$. The 'stronger' version of the subsumption of biotechnology as an information technology, however, goes further than this to claim that the organism is itself an information technology that is 'programmed' by the genetic engineer to process genetic information in a particular way. Thus, what is significant is not merely that the engineering of life requires information processing machines, but that life itself is an information processing machine and the life/non-life distinction disappears altogether.

And here we have a subtle shift in the notion of self-activity as well. Where predigital cybernetics viewed 'machines', living and non-living, as self-active because of their capacity to process information, now information itself, conceived as distinct from its 'appearance' in any particular 'machine', could be essentialized and conceived as the active force animating the world. Thus, as it turns out, the machine is not self-acting after all, but merely the formal appearance of the self-acting substance that is information.

And indeed, their limitations in this regard would seem to suggest that, whatever we might say about information, machine systems themselves are not literally self-acting. 
After all, machines must be built out of raw materials; they must be programmed in a specific way to achieve a specific task; they must be set in motion, both originally and when they 'crash'; and they must be 'operated' at some point and from somewhere, no matter how automated and 'dark' the factories. All of these interventions come from 'outside' the machine system itself and so the notion of 'self-activity' must remain for the cyberneticist a metaphor and for the engineer an ideal of machine design. While impressive, the 'self-activity' of machines systems must always remain a crude approximation of that which exists in 'nature'. And, insofar as 'biotechnology' is conceived in terms of 'information processing machines, it would be subject to all the same limitations.

However, revisiting the life/non-life distinction from another perspective may yet enable us to rescue the notion of self-acting technologies, although in a way that would likely disappoint many a cyberscientist. As geneticists Richard Levins and Richard Lewontin (1985) argue, the view of the organism as an information processing machine is based on Darwinian assumptions regarding the relation of the organism to its 'inner' biological drives and its 'outer' environment. The organism itself assumes a relatively passive role here insofar as evolution is viewed as a process whereby the environment poses particular problems for the organism whose success in solving them is dependant on genetic mutations. Thus, the organism becomes a mere moment in a feedback loop where the environment provides informational cues to which the genes respond.

The difficulty here, for Levin and Lewontin, is that this "alienation of 'inner' from 'outer"' obscures the active, constructive role of the organism in both 'interpreting' the 'information' contained in DNA and transforming the 'environment' as part of its 
life-process. They offer instead a dialectical view of life where the organism, rather than a passive vessel, is the active 'subject-object' of evolution whose interaction with its environment is an interaction with a product that is, at least in part, a product of its own life-process. Thus the 'informational cues' provided by the 'environment' are not distinct from the organism, but are only meaningfully conceived in relation to the life-process of a particular organism as it transforms its environment to meet its needs. Moreover, 'genetic information', rather than the autonomous essence of life, is only meaningful in relation to a specific organism as it engages with an environment that is always-already a product of its life-process. The value of this view is that it places the organism itself at the centre of a creative life-process from which 'information' and 'environment' are abstractions.

With this alternative conception of the organism in mind, a look at the transgenic labour process is revealing. As we have seen, this labour process is uniquely centered around the life-process of the organism and its synthetic capacities. And, while we have had occasion thus far to imagine the role of the organism as akin to that of the machine, there are important differences that derive from the unique characteristics of life itself. For, unlike the machine, whose self-activity derives from infusing relatively passive materials with human purpose, the synthetic capacities of the organism are a property of the life-process of the organism itself. "The major function of the mammary gland," acknowledges GTC, "is to produce proteins. The mammary gland is capable of producing milk that carries over $40 \mathrm{~g} / \mathrm{L}$ of protein. We take advantage of the unique properties of this 'natural protein secreting organ"” (http://www.transgenics.com/science/questions.html). An organism, during its engagement with its environment, 'reads' its genetic information 
and synthesizes the appropriate substances, and it does this independent of any workingup, programming, or setting in motion by human beings. It is true, as we have seen, that the transgenic labour process harnesses these capacities to human purpose, but it does so through a manipulation of the 'genetic information' and the 'environment'; the lifeprocess of the organism itself, and its capacity to synthesize useful substances in particular, is a presupposition of the transgenic labour process; it is something that is 'taken advantage of'.

The distinction we are making here is clearer when we enquire into what is unique about the movement of living technologies. As we saw, non-living technologies, no matter how automated, must be set in motion originally and when they break down. But there is no meaningful sense in which an organism is 'set in motion'; it is always-already in motion and must remain so if it is to be at all. Now, it is true that transgenic organisms are often immobilized at some point in their development. As we saw in the case of transgenic microbial production, transgenic microbes are frozen and stored in 'cell banks' until they are inoculated into the medium. The USFDA suggests that "if reliable techniques are available, frozen sperm or embryos from a founder and its immediate offspring could be used to establish banks to preserve a valuable transgenic strain"(15). We might even regard seed as in some sense an immobilized form of transgenic biotechnology.

However, the thawing of microbes or embryos, or planting of seed, is rather different that the 'setting in motion' of a machine system that otherwise would remain immobile; it is more akin to liberating the self-movement of organisms whose immobilization is imposed upon them (through the freezing process or the collection and 
storage of seed). And of course there is no question of life 'crashing' and requiring 'service'. Organisms can deteriorate and be tended to (e.g. by veterinarians) but they are always in motion during the process and if they are not, they are not at all. Thus, even if we assume that genetic engineering is in some sense akin to building a machine, transgenic biotechnologies are unique in the degree to which their self-movement is an essential capacity of their existence as such.

Yet, when we actually turn to look at the practices of genetic engineering, the unique self-acting capacities of organisms become even clearer. We have seen that life is best understood as the raw material that is worked-up into a transgenic biotechnology, and we have tended to conceptualize this as a process of 'molding and shaping' to use Bacon's phrase. However, living materials are active in the process of their working-up in a way that is simply not the case with the creation of machinery. The working-up of inorganic matter into a machine is largely an accomplishment of the external force of instruments acting on a raw material that remains relatively 'passive' in the process. However, the role of living things as 'materials' is considerably different insofar as the force through which an organism is 'worked-up' into a transgenic organism is found in the organism itself; and in this sense life is a self-assembling raw material. We can illustrate the point here be looking more closely at the processes of recombination and transformation.

In our discussion of the practices of recombination thus far we have used the language of 'cutting' and 'pasting' together pieces of DNA, language that implies a certain continuity with those labour processes centered around a physical transformation imposed on a relatively passive raw material. However, we can see upon further 
investigation that such metaphors obscure the degree to which the practices of recombination are a harnessing of the self-assembling capacities of life-itself. Central to industrial labour processes is the extraction and processing of raw materials, a 'cutting up' of the environment into pieces, and a 'pasting' of these pieces into a finished product through the employment of machinery. In this case the 'cutting' and 'pasting' are practices imposed upon raw materials from the 'outside', as it were, and are in no sense inherent in the materials themselves. There is no sense, that is, in which steel works itself-up into a machine, or silicon into a chip. However, practices of cutting and pasting DNA, rather than imposed from the 'outside', are capacities inherent in the evolution of life-itself. Microbes routinely employ restriction enzymes and ligases as part of their lifeprocess, the former to destroy foreign DNA, the latter as part of their DNA replication apparatus. Thus, the creation of a recombinant DNA molecule is, rather than an active assembly of relatively passive materials, a harnessing of the self-assembling capacities of the materials themselves.

The importance of the self-assembling capacities of life in the creation phase are further illustrated through a closer look at practices of transformation. We have had recourse to this point to the language of 'inserting' rDNA into cells, which has again implied a certain continuity with the industrial transformation of a relatively passive raw material largely through physical force. However, just as they do in the case of recombination, such physical metaphors obscure the degree to which the transformation of a cell with rDNA relies on capacities found in the material itself. And indeed, evolution itself is, at least in part, a history of mutations, a process of cells transforming themselves through the incorporation of 'foreign' DNA into their genome. And as 
Richard Lewontin (2000) points out, recent research on retroviruses has demonstrated that such mutations are also a product of interspecies transmission of DNA 'in nature'.

The language of molecular biology in describing the transformation process is instructive here insofar as cells are 'persuaded' to incorporate rDNA into their genome. The notion of 'persuasion' implies that the practices of transformation are more akin to a process of convincing cells to do something they might do anyway, or at least posses the capacity to do on their own. Thus the methods of transformation through which the cell membrane is made porous (chemical and electroporation) do not 'force' rDNA into the genome; rather, they constitute a weakening of the cells defenses in the hope that the cell might itself 'take-up' the rDNA. The biobalistic shot-gun method, while indeed forcing rDNA into the plant cell, must still rely on the cell itself to both 'wash' the rDNA off the bullets and take-up the molecules into its genome. And in no case is there any guarantee that the cell will take-up the rDNA, evidence enough of the degree to which the practices of transformation rely upon the capacities for self-assembly that are found in life as raw material.

Perhaps the clearest illustration of our point here regarding self-assembly during the creation phase, however, is provided by transgenic plant and animal production in particular. Where a transgenic microbe is, in a sense, complete upon the transformation of a single cell with rDNA, transgenic plants and animals require further 'working-up' from a set of totipotent cells (callus in the case of plants, stem cells in the case of animals), to the full complement of differentiated cells characteristic of a mature organism. And of course by 'working-up' we mean little more than the growth and development of these organisms, capacities which are inherent in the organisms themselves and occur as part of 
their life-process whether they are transgenic or not. The contrast here with the materials worked-up into a machine is clear. In no meaningful sense do inorganic materials work themselves up into a machine; the force of production in this case is provided primarily by an external source, the materials remaining relatively passive in the process. Plants and animals, on the other hand, grow and develop into instruments of production and thus constitute, in the most literal sense, self-assembling raw materials.

Furthermore, the disjuncture here is even more pronounced when we enquire into the origins of these self-assembling capacities. The degree to which the productive force of the transgenic labour process is 'found' in cellular life itself suggests that much of its 'working-up' has already been accomplished prior to its entry into the labour process. The productive force of a machine is an accomplishment of the working-up of inorganic materials so that they may 'come to life' as an instrument of production. There is little sense in which, for example, the capacity to produce clothing is 'found' in the raw materials that are worked-up into a sewing machine employed in the garment industry, or the capacity to produce cars is 'found' in the raw materials that are worked-up into the dies and assembly lines of the auto industry. The productive force in these cases clearly lies in the labour and instruments that work up raw materials into a useful product.

Living cells, on the other hand, produce proteins as part of their life-process, and do so independently of any working-up through the labour process. Of course harnessing this capacity to the commercial production of recombinant proteins requires practices of purification, recombination and transformation; but there is an unprecedented sense in which the productive force of the transgenic labour process as a whole lies in the "raw materials' themselves, materials whose working-up is a result of millennia of evolution. 
GTC "takes advantage of the unique properties" of its goats; Medicago "harnesses the unique properties" of its alfalfa; Sembiosys "exploits oilseed plants". Transgenic production as a whole, then, constitutes a harnessing of the self-activity of living nature that the machine metaphor fails to capture.

John Avise (2004) introduces his useful appendix entitled 'Tools and Workshops of Genetic Engineering' with the following: 'In this appendix I describe several common laboratory techniques used by genetic engineers, most courtesy of unicellular microbes and their evolved expertise in manipulating DNA" (179). And while Avise is somewhat ambivalent about the new techniques, his point is emphasized in countless descriptions of genetic engineering that seek to justify it on the 'naturalistic' grounds that, rather than something that is done to life, the techniques of genetic engineering are inherent in life itself. While this particular claim will be further assessed in Chapter 7, it is important at this point to emphasize the degree to which the practices of creation constitute a harnessing of life's self-assembling capacities. These are part of the life-process of organisms as it has developed through the evolutionary process. Living organisms are not only actively complicit in their working-up into transgenic instruments of production, but indeed provide the primary force of production in this regard in the form of their inherent self-assembling capacities.

Thus, returning to the question of self-acting instruments of production and their approximation of a 'natural process', we can now begin to see the disjuncture marked by transgenic biotechnology. We saw that for Aristotle 'nature' is distinct because of its selfmovement and that it was precisely this distinction, or rather the blurring of it, that Marx had in mind in his suggestion that machinery constitutes a 'natural process'. 
Nevertheless, the self-movement of machinery has only ever been a relatively crude approximation of a natural force and thus the distinction between 'nature' and 'technology' has managed to hold.

However, in the case of the transgenic labour process we have a much more thorough destabilization of the technology/nature distinction insofar as transgenic biotechnologies are self-acting like never before; indeed, self-activity is essential to the meaning of living nature and remains so when this living nature is harnessed to human purpose. Thus a focus on the transgenic labour process allows us to see the degree to which the harnessing of life as an industrial productive force gives new meaning to the notion of self-acting technology. Yet, it is not by 'reducing' life to a machine that we have arrived at this conclusion, but by emphasizing what is unique about living nature; that is, it is precisely because they are not living that machine systems, informational or otherwise, can only ever crudely approximate the self-activity of nature.

Thus, this shift of perspective allows us also to reconceptualize the relation between life and 'information technologies', putting the latter in their place as it were. There is no question that that the creation and employment of transgenic biotechnology requires information technologies. These would include the imaging and other technologies of genetic engineering emphasized by Castells, but we would also point to the whole range of technologies, from fermentation tanks monitored and regulated by computer systems, to automated harvesters and milking machines, that characterize the various modalities of the transgenic labour process. The important point, however, is not that information technologies figure in the process, but that their unique purpose in this case is to harness life as technology to an industrial labour process. 


\section{Consuming Raw Materials, or Just Plain Eating?}

We saw in our discussion of Marx in chapter 1 that part of the ontological significance of machinery lay in the degree to which raw materials, rather than merely worked-up by instruments of production, also became, as 'fuel', part of the self-movement of the instruments themselves. Where hand-tools transfer a human force onto a natural object, thereby mediating the relationship between two 'things' that remain relatively distinct from it, machinery must consume natural materials and thus possesses a kind of internal metabolism, or process of self-mediation

The point is made clearer when we interrogate Marx's concept of 'raw material' a little further. A raw material, for Marx, can be the 'primary substance' that is transformed during the labour process and reappears in the product; or, it can be an accessory. He further distinguishes within the concept of accessory between those that are added to the primary substance during production (e.g. chemical dyes), and, more significantly for us, those required for the self-movement of the instruments (fuel, lubricants, etc.). Thus, the self-activity of industrial instruments of production presupposes that they consume raw materials and that nature in this sense becomes 'internal' to the technology itself, disappearing into it as a moment in its self-mediation.

While changes in the instruments of production have been the focus of most interested in labour process transformations, neo-Schumpeterian have been particularly sensitive to the importance of raw materials, and new accessories in particular, in labour process transformations (Perez 1983, 1985; Freeman and Soete 1997; Freeman 2001). Neo-Schumpeterians identify distinct 'techno-economic paradigms' driving capitalist development central to which are what they call 'key inputs', which, in many cases, turns 
out to be the accessory that enables the self-movement of the instruments of production (water, steam, electricity, oil). Thus it is oil that constitutes a 'key input' of the 'Fordist' paradigm that characterized the 50 year long-wave from the 1920 s to the 1970 s. And insofar as the shape of the techno-economic paradigm becomes important in determining the broader set of social institutions required for its 'up-swing', the way in which the forces of nature are harnessed in the labour process becomes an important question for those interested in the political economy of capitalism more generally.

Yet, for all their political economic significance, such changes in the accessory material consumed by the instruments of production have done little to shake the distinction between primary substance and accessory identified by Marx as characteristic of machine production. Industry, insofar as it is centered around machinery, has remained characterized by a relatively rigid distinction between the primary substance that is worked-up into the product and the accessory materials required by the machines themselves. Indeed, we might suggest that the relative indifference toward 'raw materials' in the labour process tradition is reflective of the taken-for-grantedness of such distinctions. When the 'primary substance' is clearly distinct from the instruments and their requirements, the technology/nature distinction so characteristic of this tradition can hold.

Now, we have to this point avoided discussing information technology in this regard, and, indeed, much has been made of the significance of these technologies for the role of 'nature' in production. Castells (2000) employs a broadly neo-Schumpeterian analytical framework when he suggests that the shift to 'information' as the key input of a post-Fordist techno-economic paradigm has witnessed a certain 'de-materialization of 
production' ${ }^{39}$ His argument regarding the 'end of nature' in the network society is premised upon the notion that 'information technologies', in contrast to 'machinery', do not 'work-up' a 'material substance' in any traditional sense. Rather, information, as data, is processed, or worked-upon, by other information in the form of software. And 'genetic engineering' is implicated in this 'de-materialization' insofar as it is included as an information technology.

Now, assuming for the moment that information is indeed the primary raw material in an information technology paradigm, there is actually a great deal of ontological continuity here with machine production, at least in terms of the relation of instrument to raw material. While 'information' does indeed play a dual role as both 'primary substance' (data) and 'accessory' (software), the two remain distinct. The role of 'information technologies' in storing, processing, and transmitting 'information' implies that this information is distinct from the technology itself and that the input (data) in some sense reappears in the product. In this sense, information is the primary substance worked-up by information technology and is akin to the steel, rubber, and other raw materials worked up by 'machinery'. The software, while also 'information', is nevertheless distinct from the data that is processed by the instrument and is best regarded as an accessory 'consumed' by the 'thinking machine' in the process of its selfactivity. We can thus regard information technologies as continuous with machinery more generally in this regard, and computers as information processing machines.

The lines of ontological continuity run even deeper, however, when we avoid Castells tendency to abstract information processing from the broader techno-industrial system of which it is a part. While there is clearly some sense in which 'information 
processing' is de-materialized when compared with the processing of steel, rubber, and other objects of labour characteristic of industrial labour processes, assuming that this means an 'end of nature' in Castells sense forgets that 'information processing' is integrated into a global system of commodity production and distribution to which the transformation of these 'materials' remains central; indeed, one might argue that it is more central than ever, much to the dismay of many an environmentalist. Now, we must admit that Castells is primarily interested in a shift in the primary site of value creation, and in this sense his argument is an important one ${ }^{40}$; however, speculation on the 'end of nature' is an ontological matter and must surely attend to the materiality of production in the labour process. And if we regard the relation of instrument to raw material as central in determining what 'nature' is, as Castells clearly does, then locating information technology within the labour process more generally reveals much more continuity than is suggested by Castells.

Castells' tendency to abstract 'information processing' from its embeddedness in the materiality of the broader labour process becomes particularly limiting when he comes to assess the ontological significance of biotechnology. His subsumption of genetic engineering as an 'information technology' and, by implication, his suggestion that it witnesses an 'end of nature' insofar as it is concerned with the manipulation of 'information' rather than 'material substances', clearly obscures the degree to which biotechnology centers around the transformation and employment of organisms as instruments of production. As Karin Knorr-Cetina (1999) demonstrates in a comparison of high energy particle physics (HEP) and genetic engineering, the latter is a decidedly 'wet' endevour in which the engagement of the scientist with the materiality of nature 
(the organism), rather than its symbolic representation, as in the case of HEP, is relatively unique. Castells focus on the storage, transmission, and processing of 'genetic information', while highlighting the importance of information technologies to biotechnology fails to get at the ontological significance of this material engagement with living nature as a means of production.

Looking at the transgenic labour process, however, reveals a significant disjuncture in the relation of raw material and instrument of production that distinguishes transgenic biotechnology from all previous technologies. Such production, as we have seen, centers around the employment of transgenic organisms as instruments of production, instruments that require for their productive force that their system requirements be met. And what we have called system requirements are just the nutrients, heat, and light, required for the life-process of the organism. Now, in some sense these system requirements are akin to the accessories required for the self-activity of industrial technologies more generally. In keeping with the neo-Schumpeterian, we might thus conclude that the system requirements of organisms are a key input for transgenic production in the same sense that coal, electricity, oil, etc. have been key for labour processes centered around machinery. Thus, the broth of transgenic microbial production and the agricultural inputs (soil, fertilizer, water, sunlight, etc.) of transgenic plant production gain new significance as key industrial inputs, accessory materials required for the self-activity of living instruments of production.

However, a conceptual difficulty begins to emerge when we turn to look for the primary substance that is worked up by a transgenic organism, a substance to which the organism remains relatively indifferent, and which reappears in the product. On the one 
hand, in our description of transgenic microbial production in Chapter 4 we were relatively consistent with the biochemical engineer in regarding the feedstock as the 'raw material' that is 'worked-up' by the transgenic biotechnology into a useful substance. And we did this to make the distinction between life as the object of labour in agriculture from life as an industrial instrument of production clear. Yet, looking more closely, we see that the feedstock constitutes the same nutritional requirement that, as we have just seen, is consumed by the microbial population as accessory in order that it may be selfacting (i.e. carry out its life-process). The term 'feedstock' is itself interesting here insofar as it is simultaneously raw material and food. Unlike the primary substances of machine production, then, the feedstock is not a material that is 'other than' the instrument, but an accessory required for the self-movement of the microbial population itself.

Now, even if we, with the biochemical engineer, were to somehow distinguish between the feedstock as the primary substance distinct from, say, the electricity required for the operation of a fermentation tank, such a distinction becomes totally inadequate when we come to look at transgenic plant and animal production. We have seen that in both cases the biosphere, or some technical approximation of the biosphere, constitutes the system requirements of these higher life-forms and thus are akin to the fermentation tanks and broth of microbial production. In this sense, we would need to regard the biosphere in its entirety as the accessory material required for the functioning of the instruments of production. The difficulty again, however, is that the 'primary substance' of the labour process seems to disappear. The life-process of plants and animals, their self-movement, requires that they engage with their environment, an engagement central 
to which is the consumption of nutrients and heat and the transformation of these into energy. This transformation results in the growth and development of the organism, central to which is the synthesis of particular substances. System requirements are thus accessory materials consumed by the instruments of production in the most profound sense, since without them a transgenic biotechnology ceases to be at all.

The absurdity of regarding the system requirements of the organism as the primary substance of the transgenic labour process is brought into even sharper relief when we enquire into the degree to which transgenic biotechnologies are 'indifferent' to them on their way to becoming a product. The indifference of the machine in this regard simply refers to the fact that, while worked-up by the machine, the primary substance of machine production passes through the instruments, but is in no sense of the instruments. Thus the 'retrieval' of the product from a machine leaves the machine itself relatively intact. True, all instruments of production, by virtue of their being composed of natural materials, go through a process of decay that is, at least in part, a result of their employment. However, their 'movement' in this regard is a function of their being made of a natural material, not a function of their existence as an instrument as such. Indeed, the decay of machinery runs counter to its productive force, which, as Marx argues, explains the struggle of capital to keep machinery in motion all the time.

Clearly, living instruments do not, and cannot, remain indifferent to the raw material in this sense. The movement of life as 'natural material' is one with its movement as an instrument in the synthesis of proteins; its 'decay' is as much a productive force as its 'growth and development', which are, after all, merely two different ways of viewing the same life-process. The retrieval of the substance from a 
living system thus 'involves' the instrument in a unique way. In many cases the technology, or part of the technology, is simply destroyed. Microbes are chemically 'denatured' or 'ruptured' so that they 'release' an intracellular protein. Plant systems are harvested and then "shredded or ground up, a process that induces the plant to kick out protein molecules" (Zehr 1999).

In other cases the substance can be retrieved in a way that leaves the instrument relatively more intact, as is the case when the protein is contained in the milk of mammals or the eggs of chickens. But even in these cases it is difficult to conceive of these animals as 'indifferent' to the milking process or laying of eggs in the same sense that the instruments of a machine system are indifferent to their product. And they certainly cannot be indifferent to what awaits them in the event that they fail to 'take up' the transgene or 'breakdown' in some other way. The USFDA suggests:

In general, disposal of transgenic animals, including retired or dead animals, should be in accordance with the applicable portion of the NIH guidelines or Research Involving Recombinant DNA molecules. Nontransgenic animals associated with the herd or animals in which the attempt to insert new genetic material has failed may by used in the food supply...If the manufacturer wishes to slaughter transgenic animals for human or pet food, or render transgenic animals for livestock feed, CBER or CDER will refer the manufacturer to CVM for a food safety assessment.

The transgenic labour process is thus a matter of life and death like no other.

Thus, if living organisms are machines, they are strange ones indeed. They are machines whose employment as productive forces requires only that they be kept in motion, that is, kept alive; the distinctiveness of this capacity is perhaps clearer if we try to imagine a machine system that required no raw material other than fuel, oil, and electricity in order to produce, say, an automobile, or a computer that only required that it 
be turned on to produce a video game. The absurdity of these examples points to a certain 'dematerialization' of production in a sense far more profound than Castells suggests is engendered by information technology. Where information technology still works up a primary substance (whether regarded as data, or traditional raw materials more generally), there is, in the case of the transgenic labour process no material worked-up at all. There simply is no primary substance, no 'raw material' other than the accessories required for the self-motion of the instrument. And it is in this sense that we can regard transgenic biotechnology as self-mediating in an unprecedented sense.

Now, to this point we have troubled the notion of system requirements as 'primary substances' and so we might regard life as a unique instrument insofar as the only raw materials required are 'accessories' in Marx's sense of the word. However, the notion that the system requirements of an organism are akin to the accessories of machine production is itself problematic when we enquire into the origins of the self-mediating capacities of transgenic biotechnologies. There is, as we have seen, an important sense in which machines consume raw materials in a way that hand-tools do not. However, machines possess this capacity for consumption (and the self-motion that is its corollary) by virtue of their being the product of a working-up of raw materials into an instruments of production. There is no sense in which the raw materials that are worked-up into a machine themselves possess the capacity to consume other materials as accessories. It is only once the machine is created that its employment requires that accessories be added; and of course if they are not added the machine will continue to exist, even if in a passive state. In this sense, then, the accessory materials of machine production can also be 
conceived as 'other than' the machine itself, and certainly 'other than' the materials of which the machine is made.

However, the case is very different with transgenic biotechnologies. The capacity to consume accessory materials is not 'built into' an organism through the labour process, but is found in life itself just as its capacity for self-motion is found; indeed, mobility and consumption imply one another and are essential characteristics that distinguish life from other forms of nature. Thus, unlike the accessories of machine production which are, in a sense, added to the machine once built, the system requirements of transgenic biotechnologies are requirements for the existence of an organism as such and are always already part of the labour process from the time the organism is first 'purified' from its environment. And of course, they consume these requirements as part of what they are independent of the labour process as well, and so there is an important sense in which the system requirements of an organism are not raw materials 'other than' the instrument that are added to it, but are an essential component of living technology itself without which it would cease to be at all. Thus, this self-mediation is a found capacity of life; it is harnessed to the labour process, but is not itself a result of this process.

The important point here is that, rather than working on natural materials as mere objects, transgenic biotechnologies consume these materials as part of their self-activity and in this sense they are, like machines, distinct from hand-tools. However, unlike machines, an organism only requires that its system requirements be met in order that it may act as an instrument of production and so natural materials as objects of transformation disappear all together from the labour process. Moreover, this capacity for self-mediation lies in the organism itself; unlike a machine, whose accessories are 'other 
than it' and can be withheld from it, the system requirements of life are part of living systems themselves without which they cease to be. Transgenic biotechnologies are thus self-mediating nature harnessed to human purpose through the practices of genetic engineering. And insofar as the technology/nature dualism has been premised upon a rigid distinction between instrument and raw material, living technologies constitute a destabilization of this dualism like never before. We are thus witnessing in the transgenic labour process an important 'end' of living nature conceived as distinct from industrial labour processes, a point to which we will return later.

\section{Self-Replicating Production Systems}

We saw in our discussion of Marx in the first chapter that the capacity for 'selfreproduction' constituted a third sense in which machine systems approximate a force of nature in a qualitatively distinct way. And, while this notion of self-reproduction may appear highly metaphorical in comparison to the capacities for motion and consumption, it is less so when understood in the context of Marx's argument regarding the importance of 'machine making machines' to the development of capital as self-expanding value. As Nathan Rosenberg emphasizes, it is only when machinery (i.e. fixed capital), is, rather than dependant on methods of handicraft, dependant on itself that capitalism can 'stand on its own feet' as a mode of production. Our purpose here is to assess the degree to which transgenic biotechnology constitutes a disjuncture in the degree to which the instruments of production, and the labour process more generally, can be understood to be self-reproducing. 
The notion of self-reproduction has always been central to the cyberscientist's vision of machine systems that approximate life. Again, Lily Kay's (2000) account of the intertwining histories of cybernetics and molecular biology makes this point clear. A central figure in this regard was John Von Neuman, whose 'automata' were machines that would not only reproduce themselves, but would, in the process, produce the kinds of mutations and increasing complexity characteristic of the evolution of life. Such machines would thus possess the unique ability of life to 'violate' the second law of thermodynamics, which holds that all systems will with time demonstrate increased entropy (i.e. a tendency toward disorganization and dispersal of energy). While the debate over whether life indeed constitutes a violation in this regard and, if it does, how living things are able to achieve, through their growth and development, increased complexity (negative entropy), what is important here for our purposes is the degree to which the goal of approximating life in this regard has infused machine design.

And again, just as they do in the case of motion and consumption, developments in digitization and computer technology have given new meaning to this notion of selfreproducing machinery. Of course dystopian science fiction is rife with visions of computer systems that are not only self-conscious, but able to reproduce themselves over time. One thinks of the cyborgs of the Terminator trilogy who are mass produced by an 'artificially' intelligent computer system in self-defense against human 'revolutionaries'. However, such images should not be too easily dismissed. If information systems centered around computers are indeed self-acting in the sense that we have used this term, then there is an important sense in which they are actually self-reproducing in a way that pre-informational machinery was not. After all, what is a 'dark factory' other 
than a self-acting machine system that produces, as part of its self-activity, more machinery?

But of course, as we have seen, information systems are not truly self-acting, at least in the way nature is, and so their 'reproductive' activity can only ever be a crude approximation of that which is found in nature. All technology can be used to create new technologies that are more complex than themselves. A good example is the early use of hand tools to create machinery and of course computers can be programmed to create more complex computers. However, insofar as they must be built out of relatively inert materials, programmed, and set in motion, machine systems, no matter how 'informational', are not self-reproducing, and they certainly do not grow and develop in a way that contradicts the second law of thermodynamics. Self-reproduction in this sense must remain the stuff of cybernetic dreams and science fiction nightmares.

But by now the significance of transgenic biotechnology should be clear, for it is only living technologies that are actually capable, as technologies, of self-reproduction. Where non-living instruments of production, subject to the $2^{\text {nd }}$ law, must experience entropy, transgenic biotechnology not only increases in complexity through its growth and development, but recreates more of itself in the process. And, rather than being programmed in this way, living organisms possess this capacity in-themselves. Thus, the transgenic labour process in this sense constitutes a harnessing of the self-reproductive force of living nature as a productive force in the satisfaction of human needs.

The importance of life's capacity for self-reproduction to the transgenic labour process is perhaps clearest in the case of microbial production, where both the creation and employment of transgenic microbes as a productive force relies on their self- 
reproduction. Where our notion of 'purification' may have seemed to imply a kind of physical 'filtering' out of a target species from undesirable materials, this purification is actually achieved through creating a biochemical environment (the selective medium) in which the target species will not only survive at the expense of other forms of life, but reproduce itself and saturate the medium. When the saturation point is reached a sample is taken from the culture and inoculated into another medium where, again, the microbes reproduce themselves and so on until the desired 'purity' is reached. There is thus an important sense here in which the target species is active in the process of its purification and this 'activity' is precisely that unique capacity of life to reproduce itself.

And what is the process of scale-up other than the reproduction of the microbes themselves? We have to this point been regarding the fermentation tank as the environment conducive to the functioning of microbes as tiny factories for the production of useful substances. And we distinguished 'lab', 'small batch', and 'production scale' tanks as marking the stages of the scale-up process. But of course these are not discreet stages; rather, they are merely moments in the growth of the microbial population, a growth that is a function of the reproductive activity of the microbes themselves. Once the population saturates a fermentation tank of a given size, a larger tank must be inoculated, and the eventual saturation of the 'production scale' tank marks the end of the production run. Where the 'scale-up' of machinery implies building more and/or bigger machines, the scale-up of a transgenic system is more akin to encouraging the 'machines' to build more of themselves. And where the building of more and bigger machines is distinct from their employment in production, the self-reproduction of a microbial population is one with its employment in the synthesis of useful substances; that is, the 
microbial population at all stages of the 'scale-up' process is always already in motion and must remain so if it is to be at all. Thus, unlike machine production, the employment of transgenic microbes as instruments of production is always simultaneously the creation of new microbes; indeed, the self-reproduction of the microbial population is the central productive force of this transgenic labour process.

In the case of transgenic plant production, while not part of the production run itself, the capacity of plant life for self-reproduction remains a crucial productive force. As we saw, the goal of plant genetic engineering is not the creation of a transgenic plant for its own sake, but the creation of a living instrument for the production of transgenic seed that can then be planted in increasing quantities to yield transgenic crops at increasing scales. And again, the important point here is that this capacity to produce more of itself, in the form of seed, is a capacity unique to plants as forms of living nature. A transgenic plant is thus simultaneously an instrument for the production of useful substances and an instrument for the production of more transgenic plants. An "advantage of plant-made pharmaceuticals," suggests Aziz Albehri of the USDA, "is the large production capacity offered by plants - in particular production scalability, which requires only that new seeds be developed and that more acres by brought into production to meet additional demand" $(2005,5)$. There is clearly little sense in which a non-living machine produces a product that is 'other' than itself and simultaneously reproduces itself as part of its existence as such.

For its part, transgenic animal production harnesses the self-reproductive capacities of living nature in ways that are akin to both microbial and plant production. On the one hand, the scale-up of a population of transgenic animals into a "production 
herd' is akin to the scale-up of a microbial population in the sense that it amounts to little more than creating the conditions conducive to the reproduction of the animals themselves; the difference of course being that the scale-up of animals must accommodate the mating activities of the 'factories'. As GTC points out, "scale-up is as simply as breeding more transgenic animals."

On the other hand, an animal's reproduction of itself is not constitutive of the 'production run' in the same way that a microbial population's is. Like transgenic plants, transgenic animals are employed as relatively discreet production facilities in the synthesis of useful substances; their reproduction of themselves, while surely an advantage in scaling-up the production herd, is relatively distinct from their role as instruments of production per se. Of course, like all organisms, animals synthesize proteins and reproduce themselves as part of the same life-process, but these capacities are relatively distinct in a way that is not the case with microbes, whose force in the production of useful substances is linked much more directly to their reproductive capacities.

Despite these differences, there is visible, across the modalities, a qualitative disjuncture in the degree to which industrial technology possesses capacities for selfreproduction. The capacities of machinery in this regard have always been limited to being employed as instruments in subsequent labour processes. Machines work up materials that are other than themselves into new machines that, while like them, are not of them. Transgenic biotechnologies, however, as part of their self-activity, which in turn presupposes their self-mediation, reproduce themselves in the most literal sense and indeed the capacity for reproduction is central to the meaning of life itself. 


\section{Conclusion}

Thus, on all three counts, transgenic biotechnology constitutes a significant disjuncture in the degree to which industrial technology approximates a force of nature. They are selfacting, self-mediating, and self-reproducing in way that is unique to living technologies and qualitatively distinct from machinery. Understood in combination, these capacities endow the instruments of production with the kind of perpetual motion that has heretofore been the unique quality of life and to which machine design has aspired. It is a perpetual motion, however, that is being achieved, not through building a technology that more closely approximates living nature, but by harnessing living nature itself as a technology. Indeed, it is precisely because transgenic biotechnologies are not machines that they possess this kind of perpetual motion. Harnessing life as an industrial productive force thus brings technology to life like never before. 


\section{6 - The Relation of Living Labour to Transgenic Biotechnology}

As we saw in our discussion of Marx in chapter 1, industrial labour processes constitute not only a disjuncture in the meaning of non-human nature, but also alter the relation of living labour to the materials and forces of nature. Where the labourer of pre-industrial handicraft might be meaningfully conceived as a subject animating an artificial instrument in the transformation of a natural object, things are decidedly different with the coming of the machine. Here living labour constitutes an "objective" component of the labour process, an "appendage" of the machine that, rather than providing the principle of motion of "natural things", regulates instruments whose movement, consumption and reproduction come increasingly to approximate a force of nature. Now that we have clarified the disjuncture marked by transgenic biotechnology in the degree to which industrial forces of production approximate a force of nature, we are in a position to assess the relation of living labour to these non-human components to the transgenic labour process.

The purpose of this chapter is to reveal certain of the unique characteristics of the relation of living labour to transgenic biotechnology. Since we have defined our transgenic labour process in 'industrial' terms, it seems fitting to begin with an engagement with Braverman's degradation thesis and the particular conception of industrial labour upon which it is premised. While there is evidence that the "life industries' are indeed characterized by the division of labour, deskilling, and automation Braverman identified with industrial labour processes more generally, this traditional 'labour process approach' threatens to obscure what is unique about the labour required for the creation and employment of transgenic life as an instrument of production. We 
will next turn to the work of Ted Benton who distinguishes 3 types of labour processes central to which are specific relationships between labour and the means of production. While possessing some of the characteristics of the 'instrumental-transformative' labour Benton identifies with industry, transgenic labour has in fact much more in common with the 'eco-regulatory' labour of agriculture, where labour regulates living means of production, and the labour characteristic of the 'extractive', where the role of labour is determined by the relatively found characteristics of the materials and forces of nature. Returning to questions of 'division of labour' and 'automation' in the final section I argue that the 'fully-automated' nature of transgenic biotechnologies implies from the beginning a regulatory role for living labour and, furthermore, that the integration of nonliving automation technologies to provide the system requirements and regulate the lifeprocess of transgenic biotechnologies is endowing the transgenic labour process as a whole with the kind of self-movement previously unique to the forces of nature. I conclude by acknowledging certain paradoxes raised by regarding the transgenic labour process as a regulation of the biological processes of living means of production, paradoxes that are resolved in chapter 7.

\section{Engineering Life}

Braverman's ([1974] 1998) conceptualization of labour and the process of its degradation under industrial capitalism is as familiar as it is compelling. For Braverman, human labour is distinct by virtue of the fact that, unlike the instinctual life-activity of nonhuman animals, human labour is always, to some degree, an expression of selfconsciousness; that is, the transformative act always shapes a raw material in accordance 
with a 'plan' that exists in the 'head' of the worker prior to the transformation of the object itself. Braverman's indictment of the separation of 'planning' and 'execution' under industrial capitalism reflects this conception of labour insofar as the result is a degradation of shop floor work that is increasingly devoid of those 'conceptual' activities that give human labour its meaning. The machine enters the picture here as a material embodiment of the division of labour, designed by 'planners' and 'attended' by increasingly deskilled workers, and is thus a means by which capital, and its representatives in 'planning departments', wrests control of the labour process from the direct producers.

Braverman's work has inspired labour process studies across a wide range of industries and these have generally pointed to a long-term trend toward a division of labour and automation, processes that have, if anything, been extended and intensified with the advent of new information technologies. Contrary to the optimism of the 'flexible specialization' (Piore and Sabel 1984) thesis in this regard, studies have pointed to the role of computer integrated manufacturing in further deskilling and disempowering shop-floor workers (Rinehart, et al. 1994; Taplin 1995; Lewchuk and Robertson, 1997; Rinehart, Huxley, and Robertson 1997; Vallas 1999). Others, in contrast to the 'postindustrial' thesis of Bell and others, point to the unique capacity of these technologies in extending the degradation of labour to the 'service' industries (Shalla, 2006; Fox and Sugiman 2006). And finally, perhaps the most unique quality of "knowing machines" (Mackenzie 1996) is their capacity to incorporate the 'planning' work itself into the instruments of production. Mike Cooley (1981) pointed to an increasing division of labour and automation in engineering work in the early $1980 \mathrm{~s}$, and subsequent analyses 
have pointed to an extension of these processes to increasingly 'skilled' sectors of the occupational structure (Kenney 1997; Morris-Suzuki 1997; O'Riain 2000). The advent and proliferation of information technologies and new forms of labour, while perhaps complicating matters, has done little to discredit Braverman's analysis of a general, longterm tendency toward a more intricate division, automation, and deskilling of industrial labour.

Yet, our transgenic labour process fits uncomfortably within Braverman's conceptual framework. On the one hand, that we have to this point considered the transgenic labour process an industrial one, and had occasion to use the term 'engineering' to refer to the labour of working-up (genetic engineer) and employing (biochemical engineer) transgenic life would seem to suggest a certain continuity with the 'industrial labour' that is the object of Braverman's analysis. On the other hand, our process of 'industrialization' is rather different than Braverman's in the sense that, instead of happening to a specific form of productive activity (e.g. steel production, auto production, office work), the transgenic labour process is constituted by a convergence of previously distinct forms of productive activity (laboratory science, fermentation, agriculture, animal husbandry) under a common logic of industrial production. Thus, where traditional labour process studies can take a specific 'point of production' as a site at which to investigate 'labour process transformations', we must look to the kinds of transformations characteristic of these disparate forms of labour more generally, as well as to what might be unique to their transformation as modalities of a transgenic labour process. Nevertheless, despite these complexities, current trends in the lab, at the fermentation tank, and in the field, greenhouse, and barn suggest that the employment of 
life as a means of production poses no particular obstacle to the trends toward division of labour, automation, and deskilling identified by Braverman.

Martin Kenney's (1986) early analysis of biotechnology start-ups suggested the degree to which the development of a labour process centered around transgenic microbial life would be characterized by the trends toward division of labour, deskilling, and automation identified by Braverman. Kenney contrasts these start-ups with the structure of the universities from which they were often spun-off:

In contrast to the university, where a peer group of scientists makes collegial decisions and each faculty member has an equal vote, a company is characterized by clear hierarchy, and control is vested in corporate owners. The lines of authority are vertical: from management down to workers (scientists). (178)

He distinguishes between 'senior scientists' and 'working scientists' in this context where the former "are the interlocutors between corporate management and working scientists" (180). Of particular value in Kenney's analysis is his emphasis on the importance of 'technicians', who "do the innumerable and mundane tasks so necessary to efficient laboratory operations, such as preparing solutions and counting colonies" (187-188), tasks that Kenney suggests would become more prevalent with the growth of the industry. Looking forward, he suggests:

No doubt the genetic engineering and fermentation production processes will be highly automated. Further, technicians trained in today's techniques will become obsolete rapidly because of the constant changes engendered by the intense activity of the company and university researchers. (188)

Kenney's observations regarding the division of labour and tendencies toward increasingly 'technical' labour appear to have been borne out. The Massachusetts Biotechnology Council provides current information on the departmental and 
occupational structure of biotechnology firms and the education and skills required for the various positions ("Careers in Biotechnology"). Large firms with more than 300 employees are divided into 7 departments, with the move to commercialization being associated with the growth of 'operations' in particular. 'Operations' is in turn divided into 5 areas, the largest of which is 'manufacturing and production', which is further divided into a 5-tiered hierarchy: director, manager, supervisor, associate, and technician. 'Manufacturing technicians' share with other technical workers in the firm limited education (high school or some postsecondary for entry level positions) and the responsibility for largely routine tasks centered around non-living instruments of production and raw materials. A manufacturing technician, we are told:

Operates and maintains production equipment as it relates to cell culture/fermentation (i.e. fermentation tanks, bioreactors, cell harvests, and separation operations). May also assist manufacturing in productionscale protein purification and manufacturing of final products. Weighs, measures and checks raw materials to assure proper ingredients and quantities. Prepares media and buffer components. Maintains records to comply with regulatory requirements and assists with in-process testing.

Along with 'research and development', 'manufacturing' is identified as the industry's "greatest growth area", with a " new biomanufacturing training program for entry-level biomanufacturing technicians development" being offered at a local community college.

The routinization of the 'lab work' of genetic engineering and the concomitant shift from the 'scientist' to 'technician' was revealed early on in a case study by sociologists of science Kathleen Jordan and Michael Lynch (1992). Where once a central preoccupation of skilled molecular biologists, the task of 'plasmid prep' had even then become increasingly viewed as the 'grunt' work of molecular biology and assigned to 'technicians'. 
Although the construction of biologically functional plasmids was a major innovation only fifteen years ago, the procedure is now...one of the routine 'chores' regularly assigned to students and lab technicians, and it holds little fascination for students of science interested in cutting-edge innovations. In contemporary recombinant DNA research the plasmid prep is a preparatory procedure , and like innumerable other routines - washing glassware, inoculating mice, purchasing supplies, culturing cells - it is a humble detail within molecular biology's progressive development. (8081)

While Jordan and Lynch were not here concerned with the notion of 'de-skilling' per se, this 'routinization' of lab work would seem consistent with the trends identified by Braverman.

And along with the deskilling of the labour of genetic engineering, we would expect the same kinds of trends toward automation as 'labour process studies' have revealed in other industries. And, indeed, the automation of the lab work of molecular biology is well documented (Keating, Limoges, and Cambrosio, 1999). Such automation is often viewed within industry and engineering circles as crucial to the success of the biotechnology, with the absence of 'human hands' viewed as a sign of efficiency in terms of both processing speed and protection of the organism from 'contaminants'. An example is a study concerned with cell culture and tissue engineering in the journal Biotechnology Progress published by the American Chemical Society and American Institute of Chemical Engineers. The authors suggest:

to obviate the need for human intervention with the aim of maximizing efficiency and minimizing the risk of failure, error, and contamination in biotechnology environments, a very promising way is to introduce robots (fully programmable manipulators) into the plant process and transfer all suitable tasks to them. $(2004,1825)$ 
The study goes on to demonstrate that a "mobile robot system using unmodified laboratory equipment can be used to automate a complex technological process usually requiring human personnel" and concludes that

The potential of complete elimination of human intervention through highfidelity telepresence and teleaction techniques may pave the way not only for remote-controlled plants but also for automatic plant maintenance with these highly autonomous robot systems. (1835)

It would appear, then, that industrial labour processes centered on the genetic engineering of life pose no particular obstacle to processes of automation.

And where the 'lab' is the primary site of deskilling and automation in the case of 'genetic engineering', the 'fermentation tank' is a crucial site of transformation where the employment of microbial life as an instrument of production is concerned. Lilly engineer Joseph Alford (2004) recounts the development of fermentation technology in a way that makes clear the logic of automation and deskilling identified so clearly by Braverman. "In the early 1970s," writes Alford,

Eli Lilly and Co. had a dilemma. As one of the leading fermentation companies in the world, they realized that the fermentation process, (making penicillin), was as much art as science...Data recording consisted of operators walking through the production floor, periodically recording values from gauges onto a clipboard sheet and hand entering a few values onto the paper manufacturing ticket...Sometimes, the best indicator as to how well a fermentation was progressing was the subjective analysis of an experienced employee looking through a tank site glass at the colour and texture of the foam layer riding on top of the liquid broth. (1)

The ultimate solution to this 'problem' of relying on the "art" and "subjective analysis of an experienced employee" was not to be realized until the 1990s and is described in decidedly Taylorist terms:

Lilly decided to interview the plant operation experts and capture their expertise in analyzing process information. This information was then 
organized into 'if then rules' and other forms of knowledge. This was then coded into a real-time expert system...The resulting system would look at all the data coming in....analyze it with respect to the now captured and coded 'rules' in the expert system and make its conclusions available to CRT consoles and to paging systems. This saved nearly 50 man-hours of manual data review/plant/month. Manual routine data monitoring by technical service folks was dramatically reduced or discontinued. Instead, operations and support employees were alerted via a pager when the expert system determined an abnormal situation existed, and only then, began reviewing data and other computer generated results. (7)

That Lilly is now a leader in the manufacture of recombinant proteins via transgenic microbes suggests that transgenic microbial labour processes are subject to the same deskilling and automation of 'craft production' as characterizes those industrial labour process centered around non-living instruments of production.

Where the 'factory' setting of microbial production lends itself to a more traditional labour process approach, a labour process centered around transgenic plants is more complicated, its significance lying in a subsumption of agricultural practices with centuries of history under an industrial logic from which they had previously been excluded. Certainly agriculture has been subject to a division of labour, deskilling and automation, and indeed, this is what is normally meant be the 'industrialization of agriculture' in rural sociology. Jack Kloppenberg's (1991) early study of 'agricultural biotechnology' identified these trends and, in particular, the way in which they were mutually reinforced by the design of transgenic crops. The case of tomatoes engineered with tougher skins to enable mechanized/automated picking was emphasized by Kloppenberg. Insofar, then, as the employment of transgenic plants as biotechnologies is continuous with agricultural practices more generally, it is subject to the same processes of 'agro-industrialization'. 
Yet, if the 'fermentation tank' is the primary site of transformation in transgenic microbial production, the locus of division of labour and automation in the case of a labour process centered around transgenic plants is not the field per se, but the greenhouse (Traynor, Adair, and Irwin 2001). A central disadvantage of transgenic plant biotechnologies is that they 'manufacture' their substances in a relatively uncontrolled environment relative to microbes. The solution, of course, is to construct a controlled environment akin to the fermentation tanks of microbial production. The advantages of creating and employing transgenic plant biotechnologies in a greenhouse are two fold. First, a greenhouse allows the kind of physical containment of transgenic plants impossible in the field, containment that is necessary to avoid cross contamination with non-transgenic species. Second, a greenhouse allows for the same kind of efficient monitoring and control of the life-process of transgenic plants as is enabled by the fermentation tank in the case of microbial production. As Medicago suggests:

Based on alfalfa plants grown in hi-tech greenhouses, Proficia offers the flexibility and high-volume potential of plant-based technology together with the safety and control of confined environment production. (http://www2.medicago.com/en/tech_platform/proficia/)

As it is generally recognized that greenhouse technology will be integral to the development of transgenic plant production, a look at the deskilling and automation characteristic of greenhouse labour more generally is revealing.

A series of articles in Greenhouse Product News (many written by those with an explicit financial stake in the manufacture of greenhouses) makes clear the applicability of Braverman's analysis to a labour process centered around life. In one such article, devoted to the design of workstations used for "seeding, transplanting, potting, taking 
cuttings, and preparing plants for shipping" we are told that these tasks are "repetitive, tedious and time consuming" (Bartok 2004, 1) The solutions again have a Taylorist ring to them:

Reducing hand and arm motion will speed up the work process. The reach from the normal armrest position should be limited to a 24 -inch radius to the side and front for women and 27 inches for men. The best work area is within 16-18 inches of the resting elbow position. Tasks that can be accomplished with two hands will increase production about 25 percent over one hand movement. Hand motions should be opposite and symmetrical. The distance that both hands have to travel should be about the same. Start and stop movements require more time and energy. (2)

And if there were any doubt as to the possibility of Fordist-style automation in a labour process centered on the working-up of plant life, we are told that

The transplanting conveyor, manufactured by several equipment companies, is an alternative to building your own workstations. The concept is adapted from assembly operations in electronics and appliance industries. A slow-speed conveyor belt moves the...pots past workers who place the plugs or cuttings. The transplanters stands or sit next to the conveyor with the plugs located within arms reach. A variable speed motor on the conveyor adjusts the speed from 5 to 50 feet per minute to adapt to the type of container, the number of transplants and the experience of the workers.(3)

The centrality of greenhouse technology to the creation of transgenic plants again suggests the applicability of Braverman's analysis to our transgenic labour process.

Moreover, it is not merely the working-up of plant material that is characterized by this logic of automation, but the growth of greenhouse crops themselves. Ehret, et al. (2001) provide a review of the state-of-the-art in automated monitoring of greenhouse crops central to which are "remote sensors" that employ "machine vision" to monitor the life-process of plants life. These systems are limited, however, and still must rely on the 'art' and 'subjectivity' of growers: 
For now, monitoring systems can provide continuous data about specific aspects of crop growth and development, but do not allow automated control of either the greenhouse climate, or crop characteristics such as growth and fruit quality. The data must be integrated with the intuitive and observational knowledge of commercial growers. (411-412)

Looking forward, however, the authors suggest the possibility of overcoming these limitations in a fully automated plant-system:

Advances in crop monitoring will be of most value to commercial growers when the sensor information is fully integrated with the greenhouse control computer. At that point, a true 'speaking plant' environment will be created, whereby the crop becomes part of the control procedure. (410)

Central to such this 'speaking-plant environment' would be "a new intelligent control technique, which mimics empirical human thinking and action" (410). The trend toward the displacement of labour through automation would thus appear as clear in a labour process centered around plant life as in any non-living production 'plant'.

And what the fermentation tank and greenhouse are to microbial and plant production, the barn is to a labour process centered around the employment of transgenic animal biotechnologies. The aim of barn design similarly concerns both containment and control, but the precise shape of the environment in this case is specified by the unique life-process of the animal in question and, in particular, the way in which these higher order production systems issue in their product. As we have seen in the case of Tranxenogen, it is the highly automated character of commercial egg production that offers advantages in both control, containment, and cost.

Transgenic chickens, in a fully automated, contained and controlled facility, should be able to produce these complex proteins for a fraction of the cost of mammalian cell processes. The fully automated nature of chicken husbandry, which has been developed by the food industry minimizes the human labour costs, the benefits of which are reflected in the final costs of goods. Proteins produced by transgenic chickens are 
expressed at commercial levels and delivered in a convenient, sterile package - an egg.

(http://www.tranxenogen.com/NewFiles/hotbuttons.html)

In the case of mammals, their size and mobility does not lend itself to the 'barrier' conditions of chicken housing and, owing to their manufacturing of the product in their milk, a central site of automation is at the teat. In a study of the dairy industry Hogeveen and Ouweltjes (2002) identify two trends in "high-tech milking equipment: 1) highcapacity milking parlours with a high throughput of cows per person per hour and 2) automatic milking systems in which manual labour is replaced by a milking robot" (1). In the case of the former, the emphasis is on increasingly the intensity of labour:

the milker has to perform a number of work routines. The time spent on these routines, to a large extent determines the capacity of a milking in cows per hour. An optimization of work routines increases the maximum number of cows per hour per man from 50 to 65. (2)

In the case of and automated milking (AM) system the emphasis is on the displacement of labour all together:

Although the time that the milker spends at a cow decreases in a highcapacity milking parlor, there is still the presence of a person...With an AM system, there is no milker present at milking and thus there is no obligatory contact between the herdsman and the cows...Moreover, in an AM system, the way of working is completely changed. Cows can be milked $24 \mathrm{~h}$ per day...An AM system has to take over the 'eyes and hands' of the milker and therefore these systems need to have electronic cow identification, cleaning, and milking devices and computer-controlled sensors to detect abnormalities. (2)

Such an intermingling of mammals and robots devoid of human labour will surely characterize the development of a labour process centered around transgenic animal 
biotechnologies - a totally automated industrial production system, although one whose happiness will surely require that the lights be left on.

While we will return to discuss in more concrete terms the meaning of this division of labour and automation at the end of the present chapter, we have here enough to suggest that, for all its uniqueness, the transgenic labour process does not lie outside these tendencies identified by Braverman as being characteristic of industrial labour processes in general. And there is no question that a detailed analysis of the division of labour and automation in the transgenic labour process would be revealing. As suggested, there is likely a great deal of continuity here with industrial labour processes more generally and such analysis would be useful in dispelling some of the mythology of molecular biologists who in 'his' God-like artistry is, to use biologists Lee Silver's words, 'remaking Eden'.

At the same time, however, we must not let such continuities obscure what might be unique to the division of labour and automation when it is a living technology that is at the centre of the labour process. After all, it is not the consequences of 'transgenic biotechnology' for workers per se that is our primary interest, but the degree to which a labour process centered around these living technologies constitutes a disjuncture in the meaning of nature. As we have seen, transgenic biotechnology is unprecedented in the degree to which it gives life to the labour process, thereby giving life to the labour process insofar as it approximates a force of nature like never before. We need to now enquire into the implications of this unique involvement of life in the labour process for the relation of the human to non-human components of the labour process. 


\section{Transgenic Biotechnology and Eco-Regulation}

Environmental sociologist Ted Benton's (1989) critical reconstruction of Marx's conceptualization of the labour process centers, at least implicitly, on the important differences between living and non-living means of production. Benton takes as his point of departure the strange antipathy between ecologists and Marxists who, after all, are both supposed to be concerned with the 'material' engagement of human beings with their world. Benton's solution to this puzzle lies in an 'ecological reconstruction' of Marx's conception of the labour process. The difficulty with Marx's conception of the labour process, for Benton, is that it tends to take as paradigmatic a specific 'intentionalstructure' that tends to understate the 'natural limits' to human productive activity. This 'transformative' intentional-structure, while, perhaps, an accurate conception of 'industrial activity', neglects the unique relation of labour to the means of production in agriculture in particular, what Benton calls an 'eco-regulatory' labour process. Seeing as our 'transgenic labour process' would seem to contain elements of both of these kinds of labour, engaging with Benton's argument should prove fruitful in assessing the disjuncture engendered by transgenic biotechnology in the relation of human and nonhuman nature.

Now, leaving aside, for the moment, the problematic notion of 'natural limits', what is most important for our purposes is Benton's 'eco-regulatory' paradigm and the distinct kind of labour that is at its centre. There are 4 distinct elements and they are worth quoting at length:

1. Labour is applied primarily to optimizing the conditions for transformation, which are themselves organic processes, relatively impervious to intentional modification. The [object] of labour...is 
therefore not the raw material that will become the 'principle substance' of the 'product' but rather the conditions within which it grows and develops.

2. This labour, optimizing the conditions for organic growth and development, is primarily... a labour of sustaining, regulating, and reproducing, rather than of transforming (e.g. maintaining the physical structure of the soil as a growing medium, maintaining and regulating the supply of water, supplying nutrients in appropriate quantities and at appropriate times, reducing of eliminating competition and predations from other organic species, etc.).

3. The spatial and temporal distributions of labouring activity are to a high degree shaped by the contextual conditions of the labour process and by the rhythms of organic developmental processes.

4. Nature-given conditions (water supply, climatic conditions, etc.) figure both as conditions of the labour process, and as [objects] of labour, yielding a category of 'elements' of the labour process not readily assimilable to Marx's tripartite classification (labour, instruments of labour, raw materials).

Now, the significance of eco-regulatory labour is that it reveals, for Benton, the 'natural limits' to human productive activity in a clearer way than a 'transformative' paradigm and while his use of this particular terminology has proven a central point of controversy (as we will see when we encounter Reiner Grundmann's critique of Benton in Chapter 7) this is largely a red herring. It is clear that what Benton means is that labour, rather than transforming at will a passive object, must engage with certain of the 'found characteristics' of its material in order to realize its purpose; these are indeed limits, but they are limits that are only ever immanent in the labour process itself and are thus historically specific. In this sense, his notion of 'natural limits' is similar to our emphasis throughout the present work on nature as the field of potentiality with which human beings must engage in order to develop these potentialities into forces of production to satisfy their needs. It is perhaps more useful to thus speak of the 'materiality of labour' in this context, rather than the 'natural limits to labour'. 
This notion of eco-regulation is intended to grasp what is relatively unique about agricultural labour as distinct from the 'transformative' labour characteristic of industry. What is striking here, however, is the degree to which the employment of transgenic biotechnology as an instrument of production by bioengineers, which we have to this point considered a form of industrial labour, corresponds to this 'eco-regulatory' paradigm. We will deal with criteria 1,2, and 4 of Benton's paradigm here and leave criterion 3 for a later section.

First, where transformative labour acts upon the 'primary substance' in order to effect a change in its form, eco-regulatory labour optimizes the conditions for a transformative process that occurs in the organism itself. Now, the primary point for Benton here is that the 'primary substance' of agricultural labour processes (i.e. plant life) is not transformed as much as it transforms itself (i.e. grows and develops) into a product (food). In this sense the employment of transgenic biotechnology is distinct insofar as the organism is not the 'primary substance', but the instrument of production. However, what is important for our purposes is that the 'object' acted upon by labour, rather than a 'primary substance', is in both cases the environment within which the organism carries out its life-process.

The parallel is obvious in the case of transgenic plant and animal production where 'environment construction' and provision of 'system requirements' is precisely what Benton means by "optimizing the conditions for transformation"; after all, as we argued in chapter 4 , the transgenic labour process is continuous with agriculture and animal husbandry in this sense. In fact, it is just this continuity which makes these forms 
of transgenic production so attractive. Thus, in a Library of Parliament report outlining the "advantages of plants as expression systems", the author points out that

whereas transgenic plants...can be grown on an agricultural scale requiring only water, minerals and sunlight, mammalian cell cultivation is an extremely delicate process that is also very expensive, requiring bioreactors that cost several hundred million dollars when production is scaled up to commercial levels. (Norris 2005, 3)

And both Tranxenogen and GTC emphasize their ability to draw on the "the chicken husbandry, which has been developed by the food industry" and the "standard operating procedures that meet or exceed established practice for the dairy industry" respectively. Yet, this it is no less accurate a description of the 'object of labour' acted upon by the biochemical engineer which, as we have seen, is not a 'primary substance', but the 'broth' and other environmental conditions required by the microbial population.

And clearly, Benton's description of eco-regulatory labour as a "labour of sustaining, regulating, and reproducing, rather than of transforming" is striking in its applicability to the labour required for the employment of transgenic biotechnology. The scale-up of transgenic biotechnology does not constitute a 'transformation' of the organisms or their system requirements as much as it constitutes a regulation of their life process on increasing scales through provision of these system requirements. Labour does not 'transform' transgenic seed into a crop of mature transgenic plants, nor does it 'transform' a transgenic fetus into a herd of mature transgenic animals, or a transgenic microbe into a production scale population. In all of these cases the labour of bioengineering is a labour concerned with ensuring the life-process of these organisms as they grow, develop, and reproduce themselves at increasing scales. 
And what of Benton's $4^{\text {th }}$ dimension of eco-regulatory labour? Again, it is clear that our consideration of the 'biosphere' as providing the 'system requirements' of transgenic plant and animal biotechnologies highlights the importance of the 'naturegiven conditions' emphasized by Benton. And insofar as the labour of bioengineering is in these cases concerned with manipulating these conditions it indeed would appear to yield a category of 'elements' that are neither 'primary substances' or 'accessory materials' in the traditional sense. Where the 'artificiality' of the fermentation tank as an environment for transgenic microbes might appear to vitiate the notion of 'nature-given conditions', if we understand the fermentation tank (not to mention the greenhouse, barn and 'artificial wombs' of transgenic plant and animal production) as reproductions of these conditions, Benton's argument would still hold. The important point is that labour does not transform the system requirements of living nature as much as provide them, these 'artificial environments' merely constituting different means of ensuring that Benton's' 'nature-given conditions' are satisfied.

Thus, on all three counts, the role of labour and its relation to the non-human components during the employment phase of our transgenic labour process would seem to correspond remarkably well to Benton's eco-regulatory paradigm. And this is significant for our purposes insofar as, for Benton, eco-regulatory labour reveals the 'natural-limits' to, or, better, the 'materiality' of, labour in a way that instrumentaltransformative labour does not. Where the working-up of inert materials with non-living instruments lends itself to a view of 'nature' as a passive object of transformation, the self-movement of life as means of production implies a form of labour that is better understood in terms of 'regulation', a role that requires close attention to the requirements 
of 'nature' itself. Rather than a passive object, non-human nature is here better understood as a 'partner' with which human being must engage in order that it be harnessed to their purposes. Benton's 'ecological reconstruction' of the labour process is valuable in directing our attention to this alternative conceptualization of the humannature relation.

Yet, we must acknowledge that there is an important difference here between our transgenic labour process and the eco-regulatory labour process that is the focus of Benton's analysis. For Benton, agriculture is the exemplar of 'eco-regulation' and, indeed, it would appear that the two are synonymous. Crucial for Benton is the role of labour in regulating the organic processes of living things (plants in particular, but we could also include animals) as they grow and develop into food products. While by no means an object of labour in the traditional sense, life is still best conceived here as the 'raw material' that, while not worked-upon directly by labour, is nevertheless that which is worked-up into the product. However, as has been emphasized throughout the analysis here, the transgenic labour process is one centered on the employment of life as an instrument of production, a transgenic biotechnology, and that the unique characteristics of the transgenic labour process lie precisely in this repositioning of life as an instrument of industrial production, rather than raw material. So, does this repositioning of life as industrial technology not problematize a typology premised upon a rigid distinction between agriculture and industry? Might not the advent of biotechnology vitiate Benton's argument by subordinating 'life' to an instrumental-transformative paradigm?

It is clear that Benton is not unaware of the unique challenge of biotechnology in this regard. In response to those who would view biotechnology as indicating a shift to 
instrumental-transformative control over living materials, he mounts two kinds of arguments in defence of the concept of eco-regulation. On the one hand, he simply denies that developments in biotechnology constitute greater control over organic processes. He suggests that "the newer biological technologies have been 'sold' within a voluntaristicPromethean discourse which has invariably occluded or rendered marginal the limits, constraints and unintended consequences of the deployment in agricultural system" $(1989,10)$. On the other hand, and more indirectly, Benton suggests that the distinction between 'agriculture' and 'industry' might not be that rigid after all insofar as industry is, and has perhaps always been, characterized by some of the same 'eco-regulatory' labour so central to agriculture. While this part of his argument is somewhat ambiguous, as we will see in chapter 7 , we can at this point extrapolate from these suggestions that, while incorporating life into a broadly transformative paradigm, the employment of transgenic biotechnology still relies on 'nature-given' organic processes and thus might be a kind of hybrid typology exhibiting characteristics of both transformative and eco-regulatory labour. In any case, Benton seems willing to admit that biotechnology constitutes part of a broadly transformative paradigm, merely denying its efficacy in this regard in the first case, and emphasizing residual eco-regulatory aspects of the process in the second.

However, our analysis of the transgenic labour process provides us with a rather different vantage point here; one that suggests a more radical reconstruction of the labour process than Benton desires, although one that is perhaps less at odds with Marx's own than he imagines. Now we must admit here that when Benton regards 'biotechnology' as part of an 'instrumental-transformative' intentional structure he is thinking of the 'genetic engineering' of food, rather than the employment of life as technology per se. Thus, in 
order to properly assess the value of Benton's argument we need to first clarify the role of human labour and its relation to the non-human components in the 'working-up' of life and its parts and determine the place of 'genetic engineering' in his typology.

\section{Transgenic Labour as Regulatory Labour}

At first glance, the genetic engineering of life would indeed seem to confound Benton's typology, at least insofar as his distinction between instrumental-transformative and ecoregulatory labour is premised upon a living/ non-living distinction. As we have seen, genetic engineering is best understood as the working-up of life and its parts into a transgenic organism, which, for our purposes, is most significant in its capacity to serve as an instrument of production, a transgenic biotechnology that issues in useful substances that the 'found' organism would not otherwise produce. The difficulty here is that life constitutes the raw material of the labour process, as it does in agriculture, but the 'intentional structure' of genetic engineering would appear to be 'instrumentaltransformative' insofar as the purpose, rather than merely 'regulating organic processes', is precisely to transform these processes in a way that harnesses them to an industrial labour process.

And indeed, we have to this point regarded the role of the 'genetic engineer' in precisely such 'instrumental-transformative' terms. We have regarded the organism as the raw material that is transformed by the genetic engineer using both living and nonliving instruments of production. Whether the components of this process are living or not would seem less important than their correspondence to the 'subject-instrumentobject' model that Benton ascribes to the 'instrumental-transformative' paradigm. The 
genetic engineer is here the 'subject' employing living and non-living 'instruments' in the transformation of a living 'object' into a transgenic product.

Now, Benton may be correct in his critique of the hyperbole surrounding genetic engineering and the capacity of the molecular biologist to 'control' nature, but this objection is beside the point. Benton's argument rests on the concept of 'intentionalstructure' and it would seem that the genetic engineer is concerned precisely with a transformation of a raw material and acts directly upon that raw material with the intention of effecting such a transformation. The quantity of control of life this implies would seem less important than the incorporation of living nature into an intentional structure from which it had previously been excluded. After all, genetic engineering does work and, whether we regard this 'working' as evidence of greater 'control' or not, it is clear that the life-process of organisms has become an object of transformation like never before.

Yet, when we look a little more closely at the labour of genetic engineering, we find that things are a little more complicated. As we have seen, even if we regard a living organism as the raw material of the genetic engineer, it is a unique material whose capacity for self-assembly is a central force in the production of a transgenic organism. Labour, rather than acting upon living material itself, is better understood as creating an environment conducive to its 'taking up' the target gene, thereby 'persuading' the organism to assemble itself in a particular way. What is striking here, then, is the degree to which the genetic engineer is engaged in the same kind of 'regulatory' labour that Benton views as central to agriculture. Rather than acting on and effecting a transformation of the organism per se, the genetic engineer is engaged in "optimizing the 
conditions for organic growth and development,... a labour of sustaining, regulating, and reproducing, rather than of transforming". Now, there is of course a 'transformative' element here that is relatively absent in agriculture in the sense that the organism, rather than merely growing and developing, is made into a new transgenic organism; however, the important point here is that the labour involved in this process looks more like the 'eco-regulatory' labour of agriculture than the 'transformative' labour of industry centered around non-living means of production.

The waters become even murkier here when we look at the other type of labour process that Benton identifies as revealing the 'natural limits' to human labour. In addition to 'transformative' and 'eco-regulatory', he distinguishes the extractive industries as involving a unique kind of labour and again the criteria are worth quoting at length:

1. The conversion of the [object] of labour into a use-value cannot be adequately described as 'Nature's material adapted by a change of form to the wants of man." This conversion is rather a matter of selecting, extracting, and relocating elements of the natural environment so as to put them at the disposal of other practices (of production or consumption). These primary labour processes, then, appropriate but do not transform.

2. They, like ecoregulatory processes, are highly dependant on both naturally given contextual conditions and the properties of the [objects] of labour. In these practices, the place of principal and accessory raw materials is taken by 'naturally given' materials or beings, whose location and availability are relatively or absolutely impervious to intentional manipulation. $(1989,10)$

Now again, Benton's point here is that extractive labour processes reveal the materiality of labour in a unique way. In contrast to transformative labour, extractive labour does not change the form of 'natural elements', but selects, extracts, and relocates these elements. Moreover, such labour is 'highly dependant on the properties of the 
object of labour insofar as the labour of extraction must attend to the qualities of the material extracted. Thus, as is the case with eco-regulatory labour, rather than transforming a passive object at will, labour in the extractive industries is better regarded as attending to the 'natural' characteristics of the object of labour and harnessing these characteristics to the 'instrumental-transformative' labour process in their relatively found form.

And again, what is striking here, is that there are aspects of the labour of genetic engineering, which we have to this point been regarding as form of industrial labour, that correspond remarkably well to Benton's extractive type labour. The purification of the organism and the components of the rDNA molecule is very much a form of extractive labour. The organism, or its 'germ cells', the gene of interest and the vector, as the primary raw materials of the genetic engineer, are not made in any traditional sense, but found elements of the natural environment that are extracted from their environment, separated from undesirable materials, and relocated so that they may be worked-up into a transgenic organism. In this sense, genetic engineering is premised upon the same kind of appropriation of elements of the natural environment characteristic of Benton's 'extractive industries'.

More significantly, however, there is an important sense in which the working-up of the organism itself through practices of recombination and transformation is "highly dependant" on the "properties of the object of labour". Unlike the non-living materials of the 'extractive industries' proper, the 'properties' of the living materials of the genetic engineer include the capacity for self-assembly, a capacity that is not itself a result of any transformative labour, but is rather found in life as an element of the natural environment. 
And insofar as the genetic engineer is concerned with creating an environment conducive to the self-assembly of the organism, the labour of the genetic engineer is "highly dependant" on the "properties of the object of labour". Indeed, the differences between our microbial, plant, and animal modalities of genetic engineering arise precisely out of the found properties of the organisms themselves. Thus, the practices of recombination and transformation employed by the plant genetic engineer are qualitatively distinct from those employed by the microbial and animal engineer precisely because plants 'selfassemble' in unique ways, a capacity that lies in the object of labour itself. Insofar as meeting the system requirements of self-assembling object of labour is the intention of the genetic engineer, his/her labour is shaped by the found capacities of the object of labour in much the same way as it is in the extractive industries.

But we might go even further still and consider transgenic labour in its entirety as a kind of extractive labour process highly dependant on the 'found' properties of elements of the natural environment. A fermentation tank and broth, for example, constitute an environment conducive to the growth, development and reproduction of self-acting means of production whose specificity derives from the system requirements of the microbial population, requirements that are found in the organism itself, an element of the natural environment that has been 'selected, extracted, and relocated'. True, it is a 'transgenic microbe' created by the genetic engineer; but as we have seen, this 'creation' is itself highly dependant on the found capacities of life and its parts. The transgenic labour process is thus dependant for its productive force on the found selfacting capacities of life both as the 'object' of the genetic engineer's labour and as the 'instrument' employed by the bioengineer in the production of useful substances. 
What is perhaps most striking here, then, is the degree to which transgenic labour transcends Benton's types and witnesses a synthesis of intentional structures that have remained relatively distinct. On the one hand, it possess elements of the 'instrumentaltransformative' type in the sense that the intention of the genetic engineer is to transform the organism as object into a transgenic organism; in this sense it is unlike 'ecoregulatory' labour proper which does not transform as much as facilitate the growth and development of relatively found life. On the other hand, since, as we have seen, so much of this transformation is itself a function of the self-movement of living nature, there are clearly eco-regulatory elements that are absent in the creation of machinery out of nonliving materials; and the employment of biotechnology is clearly more eco-regulatory than instrumental-transformative. And, we have also seen that extractive labour is also present, which is reflected in the attentiveness of transgenic labour to the found capacities of the living object of labour, which, upon closer inspection is not 'transformed' as much as positioned within an environment in such a way as to take advantage of its found capacities for activity, consumption, and reproduction. The harnessing of life as an industrial productive force thus implies a unique relation of labour to the non-human elements of the labour process.

In fact, the term 'synthetic' seems appropriate to capturing what is unique about transgenic labour in two senses. First, it constitutes a synthesis, a putting together, of previously distinct types of labour, at least insofar as the relation of human to non-human components of the labour process is concerned. Second, the material practice of transgenic labour itself is uniquely concerned with the synthesis of materials. Rather than breaking down the materials of nature and reshaping them with the use of technology - 
what we might call 'analytic labour' - transgenic labour juxtaposes self-acting materials in a way conducive to their self-assembly in a particular way, and regulates their selfmotion (activity, consumption, reproduction) through the provision of their system requirements. This uniquely synthetic quality of transgenic labour is, in both senses, a reflection of its concern with harnessing life as an industrial technology. While we will explore this synthetic quality further in the next chapter, we can return now to assess the meaning of automation in light of these unique characteristics.

\section{DeSkilling and Automating Synthetic-Regulatory Labour}

Returning now to the question of automation and deskilling, we can seen the degree to the tradition of labour process studies has taken as paradigmatic a transformative labour process. For Braverman, the 'worker' is the subject of the labour process and is ontologically distinct from the relatively passive object onto which his/her transformative activity is transmitted via an instrument. The division of labour refers to the analytical breakdown of the transformative activity of the subject into its component physical and mental operations and the dedication of increasingly de-skilled workers to these 'fragmented' tasks, tasks that can eventually be incorporated into machinery itself, thereby reconstituting the division of labour around the machine. Deskilling and automation are thus conceived here as a dialectical relation between living labour and the instruments of production where there is a general transfer of skills from the former to the latter.

The 'limits' to deskilling and automation would here be set by the elements of the transformative moment of the labour process - on the one hand, by labour itself (both its 
'objective' susceptibility to deskilling and automation and 'subjective' resistance to these processes), and, on the other, the state-of-the art in production technologies. So, the limits to the division and automation of 'engineering' work, for example, were traditionally set both by the objective complexity and subjective resistance of the labour itself, as well as to the absence of any viable technological alternative to such 'mental labour'. Of course these limits were only ever immanent, as the development of 'knowing machines' and the deskilling of engineering work over the past few decades has made clear. But that these limits are conceived in terms of the human and technological components of the labour process is clear.

The great value of Benton's identification of the unique intentional structure of agricultural labour processes here is that it enables us to identify another kind of 'limit' to deskilling and automation, one that is obscured by a tendency to universalize an instrumental-transformative paradigm. As we have seen, there is indeed a 'transformative' moment in agriculture; however, rather than having its origins in living labour and the instrument of production, the transformation of life as raw material takes place in the raw material itself as the organism grows and develops. And this unique capacity of life for self-transformation means that the role of labour is primarily one of synthesizing and regulating life and its requirements in a way that harnesses this capacity to human purpose. While Benton does not address the questions of deskilling and automation in his discussion of eco-regulation the implication is clear: the deskilling and automation of agricultural labour is unique insofar as what is being deskilled and automated is not a transformative act, but a regulatory one, the transformative moment lying in life as raw material, outside the logic of automation, as it were. Thus, agricultural 
technologies do not 'transform' seeds into plants as much as they create the conditions for and regulate the transformative moment that is the life-process of living raw materials.

Now, there have certainly proven to be the same kinds of 'limits' to automation posed by the living labour and instruments of agricultural production. Indeed, much of the work in 'rural sociology' has been concerned with just these limits and the kinds of technological developments and struggles that have characterized their transcendence. But Benton, in his $3^{\text {rd }}$ characteristic of an eco-regulatory intentional structure, suggests that

The spatial and temporal distributions of labouring activity are to a high degree shaped by the contextual conditions of the labour process and by the rhythms of organic developmental processes.

Here, then, we have a unique limit to the deskilling and automation of the labour required to regulate the growth and development of life as raw material, and it lies in the raw material itself, in the rhythms of organic developmental processes process, or what Goodman, et al. refer to as the "natural production process' ${ }^{41}$ The unique selftransformative capacities of life pose a 'natural limit' to the division and automation of labour insofar as both must always attend to the specific characteristics, capacities, and requirements of living nature, none of which are a property of the labour (objective or subjective) or the instruments of agricultural production, but of the raw material itself. Agricultural labour processes thus point to the materiality of the division and automation of labour in a way that is obscured by a transformative intentional structure; and they do so precisely because they take living nature as their raw material. 
Insofar, then, as it takes life and its parts as the raw material in the genetic engineering of a transgenic biotechnology, we would expect to find the same kinds of 'natural limits', or 'materiality', revealed in our transgenic labour process. Just as is the case in agriculture, life is, for the genetic engineer, not a passive object of transformation, but a self-transformative material whose found capacities for assembly, growth and development are themselves harnessed as productive forces in the creation of a transgenic biotechnology. And, just as is the case in agriculture, the role of labour is one of synthesizing and regulating these living materials, only now in a way that is conducive to their transgenesis. Thus, while the division and automation of labour are indeed characteristic of the process of genetic engineering, the non-living technologies characteristic of the process, rather than means of transforming life, are means of juxtaposing and regulating the self-transformation of living materials.

Returning to the 'labs' of genetic engineering we can begin to see what is unique here. As we saw earlier, there is little question that there is an increasing reliance on relatively deskilled 'technical' labour and high levels of automation and that, in this sense, there would appear to be continuity with industrial labour processes more generally. However, the specific kind of labour that is being deskilled and automated is in the case of genetic engineering more akin to the eco-regulatory labour of agriculture. As Knoll, et al. (2004) tell us in their study of lab automation, "biotechnology plants critically depend on human interaction with the process" and they provide examples of such "interaction": "material and fluid handling, transportation, operation of equipment, and maintenance" (1825). Amongst the pieces of equipment here we would include microscopes, glassware, pipettes, centrifuges, incubators, etc. and other instruments with 
a long history in biology labs more generally. ${ }^{42}$ While this list is of course not exhaustive, the important point here is neither the labour nor the technology of genetic engineering can be considered transformative; rather, it is the labour and technology of juxtaposition and regulation of living materials, the transformative moment taking place in the living materials themselves.

And so, since the purpose of laboratory automation is in this case to replace the labour specific to the genetic engineering of transgenic organisms, the role of laboratory robots is precisely the juxtaposition and regulation of living materials, rather than any transformation of these materials per se. Robots do not build transgenic organisms; not because of some technical deficiency they might possess, but because transgenic organisms do not need 'building' any more than plants need 'growing and developing'. While the juxtaposition and regulation of living materials may become totally automated, (with sensor equipped robots taking care of "material and fluid handling, transportation, operation of equipment, and maintenance") the transformative process itself is one that is a found capacity of life and in this sense requires no automation.

Thus, there is a unique relation here between raw material on the one hand and labour/technology on the other. Whereas for Braverman, and others focused on a 'transformative' paradigm, the deskilling and automation of labour (and what are often called 'labour process transformations' more generally) occur in relative abstraction from the raw material, we have in the case of genetic engineering the raw material as a crucial determinant of the shape of the labour process as a whole. Life and its parts possess, as part of what they are as such, system requirements that must be met in specific ways if their found transformative capacities can be harnessed to the human purpose. As the 
labour and technology of genetic engineering have as their central purpose the satisfaction of these requirements, life as raw material sets 'limits' to, or better, reveals the 'materiality' of the labour process and its transformation in a unique way.

Yet, this materiality is revealed even more clearly in the employment phase of the transgenic labour process, where life serves not as a raw material, but as an industrial instrument of production. Just as in the case of agriculture, the transformative moment during the employment phase lies in the organism itself as it consumes its system requirements and synthesizes proteins as part of its life-process. And, just as is the case with agricultural labour, the role of living labour in the employment phase is to juxtapose and regulate the life-process of organisms whose specific system requirements for food, heat, and light, play a crucial role in determining the role of labour, its deskilling, and automation. However, there is an important difference here, as it is life as technology, rather than raw material, that is juxtaposed and regulated by labour; it is thus transgenic biotechnology, an industrial instrument of production, that determines the role of both living labour and the non-living technologies and 'limits' processes of deskilling and automation. We can make this point clearer by revisiting the sites of automation and deskilling identified in our first section: the fermentation tank, the greenhouse, and the barn.

Alford's description of the automation of Lilly's fermentation tanks makes clear the regulatory role of the living labour and non-living instruments of production, as well as the unique characteristics of automation in a labour process centered around microbial life. The role of living labour in fermentation processes has always been one of 
juxtaposing and regulating a transformative process that occurs as part of the life-process of microbial life. As Alford puts it:

In the early $1970 \mathrm{~s} . . .[\mathrm{m}]$ aking antibiotics wasn't much more sophisticated than making wine. Ingredients were put into a tank which was then manually sterilized, manually inoculated with living cells, and then agitated and aerated for several days. Data recording consisted of operators walking through the production floor, periodically recording values from gauges onto a clipboard sheet and hand entering a few values onto the paper manufacturing ticket. $(2004,1)$

The fermentation tank, rather than an instrument of transformation, is an environment constructed to provide the system requirements of microbial life, to 'agitate and aerate' the microbial population, and monitor the life-process of the microbes as they synthesize a desired protein. The specific design of the tank itself as well as the role of living labor is here determined primarily by the system requirements of the microbial population. The robots and expert systems that have come to displace this labour are best understood in terms of the automation of the labour of juxtaposition and regulation, instruments whose specific design reflects the found transformative capacities and requirements of microbial life - life which, at least in the case of Lilly, is now a transgenic biotechnology, an industrial technology that specifies the shape of automation, while itself remaining outside of this process of automation.

The development of greenhouse technology similarly points to the unique relation of labour and non-living technologies to biotechnology. As we have seen, agricultural labour has always been a labour of juxtaposition and regulation that attends to the systems requirements of plant life in order that it transform itself in a way that satisfies human needs. While the physical labour of planting and harvesting has become highly mechanized throughout the $20^{\text {th }}$ century, ${ }^{43}$ the monitoring and regulation of crops has 
relied on human beings due to the complexity of the relationship between plants and their environment and, in particular, the unpredictability of changes in the latter. While aerial and satellite monitoring has gone some distance toward addressing these challenges in open-air crops, a greenhouse, like a fermentation tank, constitutes a much more controlled environment for plant life and therefore facilitates a more sophisticated monitoring of crops and regulation of their system requirements. Developments in sensor technology and artificial intelligence in this case constitute an automation of 'eco-regulatory' labour as a whole, where the purpose of non-living technology is to attend to the system requirements of the plant whose life-process constitutes the pivotal transformative moment of the labour process.

The barn, too, as a site of deskilling and automation, reflects the unique role of labour and non-living technology in a labour process whose transformative moment lies in living means of production. As Benton emphasizes elsewhere (1993), the living labour of animal husbandry is regulatory insofar as it does not transform animals as much as it regulates animal life as it grows and develops in a way the satisfies human needs. The barn, then, just like the fermentation tank and greenhouse, constitutes a relatively controlled environment conducive to greater sophistication in the monitoring of the lifeprocess of animals, the provision of their system requirements and, in the case of egg and milk production, the extraction of the product. Automated milking systems are an excellent example of the unique meaning of automation in a labour process centered around life. Not only do robots extract the product without the use of 'human hands' but also, through the use of sensors, monitor the health of the animals, thereby replacing the 'eyes' and 'ears' of the farmer. Yet, even in the case of a totally automated milk 
production facility, the robots are not concerned with transformation of a raw material, but with the monitoring and regulation of a transformative moment that occurs in the life process of the mammal, a life-process that determines the design and movement of the robot, but remains outside of the process of automation per se.

Thus, while the transgenic labour process is surely subject to the processes of deskilling and automation that is characteristic of industry more generally, these processes have a unique significance in a labour process centered around life. In the case of a labour process centered around handicraft, the transformative moment lies in the subjectivity of labour as it works-up a relatively passive raw material with the use of hand tools. Industrialization is in this case characterized by a shift of the locus of the transformative act to the machine and a consequent deskilling of the living labour whose movement is now determined by the operation of the machine.

However, in a labour process centered around the life-process of the organism labour is, from the beginning, 'displaced' from the transformative moment, its role being primarily to juxtapose and regulate self-transformative means of production. The labour of biochemical engineering, agriculture, and animal husbandry is thus always-already determined by a transformative moment that lies outside of itself, its movement subordinate to that of the specific organism in question. And, as automation in this case can only ever be an automation of the labour of juxtaposition and regulation of life, the machinery characteristic of a labour process centered around life is itself determined by the life-process and system requirements of the organism, its movement subordinate to the principle of movement characteristic of life itself. The fermentation tank, greenhouse, 
and barn, and all of the robots, sensors, and expert systems attached, can only ever be more sophisticated means of regulating the relatively found life-process of the organism.

Now, we must distinguish our transgenic labour process from these more general considerations. On the one hand, the transgenic labour process constitutes a convergence of labour processes centered around microbial, plant, and animal life, and so the automation of transgenic labour might simply be considered a special case of the automation centered around the fermentation tank, greenhouse, and barn more generally. On the other hand, there is crucial difference here: in the case of transgenic production the organism is a transgenic biotechnology composed of materials of nature worked-up through the process of genetic engineering so as to harness the synthetic capacities of life as an industrial productive force. As we have seen, the 'industrialization of agriculture' is characterized by the movement of the machine from industry to the field, only to encounter the 'natural production process' as a limit to industrial productive forces. In the case of transgenic production, however, the 'natural production process' is the primary force of industrial production, the deskilling and automation of labour being determined now by a living technology that is always-already fully 'automated'. Thus, rather than the 'industrialization of agriculture', we might here suggest that a transgenic labour process constitutes an 'agriculturalization of industry' insofar as the same 'natural limits' Benton sees in an eco-regulatory paradigm become characteristic of an industrial labour process. Yet, in suggesting this semantic twist, we are forced to confront two paradoxes that have become increasingly apparent throughout the analysis to this point. First, it would seem that we have drawn a distinction between industry and agriculture only to dissolve it again. In chapter 4 we began by drawing a fairly rigid distinction between the 
two in order to distinguish a transgenic labour process, as an industrial labour process, from previous uses of life as means of production. In chapter 5 our distinction began to destabilize as we revealed the degree to which living technologies, despite an overarching continuity with non-living instruments of production, mark a disjuncture in the degree to which the instruments of production approximate a force of nature. And now we have suggested that, while characterized by certain 'transformative' elements, the living labour of the transgenic labour process - its role, division, and automation - looks much more like non-industrial labour, and the eco-regulatory labour of agriculture in particular.

The second paradox concerns our interpretation of Marx. We saw in chapter 1 that, for Marx, industry marked a crucial ontological disjuncture in the meaning of nature insofar as, in harnessing the forces of nature as forces of production, machine systems come themselves to approximate a force of nature and the role of living labour comes increasingly to be a regulatory one. Yet, our employment of Benton's typology to draw out the unique characteristics of transgenic labour would seem to have bracketed this interpretation. We have to this point assumed that Benton's typology of 'transformative', 'eco-regulatory', and 'extractive' labour processes corresponds to 'industry', 'agriculture', and 'primary appropriation' respectively. We used this characterization of industry as 'transformative' labour to draw out the unique 'eco-regulatory' aspects of a transgenic labour process. But there is problem here: Marx's conceptualization of industry as the regulation of forces of nature qua forces of production does not appear consistent with a 'transformative' paradigm in the first place insofar as industrial labour is distinct from handicraft precisely in its regulation of self-acting machinery. We will devote ourselves to solving these paradoxes in chapter 7. 


\section{7 - The Labour Process as a Living Force of Nature}

We can begin resolving these paradoxes, strangely enough, by bringing to light another that was raised in chapter 1 only to be left lurking beneath the surface of our analysis to this point. As we saw in chapter 1 , and as we have emphasized throughout, the disjuncture in the meaning of nature Marx attributes to machinery rests primarily on a contrast of large-scale industry with pre-industrial handicraft rather than agriculture; indeed, Marx is explicit in regarding agriculture as outside of his historical analysis of the industrialization process proper and as a labour process sui generis insofar as it 'merely regulates biological processes' as opposed to the kind of 'harnessing' of nature that is central to industry. Now, there is nothing all that unusual about the distinction between agriculture and handicraft/industry that Marx is drawing here and it is one that is commonly accepted by both labour process analysts, who have tended to focus on the latter, and rural sociologists, who have focused on what is unique about the former.

However, there is a paradox here that none have recognized: while regarding the 'regulation of biological processes' in agriculture as a limited form of the labour process, Marx describes industrial forces of production in precisely these same terms, only now to convey the degree to which industrial labour processes harness the forces of nature like never before. Machinery is variously described as "living", a "mighty organism", as possessing a "soul" and "limbs", and as "consuming coal just as the worker consumes fuel". And, as we have emphasized, industrial labour is distinguished from the labour of manufacture precisely in terms of the degree to which it regulates these "mechanical monsters". How can we make sense of this? Why would Marx, in order to make the ontological disjuncture engendered by machinery clear, use the language of 'life' and 
'regulation', the same language he uses to highlight the limitations of agricultural labour processes?

Taking this puzzle as an entry point, this chapter makes clear the disjuncture marked by the transgenic labour process in the meaning of nature. It proceeds through a critical engagement with three interpretations of Marx dominant in environmental sociology and assess their ability to solve our puzzle. Highlighting the limitations of each in this regard will point us in the direction of an alternative interpretation of Marx; one that will both solve our puzzle and, in doing so, make the significance of transgenic production clear. I argue that Marx's use of the language of biological process and regulation to describe machinery and industrial labour, rather than merely rhetorical, reflects his conception of industrial forces of production as approximating the selfmovement of nature, a movement that is most clearly exemplified in living organisms. In light of this interpretation, the significance of transgenic production is clear: insofar as it constitutes the harnessing of life-itself as an industrial productive force, and labour plays the role of regulating the life-process of these living technologies, we have before us an unprecedented sense in which industrial labour processes constitute a force of nature infused with human purpose.

\section{Promethean Marxism and the Transformation of Nature}

The traditional skepticism amongst Marxists toward claims that there are 'natural limits' to human productive activity has been given its most sophisticated theoretical articulation in the work of Reiner Grundmann (1991a, 1991b). For Grundmann, attempts by 'ecologists' and 'eco-Marxists' to identify such limits in nature itself assumes that 
'nature' can be viewed as something other than an object of human control. He points to the fact that 'environmental problems' can only be conceived in relation to human wellbeing and that our identification of a 'problem' in the first place always implies constructing some part of the 'environment' (generally higher organisms) rather than another (e.g. microbes) as worth saving. In a semantic twist, Grundmann suggests that the current environmental degradation that is often attributed to human hubris and attempts at technological control of nature are in fact evidence of a lack of control and, if anything, point to the need for greater control. While the notion of 'control' for Grundmann is more than a mere technological issue, the 'social relations' of capitalism being a crucial 'barrier' to its realization, what is important here is that technological change is conceived in terms of a 'Promethean' mastery of nature that pushes back the 'natural limits' to human productive activity. The result may of course be environmental problems, but such problems can never be attributed to attempts to 'control' nature per $s e$, but only to the limitation to such control posed by specific sets of social relations, and those under capitalism in particular.

Now, employing Benton's typology of 'intentional structures' we can see that Grundmann appears to take as paradigmatic a 'transformative' form of the labour process. Technology is conceived as an instrument of control with which humanity, as subject, transforms an ontologically distinct 'natural' object to satisfy its needs. Indeed, Grundmann is explicit in subsuming of human productive activity under a transformative paradigm, as his dispute with Benton in the pages of the New Left Review reveals. Benton, he writes, seems to overlook the fact that for Marx human interventions into [agricultural] processes also count as transformative actions, since 
prepared ground is quite different from untouched nature. I therefore simply cannot see the significant difference between transformative and 'eco-regulatory' labour processes. (1991b, 3)

Thus, living nature is for Grundmann merely another form of natural object transformed with increasingly sophisticated instruments of production.

Most importantly for our purposes, Grundmann uses the example of genetic engineering as evidence of the transcendence of previous 'natural limits' to an transformative labour process. "It is ironic," he suggests,

that Benton stresses the rigid character of 'contextual conditions' and 'natural limits' in a world where actual industrial societies explore the possibilities of pushing these barriers further and further back - the substitution of raw materials, development of new synthetic materials, genetic engineering and information technologies being the main examples. (1991b: 3)

This view contrasts with that of Benton, whose critique of genetic engineering is premised precisely on its inevitable failure to overcome the natural limits to agricultural labour processes. For Grundmann, 'biological processes' pose no unique limit, but are merely the most recent frontier to be explored and 'controlled' by capitalist industry.

While Grundmann nowhere explores Marx's use of biological metaphors in his descriptions of machines and the kind of labour they imply, we might suggest, in light of his 'Promethean' interpretation of Marx, that they are merely a rhetorical device used to highlight the profundity of the technical accomplishments of capitalist industry. Would not such poetic allusions be consistent with Marx's style more generally, the power of which lies as much in its ability to inspire outrage and activism as in its analytical clarity? After all, as we have seen, machines are not literally alive; for all their self-movement they must be built out of inert materials, set in motion, and fixed when they break down. 
And even if we suggest that the 'dark areas' of computer integrated manufacturing are characterized by self-acting instruments that are merely 'regulated' by labour, such a description would surely have been mere poetry in the mid $19^{\text {th }}$ century when industrial capitalism was still dominated by glorified 'workshops'. Thus, we might conclude that industrial capitalism indeed marks a qualitative leap forward in the 'mastery of nature' and that the biological metaphors in Marx should be taken merely as rhetorical devices to make this clear.

And there is a great deal of textual evidence to support Grundmann's 'Promethean' interpretation of Marx. The pages of the Communist Manifesto contain Marx's most explicit, and oft quoted, praise of the technological dynamism of industrial capitalism, but the notion that industrial technology has facilitated an epochal subordination of nature to human needs runs through Marx's work, both 'early' and 'late'. And in the Grundrisse Marx explicitly contrasts the control of nature in industry with the 'mere regulation' of biological processes in agriculture and ridicules the "rural idiocy" and "nature idolatry" bred of an agricultural mode of production (1973, 409-411). It is clear that Marx did indeed regard industrialization as marking a greater 'mastery' of nature and that he expressly viewed this as a kind of advance over the subservience to nature characteristic of agriculture. Thus, insofar as genetic engineering is viewed as subordinating agriculture to industry, it can indeed be regarded as transcending the 'limits' to the human mastery of nature.

Yet, Grundmann's 'Promethean' interpretation is ultimately unsatisfactory in its ability to account for Marx's use of biological metaphors in his description of industry. Why, if industrial technology indeed marks such a qualitative disjuncture by virtue of its 
transcendence of the limits to human productive activity in agriculture, would Marx need to punctuate his point by describing machines as 'organisms' and industrial labour as a labour of 'regulation'? Grundmann's interpretation of Marx might be able to account for his use of metaphors as rhetorical devices, but seems incompatible with his use of specifically biological metaphors insofar as the 'regulation of life' is precisely the limited form of productive activity that industrial technology has supposedly transcended.

The primary difficulty with Grundmann's notion of 'mastery' and the transformative 'intentional structure' he takes as paradigmatic is that it simply ignores the ontological shift in the relation of human and non-human components of the labour process engendered by machinery and large-scale industry. Grundmann's use of a violinist as an analogy for the 'mastery' implied by technological change is telling in this regard. While a skilled craftsperson may be analogous to a violin player in their mastery of nature, it is difficult to see how it can capture what is unique about large-scale industry. As we have seen industrial labour processes are characterized by instruments that are largely self-acting and merely regulated by labour. This is hardly analogous to a musician playing an instrument. Of course Grundmann might be referring more abstractly here to 'humanity's' mastery, rather than that of living labour per se; but this risks losing sight of the material engagement of humans and non-humans that is the site at which nature is constituted as such. Our focus on this labour process has allowed us to identify a crucial shift in the meaning of nature that is obscured by notions of 'mastery'. A critique of such Prometheanism is central to what has come to be called 'green Marxism' and it is to this perspective that we now turn. 


\section{Green Marxism and the Violation of Nature}

Sensitive to the anti-ecological tendencies in traditional interpretations of Marx, a number of environmental sociologists have attempted to 'green' Marx; that is, they view Marx as himself an ecological thinker. ${ }^{44}$ John Bellamy Foster's (2000) interpretation of Marx has been influential in this regard and is particularly important for our purposes as it rests upon a very different view of the relation of agriculture to industry and the significance of industrialization for the human-nature relation. Foster focuses on Marx's conception of the human-nature relation as a 'metabolism' and, in particular, his rather scattered suggestions that the 'industrialization' of agriculture is creating a 'rift' in this metabolism. Thus, rather than viewing industrial technology as transcending the limited human-nature relation in an agricultural mode of production and 'mastering' nature, Foster regards this technology as a kind of 'violation' of the human-nature relation in agriculture and a threat to the well-being of both non-human and human nature. The argument here is thus consistent with much of the ecological tradition in taking relatively small scale agricultural practices as constituting a more 'balanced' relation with nature and regarding large-scale industry as a threat to this balance.

While the details of Foster's argument are beyond our scope, it is important to note the degree to which he is taking as his model of a 'balanced' human-nature relation something that looks very much like the 'eco-regulatory' labour process identified by Benton. As we have seen, Grundmann conceptualizes the human-nature relation in terms of mastery and views industrial technology as, at least potentially, furthering the struggle of the human subject for greater control over the natural object, control that was relatively limited in an agricultural mode of production. For Foster, on the other hand, it 
is agriculture that better reveals the essence of the human-nature relation since it is here that "man", as Marx puts it, "mediates, regulates, and controls the metabolism between himself and nature" $(1976,283)$. Insofar as agricultural productivity has required a reproduction of the conditions of production (e.g. crop rotation to ensure the quality of the soil) agricultural labour has historically been more attentive to the 'natural limits' posed by 'nature' to 'labour'. And, it is the degree to which industrialization proceeds without heeding these limits that it threatens to effect a rift in the metabolic balance of human and non-human nature.

While Foster, and eco-Marxists more generally, have paid scant attention to the significance of specific technological developments and their significance for the meaning of nature, the implication of this conceptual framework for understanding 'genetic engineering' is relatively clear. For Grundmann, genetic engineering is regarded as an industrial technology that pushes back the natural limits in agriculture. For Foster, on the other hand, this technology would be regarded as, at least potentially, exacerbating the rift in the human-nature metabolism insofar as it is premised on industrial control rather than attending to the 'natural limits' of the agricultural labour process. And again, the argument here is relatively consistent with ecological perspectives on genetic engineering more generally which tend to condemn it for just these reasons.

Now, it is difficult to imagine what Foster would make of Marx's use of biological metaphors in his descriptions of large-scale industrial labour processes, but we might view them again as a rhetorical device, only now expressing, not admiration, but outrage at an industrial perversion of nature. After all, Marx's descriptions of machines as "animated monsters" and "cyclops" convey anything but the kind of balance that 
Foster wants to find in pre-industrial agriculture. And the regulatory role of labour is a reduction of the worker to a "mere appendage" of the living machine. We might thus regard Marx as a romantic thinker who regarded machines as transgressions of nature that come back to haunt their human creators. Transgenic biotechnologies could be regarded as the ultimate transgression in this sense, a "gruesome parade of horribles" that confront us as living proof of the metabolic rift borne of our hubris. ${ }^{45}$

Interestingly, Foster universalizes something that looks very much like the "ecoregulatory' structure distinguished by Benton. And, like Benton, Foster views agricultural labour process as exemplars of 'eco-regulation' because they are centered on biological processes. Unlike Benton, however, Foster does not distinguish between types of labour processes and the distinct kinds of human-nature relations in each. Rather, eco-regulatory labour processes are conceived as the human-nature relation and industry in terms of a violation of this metabolism.

The limitations of this interpretation of Marx should be clear. The notion that industry constitutes a violation of, or a rift in, nature, is simply inconsistent with so much that Marx wrote about the role of nature in industry. As we have seen, large-scale industry is unique in the degree to which nature is itself harnessed as a force of production and the labour process itself comes to approximate a force of nature. If anything, we might argue that industrial labour processes are more natural in this sense. At the very least, we would suggest that large-scale industry marks a disjuncture in the meaning of nature as the labour process comes to constitute a force of nature infused with human purpose. The notion of 'metabolic rift', while perhaps politically efficacious, is simply inadequate to grasping such disjuncture. With these limitations of the Promethean 
and Green interpretations of Marx in mind, we can now return to Benton and see both the importance of his ecological reconstruction of the labour process, as well as its limitations, limitations that will point us toward a more radical solution to our riddle regarding Marx's use of biological metaphors and language of 'regulation' to describe large-scale industrial labour processes.

\section{Benton and Eco-Regulation}

The value of Benton's work, as we have seen, lies in his typologies of the labour process and, for our purposes in particular, the centrality of biological processes to his notion of eco-regulation. Benton is critical of Marx's universalization of an 'instrumentaltransformative' form of the labour process, which fails to adequately account for the 'natural limits' to human labour, which, as we have noted, is best regarded in terms of the materiality of the labour process. He advances two additional 'intentional structures' of the labour process, 'eco-regulatory' and 'extractive', which are intended to highlight the unique relation of labour to 'life' on the one hand, and relatively found objects of labour on the other. Benton's typology highlights the 'materiality' of labour in a way that has been obscured by 'labour process studies', most of which take an 'instrumentaltransformative' form of the labour process as paradigmatic. But what about Benton's ability to account for Marx's use of biological metaphors in his descriptions of machinery and his description of large-scale industrial labour as 'regulation'?

As we have seen, biotechnology does not fit comfortably within Benton's analysis precisely because it destabilizes the kind of distinction that Benton wants to make between industry and agriculture. On the one hand, biotechnology is a living means of 
production and our analysis of transgenic production has revealed the degree to which the labour of working-up and employing transgenic life has much in common with the 'ecoregulatory' labour identified by Benton. On the other hand, transgenic production, rather than treating life as a relatively found 'object of labour', is unique in its repositioning of life as an industrial instrument of production through practices of genetic engineering, which, as we have seen, have at least something in common with the 'instrumentaltransformative' labour that Benton tends to equate with industrial production. Seemingly aware of the difficulties posed by living technology to the distinction between 'ecoregulatory' and 'instrumental-transformative' labour process, Benton tends to merely downplay their significance and, as a result, fails to take seriously the disjuncture marked by the employment of biological processes as a force of industrial production.

Now, it is important to mention at this point that Benton's assumption that Marx, explicitly or otherwise, subsumed agriculture under a transformative paradigm is problematic. In fact, Marx is explicit in acknowledging the unique characteristics of agriculture and goes so far as to consider it sui generis for precisely the same kinds of reasons that Benton does. "Agriculture," writes Marx, "forms a mode of production sui generis, because the organic process is involved, in addition to the mechanical and chemical process, and the natural reproduction process is merely controlled and guided" $(1973,726)$. This is not to suggest that there is not a tension in Marx's analysis of the labour process; Benton is on firm ground when he suggests that Marx tended, particularly in his more concrete analyses of the labour process, to ignore certain of the unique characteristics of non-industrial labour processes. It does suggest, however, that he did not so easily view agriculture in this way. 
In light of this, we might respond to Benton by suggesting that Marx understood the differences between 'instrumental-transformative' and other forms of labour, but excluded the latter from his analysis because of his interest in uncovering the laws of motion of industrial capitalism. We might further suggest that Marx's focus on 'instrumental-transformative' labour reflected his understanding of these laws of motion and that, indeed, the development of capitalism itself has vindicated his 'universalization' of instrumental-transformative labour on two counts. First, we might suggest that agriculture and extractive labour processes become increasingly subsumed under an 'instrumental-transformative' paradigm with the development of capitalism. This would appear to be central to Grundmann's critique of Benton and to the 'industrialization of agriculture' thesis more generally. Second, even if we were to maintain a distinction between industrial and non-industrial labour processes, we might suggest that with the development of capitalism the latter would comprise an ever smaller portion of human productive activity and become increasingly tangential to understanding the movement of capital. Thus, if Benton's argument were limited to merely distinguishing between these 'intentional structures', we might suggest that his 'ecological reconstruction' of the labour process is not so radical after all as 'instrumental-transformative' labour, while perhaps not 'universal' in the abstract, has certainly become dominant.

In fact, however, Benton's argument points in a more radical direction than this. He suggests that a 'transformative' model of the labour process is limited, not only when applied to agricultural and extractive labour processes, but even with regard to industrial labour processes themselves. A 'transformative' model is for Benton, as it turns out, most applicable to pre-industrial handicraft. Here is where the 'subject-instrument-object' 
relation is clearest and the tendency to regard 'nature' as a relatively passive object of transformation most likely. The model requires some modification, however, in the case of an industrial labour process where, Benton suggests, the "intentionality which assigns each element to its place in the structure is not that of the individual agents in the process"(1989, 9). Interestingly, then, Benton appears to admit certain characteristics of eco-regulatory labour into an industrial labour process that he otherwise regards as transformative. Workers take on the role of 'regulating' instruments of production whose movement is reflective of an 'intentionality' that lies elsewhere. Now, Benton is of course not regarding this as akin to the regulation of biological organisms in agriculture, but it is regulation nonetheless and indicates an important disjuncture with pre-industrial labour.

In the end, however, this modification of the 'subject' notwithstanding, Benton allows the 'transformative' model to stand as a description of industrial labour processes. Here the subject, albeit one that is relatively distinct from 'living labour', employs instruments of production in the transformation of the object of labour. And, insofar as the 'object' is regarded as the form 'nature' takes in the labour process, nature can be regarded as a relatively passive object of transformation. In this sense Benton appears to be willing to grant Grundmann's 'Promethean' description of industrial labour processes and the conception of nature as an object of control and mastery; it is really only in nonindustrial labour processes that this conception of nature proves inadequate insofar as agriculture and extractive industries reveal the 'natural limits' to labour. Thus, while Benton's argument points in the direction of a radical reconstruction of the labour process, central to which would be a rethinking of the role of nature in industrial labour 
processes themselves, he stops short of such a reconstruction. While recognizing certain 'eco-regulatory' aspects of industrial labour, he nevertheless accepts a broadly instrumental-transformative paradigm as capturing the human-nature relation as one between subject and object mediated by an instrument of production.

Nevertheless, Benton's argument here sheds light on Marx's use of biological metaphors to describe industrial labour processes in a way that neither the Promethean or ecological models can. The natural limits to, or materiality of, the labour process is revealed clearly in agriculture where nature, rather than a passive object of transformation, is better conceived as a set of biological processes of growth and development that are regulated by labour. This materiality becomes less clear in instrumental-transformative labour processes where the relatively passive object is transformed by the subject using a hand-tool; here we have the subject-instrument-object model that, as we have seen, is most appropriate to pre-industrial handicraft. In the case of large-scale industry, however, the means of production again possess capacities for self-movement akin to the biological processes of agriculture and living labour is again better characterized as a regulation of this self-movement. Nevertheless, machinery only ever approximates the self-movement of living nature in a relatively crude way and, as we have seen, machinery requires much more than mere regulation. Thus, while the materiality of the labour process is revealed more clearly in industry than in handicraft, it is nevertheless still in agriculture that it is most clear. Marx's employment of biological metaphors and language of regulation in his descriptions of industrial labour processes thus remain metaphorical while the materiality of the labour process remains literally most clear in the eco-regulation of agriculture. 
Yet, there is still a difficulty here and it revolves around Marx's dual use of the term regulation. For Benton, regulatory labour is most characteristic of agriculture and, indeed, he does not use the term to describe the labour of industry at all, despite his acknowledgment that it possesses certain characteristics in common. However, not only does Marx use the term regulation to apply to industrial labour, but he explicitly contrasts the regulation of machine systems with the mere regulation of biological processes. Thus, there remains a paradox here that Benton's model, despite its value, cannot address. While the means of agricultural production are actually biological, the labour process is regarded as limited to mere regulation; on the other hand, while means of industrial production are only metaphorically biological, the labour process is regarded as regulatory in a way that transcends the limitations of agriculture. Perhaps there is more to these biological metaphors.

\section{The Role of Biological Metaphors in Marx's Analysis of the Labour Process} We can begin by returning to the relation of the labour process to nature and the disjuncture marked by large-scale industry in this regard. As we have seen, all labour processes require means of production that are 'natural' in the sense that they are composed of materials that possess self-movement. Large-scale industrial labour processes are unique, however, in the degree to which they harness the forces of nature as forces of production and the instruments possess self-movement in themselves and therefore come increasingly to approximate a force of nature. This stands in contrast to pre-industrial labour processes centered on handicraft in which the instruments of production are distinct from nature per se insofar as their movement, as means of 
production, is provided by human hands. And it is in this sense that we have argued that machinery reveals the labour process as a force of nature infused with human purpose in which living labour increasingly serves a regulatory role.

Now, when Aristotle, and Marx, suggests that nature is 'self-movement', there is little question that they have living nature in mind. While all of nature is 'in-motion' in a rather abstract way, it is organisms that provide the clearest expression of what is unique to nature as such. Capacities for mobility, consumption, and reproduction are in fact central to what distinguish living from non-living materials of nature and it is just these capacities that reveal most clearly the contrast between 'nature' and 'artifice'.

Environmental organizations demonstrate an awareness of this contrast in their use of living things as, what Steven Yearley (2002) calls, "surrogates for nature". Insofar as environmentalists seek to protect nature from artifice, and technology in particular, they need to invoke a relatively rigid distinction between the two. While it is often difficult to portray inorganic materials as victims of artifice, living things, particularly those visibly affected by 'technology' (e.g. oil-soaked wildlife), are useful in mobilizing public sentiment around 'saving nature'. And it is precisely their capacities for selfmovement that make them valuable in this regard. More generally, Newton's clockwork universe, and its malleability as an object of human mastery, was premised upon an exclusion of life, which explains why some notion of a 'living' universe (e.g. the Gaia hypothesis) has proven so important for environmentalists. Indeed, 'ecology' is itself defined as the science of the relation of organisms to their environment. Thus, the technology/ nature distinction is one that is often premised upon what is unique to living nature in particular. 
And such a distinction has remained relatively stable in light of the historical exclusion of living nature from industrial production; and Marx's thinking here is clearly a product of its time. In his discussions of the 'subjugation of the forces of nature' Marx clearly has in mind the chemical and physical forces of nature and the capacity of machinery to harness these forces as forces of production. At most, he may have been aware of early developments in brewing. However, as microbes are only 'living' in a largely technical sense - after all, they are never used as surrogates - we can imagine that he would have likely subsumed these within the 'chemical industries', his discussion of which is nevertheless valuable for its troubling of the relation between components of the labour process. But living nature itself, its unique capacities for movement, consumption, and reproduction, has tended to remain 'other than' industrial technology and insofar as 'nature' is equated with 'life', the technology/nature dualism so central to 'modern' thought has reflected this exclusion.

Marx's use of biological metaphors in his discussion of industry reflects this central paradox underlying his argument regarding the development of machinery and large-scale industrial labour processes. We have seen that central to this argument is the notion that these labour processes come to approximate a force of nature and that this marks a radical disjuncture with pre-industrial labour processes centered on handicraft. Yet, the particular force of nature that best exemplifies the kind of 'self-motion' that Marx attributes to industrial forces of production is precisely that which is excluded from the labour process. It is thus no mere rhetorical flourish when he describes machinery in biological terms, nor when he refers to labour as the regulation of these 'organisms', for the disjuncture marked by industrial forces of production lies precisely in their 
approximation of living nature. Yet, 'living nature' itself is that force of nature that remains other than the forces of production and so the notion of a labour process that moves as a force of living nature infused with human purpose must remain, for Marx, largely metaphorical.

But as it stands, our argument here is still inadequate. Let us assume with Marx that the significance of large-scale industry for the question of nature lies in its revealing the labour process as itself a force of nature. Let us further assume that this disjuncture is a function of machinery and its approximation of a force of living nature that is regulated by human labour, and that this is distinct from pre-industrial labour processes centered around handicraft which, while employing means of production composed of 'natural materials', are not forces of nature per se insofar as they lack their own principle of movement.

The problem is this: why does Marx attribute such significance to 'industry' in this regard, where self-movement and regulation are largely metaphorical, when human beings have for millennia engaged in agricultural production, a form of the labour process that literally employs organisms as means of production that are literally regulated by human labour? After all, isn't it precisely Benton's point (not to mention Foster's and other eco-Marxists') that these unique characteristics of agriculture reveal the degree to which the labour process regulates a certain 'metabolism' of human beings and nature? Yet, Marx clearly regards agriculture as necessarily limited in this regard, referring to it as 'nature idolatry' and 'mere regulation of biological processes'. Why, in short, does industry pave the way for a 'resolution of the conflict between man and nature' in a way that agriculture does not? 
The answer to this puzzle lies in an important contrast between agriculture and industry that is crucial if we are to understand the significance of biotechnology for the question of nature. We can agree with Benton and others that agriculture is characterized by the regulation of biological processes. Yet, as we have seen in our discussion of agriculture early on, these biological processes are relatively 'found' and are regulated as objects of labour, albeit ones with relatively unique capacities for self-motion. This accounts for Marx's attitude toward agriculture as a dependency on nature and agricultural labour as mere regulation of biological processes. On the other hand, machines, while not literally 'living' and thus only a crude approximation of a force of nature, are "products of human industry; natural material transformed into organs of the human will over nature, or of human participation in nature. They are organs of the human brain, created by the human hand; the power of knowledge, objectified"(1973, 706). That is, the means of production are themselves materials of nature infused with human purpose, products of human labour. Thus, rather than 'mere' regulation of a found force of nature, industrial labour processes constitute a regulation of a force of nature that is itself infused with human purpose. And it is in this sense that industry constitutes an epochal 'humanization' of nature, a unity of nature for human beings, and a 'naturalization' of human beings who reveal to themselves their essence as self-conscious nature.

Now, this distinction between agriculture and industry is more than just a matter of ontology; rather, it explains the importance of industrialization to the development of capitalism and the relative obduracy of agriculture in the face of this development. Capitalism is premised upon the development of the means of production as capital, as 
dead labour under private ownership, alienated from the living labour that is its origin. Machinery is a means of production particularly compatible with capitalism insofar as it harnesses physical and chemical forces of nature, thus repositioning labour as an objective component in a labour process whose starting point for transformation becomes the instruments themselves. The development of capitalism is thus premised upon a humanization of nature insofar as the forces of nature are harnessed as forces of production and the labour process itself comes to approximate a force of nature infused with human purpose.

Yet, as the work of Goodman, Sorj, and Wilkinson makes clear, agriculture has proven relatively obdurate in the face of this 'humanization' as the found biological processes of living nature, the central force of agricultural production, cannot be 'mechanized' in the same way that handicraft can be. This obduracy has led to the irony in Marx's work that the revolutionary force of capitalist industry in infusing nature's movement with human purpose has tended to exclude the one force that best exemplifies the kind of self-movement that Marx is suggesting. Thus, industrial labour processes, despite their increasing approximation of a force of nature, have always been relatively crude in this regard and the technology/ nature distinction has retained relative stability amongst Marxists and non-Marxists alike.

Thus, there is indeed a tension in Marx, but its source lies elsewhere than in the tendency to universalize an 'instrumental-transformative' paradigm supposed by Benton. While living nature exemplifies the kind of movement Marx wants to attribute to industrial labour processes, life itself is relegated to non-industrial (i.e. non- or semicapitalist) production. Marx must invoke images of life in his descriptions of industrial 
instruments of production to make their ontological significance clear, but these images must always be metaphorical as long as the technologies themselves are non-living. Hence agricultural labour processes merely regulate biological processes that are not themselves infused with human purpose, while industrial labour processes regulate forces of production that are themselves products of labour but move only as if they were alive. The tension in Marx's work is thus reflective of an historical tendency for the development of industrial technology to proceed in the absence of the very living forces of nature that it comes to resemble. This is a tension, however, that is currently being resolved with the advent of transgenic biotechnology.

\section{Transgenic Biotechnology and the Forces of Nature}

We have now only to flesh out the conclusion of the analysis here to see the crucial disjuncture marked by transgenic biotechnology in the meaning of nature. Machinery harnesses the forces of nature as forces of production in a way that marks a qualitative disjuncture in the meaning of nature. In doing so, these instruments of production approximate a force of living nature, but do so in a relatively crude way insofar as their self-movement is always a kind of mechanical/ chemical mimicry of that which is a unique capacity of life itself. Industrial labour, while increasingly concerned with the kind of regulatory role reminiscent of agriculture, must always be more than this owing to the imperfections of non-living technologies compared to the "natural production process'. Nevertheless, insofar as machinery, rather than relatively found materials of nature, is itself a product of human labour, industrial labour processes constitute a force 
of nature infused with human purpose, a humanization of nature, in a way that the 'mere regulation of biological processes' do not.

The disjuncture in the meaning of nature marked by a transgenic labour process thus lies precisely in the degree to which it harnesses living nature as an industrial force of production. Where industry has heretofore worked-up inert raw materials into machinery whose unique productive capacity lies in their harnessing physical and chemical forces of non-human nature, the transgenic labour process takes life as both its raw material and instrument. This is distinct from past uses of life in production which have merely exploited the found capacities of life and taken organisms primarily as the raw material of food and fiber production. A transgenic biotechnology is composed of natural materials worked-up at the molecular level through practices of genetic engineering so as to harness the synthetic capacities of the organism to the production of proteins that it would not otherwise produce. Transgenic biotechnologies are thus "products of human industry; natural material transformed into organs of the human will over nature, or of human participation in nature" $(1973,706)$. And, insofar as life is exemplary of the self-movement of nature per se, we have an unprecedented sense in which nature itself confronts us as an industrial productive force.

And, in harnessing the principle of motion of life-itself, transgenic biotechnology reveals in a unique and unprecedented way the degree to which industrial technology is itself a force of nature infused with human purpose. Like all technologies, transgenic biotechnologies are natural materials infused with human purpose. And, like all industrial technologies, they possess in themselves a principle of motion, rather than having their movement provided 'externally' by human hand. However, rather than a relatively crude 
mechanical/chemical approximation of the movement of living nature, transgenic biotechnologies of course are this movement; they do not move, consume, and reproduce as if they were alive, but by virtue of the fact that they are alive. Thus, the ontological shift in the meaning of nature that Marx identifies with the coming of the machine is in fact must clearer with the emergence of transgenic biotechnology, an instrument of production that is the very essence of the kind of natural process Marx equates with machinery.

Moreover, the shift in the relation of living labour to the means of production that Marx identifies with industry has never been more clear than in a transgenic labour process. For Marx, machinery's harnessing of the physical and chemical forces of nature means that living labour increasingly comes to regulate instruments that move as a force of nature, a regulatory act that nevertheless differs from that in agriculture insofar as the means of production are themselves infused with human purpose. The human component of the labour process thus becomes subordinate to non-human materials and forces of nature, becomes a 'mere appendage' of the machine, an objective component of a labour process whose starting point for transformation is the machine itself.

And, just is the case in a labour process centered around machinery, the role of living labour of the transgenic labour process is specified by the self-movement of the means of production. The role of both the 'engineer', as we have seen, is best understood as that of juxtaposing and regulating life and its parts. The difference, of course, is that rather than specified by means of production whose self-movement approximates that of living nature, the role of transgenic labour is specified by means of production that are a force of living nature, now a force of production infused with human purpose. Thus, 
Rather than the mere regulation of relatively found biological processes as objects of labour, or the regulation of natural materials infused with human purpose that approximate a force of living nature, transgenic labour regulates the movement of living nature itself, now an industrial technology infused with human purpose.

Now, all this talk of 'human purpose' should of course alert to us to the problems associated with abstracting nature, technological change, and humanity, from the specific form that these take in a particular mode of production. And it might seem odd that to this point there has been so little mention of 'capitalism' in this regard, particularly in an explicitly 'Marxist' analysis. However, it a central premise of the argument here that 'capitalism' is not the answer to the question concerning nature in general, nor to the question concerning the significance of biotechnology for the meaning of nature in particular. Rather, it is the labour process that is Marx's central ontological category and it is here that the analysis must begin. But of course no form of the labour process exists in the abstract and so we must turn now to assess the significance of our ontological disjuncture in the meaning of nature for capitalism. 


\section{8 - Transgenic Biotechnology and the Living Materiality of Capital}

Central to recent work in environmental sociology is the notion that questions of nature are intimately related to questions of capitalism. More often than not, this tends to mean that 'nature' must be explained through an analysis of 'capitalism'. Now, we have clearly taken a rather different approach in the sense that we have focused on the labour process to assess the significance of biotechnology for the question of nature and have tended to leave the concept of 'capitalism' bracketed. This focus on the labour process in relative abstraction has proven valuable in enabling us to see a disjuncture in the meaning of nature that has otherwise been obscured. Having identified this disjuncture, however, we must now assess its significance for capitalism.

This final chapter thus addresses the relation of the transgenic labour process to capitalism; more specifically, it attempts to clarify the significance of life as a force of production for the way we conceptualize the relation of capitalism to nature. First, it identifies a false dichotomy underlying current debates in environmental sociology between capitalism, as a set of social relations, and nature, as that which is 'other than' these relations, or a 'reflection of' these relations. We next move on to critically engage with two influential accounts of biotechnology and its significance for 'nature' that, despite their value, in the end succumb to this false dichotomy. We then move on to discuss the difference that our labour process approach makes for understanding the relation of nature to capitalism and finish by assessing the meaning of transgenic biotechnology for this relation. The argument here is that a labour process centered on transgenic biotechnology enables and constrains the expansion of capital in qualitatively distinct ways. 


\section{The False Dichotomy of Capitalism and Nature}

Cotemporary debates surrounding the significance of new technologies often revolve around a society/technology dualism. On the one hand, there are those who view technological development as a relatively autonomous force that engenders or requires specific social, political and cultural changes. Here we would include both 'technological determinists' proper, as well as the various forms of 'post-Fordism' that view the 'social' as somehow 'adapting' to a new technological paradigm in order that it might drive a new period of economic development. ${ }^{46}$ On the other hand, social constructivists seek to explain technological change with regard to some constellation of social relations, political institutions and cultural forms ${ }^{47}$ And while there are of course many who suggest the 'mutual constitution of' or 'reciprocal relation between' the two, such notions, while dispelling simple 'monocausal' explanations, often sacrifice analytical clarity in doing so.

For their part, most Marxian analyses assume a form of social constructivism that, while more specific regarding the particular 'society' involved in the process of construction, nevertheless draws the lines of causation from the 'social' toward the 'technological'. Opposed to the often optimistic predictions regarding the ameliorative, if not liberating, potential of new technologies in the 'post-Fordist' literature, Marxists emphasize the historical continuity of capitalist class relations and their role in 'shaping' or 'constructing' technological development. Ellen Wood has been an influential 'skeptic' of post-Fordist claims surrounding new information technologies in particular. "What is new, then, about this so-called new economy", she writes, is not that the new technologies represent a unique kind of epochal shift. On the contrary, they simply allow the logic of the old mass production 
economy to be diversified and extended...To see these developments as a major epochal rupture, we must focus on the more or less autonomous logic of technology, whether the technology of the labor process of the technology of marketing. My emphasis here is on the logic of capitalism, not some particular technology or labor process but the logic of specific social property relations. $(1998,39-40)$

Thus, the 'social property relations' of capitalism are attributed primacy here and viewed as determining the shape and use of 'new' technologies.

Now, while there is no doubt value in emphasizing the importance of theorizing capitalism to understanding technological change, we should be clear that this 'skeptical' argument of Wood and others rests on a particular conception of capitalism that, while certainly common amongst neo-Marxists, is largely at odds with Marx's own. In fact, it is difficult to find anywhere in Marx any consistent line of argumentation that would suggest that the 'social relations' of capitalism are anything other than the relations between those engaged in a specific mode of production, relations whose particular form is determined by the mode of production itself. In the " 1857 Preface to the Critique of Political Economy" Marx is explicit:

In the social production of their life, men enter into definite social relations that are indispensable and independent of their will, relations of production which correspond to a definite stage of development of their material productive forces...The mode of production of material life conditions the social, political, and intellectual life process in general. $(2000,425)$

Of course history is complex and cannot be simply read off an analytical model, but Marx is clear: understanding the development of history requires that we attribute primacy to the mode of production; after all, he distinguishes his approach from simple 'materialism' not by suggesting the importance of 'social relations', but the importance of 'labour'. ${ }^{48}$ 
Textual evidence aside, the more significant point to be made here is that, whatever its value in shifting attention to 'capitalism', a skeptical argument that attributes analytical primacy to 'social relations' in the development of capitalism leaves the labour process in an awkward position; moreover, it makes the claim of Marxism to a 'materialist' perspective a difficult one to sustain. If the 'social relations' are primary, then the labour process tends to be taken as either a 'reflection' of these relations, or as a largely 'technical' issue that is ontologically distinct from the appropriate subject matter of the social sciences. In any case, the materiality of capitalism as a mode of production is lost as analytical primacy is attributed the relations of production, or, even more specifically, to capitalist class relations, at the expense of a focus on the material practices to which those relation correspond. Needless to say, it is an odd "historical materialism' that regards the labour process as the product of the class relations of capitalism.

A most unfortunate result of this tendency to attribute primacy to 'social relations' is that it has come to structure Marxian approaches to the question of nature and its relation to capitalism. For the most part, it has meant a neglect of such ontological matters entirely as nature is simply regarded as the raw material transformed through the labour process conceived as an essentially technical matter. In this sense nature is simply the empirical object of the natural sciences and therefore other than the appropriate subject of the social sciences, Marxian or otherwise. On the other hand, there is the loose band of 'eco-Marxists' who have sought to address the question of nature within the paradigm of Marxian social science and have thus engaged in a battle on two fronts. First, in response to 'orthodox' Marxism they have emphasized the need to incorporate 'nature' 
into the corpus in light of the environmental problems that have forced their way onto the political landscape over the past few decades; rather than assuming an objective nature that is other than capitalism as the object of Marxian social science, we have here the development of an ecological Marxism where the meaning of nature becomes problematized. Secondly, these eco-Marxists are critical of an 'ecological' paradigm that has too often abstracted questions of nature from an analysis of capitalism; thus, the question of nature for an ecological Marxist must always attend to the specificity of capitalism.

Now, as 'capitalism' has tended to be defined in terms of 'social relations' and the 'labour process' regarded as in some sense a reflection of these relations, the question of nature for eco-Marxists has taken one of two forms. First, there are those who view capitalism and nature as ontologically distinct kinds of things and seek to understand their interaction with one another. James O’Connor's (1998) notion of a 'second contradiction' of capitalism is premised on this kind of distinction; while raising the 'question of nature' within a Marxian paradigm, this question tends to be framed in terms of what capitalism does to nature and what, it turn, the degradation of nature does to capitalism. O'Connor is thus generally consistent with the orthodox tendency to regard nature as an inert raw material, albeit one that is being exhausted within a particular set of social relations, which poses obstacles to their continued existence. On the other hand, there are those that regard nature as itself a reflection of capitalism. ${ }^{49}$ While there are important variations on this thesis, they share a commitment to explaining nature (as ontological category and/or material reality) with reference to the social relations of capitalism, and class relations in particular. 
In all of these cases, despite claims to the contrary, there is a tendency to reaffirm a society/ nature dualism, the primary difference being that for eco-Marxists it is 'capitalist social relations' that constitute the 'society' pole. Capitalism is viewed as either 'interacting' with nature, in which case 'nature' is in a kind of silent partnership with 'society', or capitalism 'produces' nature, in which case 'nature' is allowed to speak briefly as a reflection of 'society', only to be silenced again as attention turns back to the 'society' that is reflected. There is thus an important sense here in which serious attention to nature as anything but an epiphenomenon of capitalist development is ruled out from the beginning insofar as capitalism is conceived in decidedly non-material terms. That so many of the debates amongst eco-Marxists revolve primarily around whether there are 'natural limits' to 'capitalism' is as clear an indication as any of the capitalism/nature dualism underlying the paradigm as a whole, a dualism that, as we have seen, reflects a particular conception of capitalism that attributes primacy to social relations.

As we shall see, the limitations of such an approach to understanding the relation between capitalism and nature are revealed more clearly than ever with the advent of a labour process centered around the creation and employment of life as an industrial productive force. First, however, we will engage with two analyses of biotechnology that exemplify, albeit in different ways, the neo-Marxist tendency to regard capitalism and nature as ontologically distinct.

\section{Biotechnology and the Mode of Development}

For Castells, biotechnology is a central constituent, along with microelectronics and new materials, of a new 'information technology paradigm' which began to take shape in the 
early 1970s. This paradigm in turn constitutes the core of a new 'mode of development' defined as the "technological arrangements through which labor works on matter to generate the product" (16). What distinguishes an 'informational mode of development' from the agricultural and industrial modes that preceded it is the degree to which it relies on the "action of knowledge upon knowledge itself as the main source of productivity" (17). Castells is consistent here with neo-Schumpeterian analysts who emphasize a certain 'de-materialization' of production as advances in biotechnology, microelectronics, and new materials engender a shift away from energy processing to information processing as the primary productive activity and source of economic development.

While for neo-Schumpeterians a shift to an information technology paradigm tends to be narrowly conceived as a 'techno-economic' issue, Castells is much more concerned with drawing out its more ontological implications. Central among these is a fundamental shift in the relation of human beings to nature where nature, rather than an object standing opposed to human beings, takes the form of information that can be generated, stored, retrieved and processed. "We live in a world," claims Castells citing Nicholas Neagroponte approvingly, "that has become digital" (30). Biotechnology thus 'converges' with other 'information technologies' insofar as it reduces living nature to a set of information codes that can be reconfigured to meet human needs, thereby "taking the copyright on life away from God and Nature" (48). Thus, as part of a new information technology paradigm the emergence of biotechnology, for Castells, marks an epochal shift in the relation of human beings to nature.

The notion that an informational mode of development in many ways marks the 'end of nature' is a provocative one, and while Castells treatment of biotechnology in this 
regard remains limited to a few preliminary remarks, his attention to the 'material' transformation of nature makes him attentive to the possibility of qualitative changes in the meaning of nature. In locating biotechnology within an informational mode of development, Castells sees a profound change in the human-nature relation. While product innovations are always central to any technological paradigm, what is especially significant about an information technology paradigm, for Castells, is that it is characterized by radically new process innovations centered on the manipulation of information. Central to the qualitative shift in the human-nature relation marked by genetic engineering is thus the unique way in which living nature, as coded information, is stored, transmitted, and processed within the production process itself. While genetically modified products are clearly an important dimension of these developments, Castells strength lies in his attention to the fundamental transformations of the process through which these products come to be.

Now, while we have already seen, in chapter 5 , the difficulties in reducing biotechnology to an information technology, we might nevertheless find this theoretical framework valuable. There are, after all, clear similarities between our conception of the labour process as a set of material practices and Castells notion of 'mode of development'. And we have seen that transgenic biotechnology indeed constitutes an important disjuncture in these material practices and, insofar as 'nature' has tended to be regarded as 'other than' the labour process, we might find kinship here with Castells in his assessment of biotechnology as marking the "end of nature. Thus, while his focus on 'genetic engineering' remains limited in its capacity to account for the repositioning of 
life as technology, we might nevertheless be able to locate our transgenic labour process and its ontological disjuncture within this analytical framework.

Yet, even if, with some modification, we were to able to assess the significance of biotechnology for the question of nature in terms of the 'end of nature' in an informational mode of development, we are faced with a certain ambiguity with regard to the relation of this ontological disjuncture to capitalism. Castells distinguishes between the 'mode of development' and 'mode of production' and while his use of the term 'mode of production' is confusing here this distinction roughly corresponds to that made by Marxists between the 'labour process' and 'social relations' (Hrynyshyn 2002). And he is consistent with neo-Marxists more generally in conflating 'capitalism' with a specific set of 'social relations' as distinct from the material engagement with 'nature' in the mode of development/ labour process. Indeed, he makes this clear in his definition of capitalism as a 'mode of production', which, rather than a way of producing per se, is "the rules for the appropriation, distribution, and uses of the surplus" which in turn define the "social relationships of production (16). Thus, in Castells we are faced with an ontological dualism where the relation between the 'material' and 'social' spheres becomes unclear. In the end, he tends to waver between a kind of technological determinism where the social relations of capitalism respond to changes in an asocial mode of development, or a kind of (post)structuralist relativism where mode of development and mode of production are understood as being 'relatively autonomous' from one another. ${ }^{50}$ More importantly, with the explicit exclusion of social relations from the material practices of the "mode of development' Castells renders the separation of questions of nature from questions of capitalism complete. 
Castells use of the concept of mode of information gives us a decidedly dematerialized notion of capitalism and the result is that, for all his sensitivity to the ontological disjuncture marked by genetic engineering, this disjuncture remains in the 'material sphere' whose significance for capitalism must remain unclear. At the same time, Castells attention to the materiality of the engagement of humans and non-humans is a valuable corrective to a tradition of labour process studies that has tended to neglect it. What we need to do is retrieve this materiality of production and the kinds of ontological disjuncture it reveals, but in a way that avoids a rigid distinction between this 'material' disjuncture and the 'social relations' of capitalism. We will thus move on now to a perspective that goes some distance toward reintegrating ontological questions concerning nature with a political economy of capitalism.

\section{Biotechnology and the Production of Living Nature as a Commodity}

Neil Smith's 'production of nature thesis' offers a perspective on nature that seems especially relevant to understanding the significance of biotechnology (1984). Smith advances the thesis that nature, rather than a distinct ontological sphere, is itself a social product. His argument rests on two assertions: first, that even to discuss 'nature' is to enter into a social relationship with it; and second, that the world we experience around us is always, to some degree, a product of our own transformative activity. Contrary to those who would view nature as something to be 'saved' from society, or some part of society, the central question for Smith is not "whether, or to what extent nature is controlled," but "how we produce nature and who controls this production of nature" (63). 
In a social formation centered on the capitalist mode of production, nature increasingly comes to be produced as exchange value in the interests of capital accumulation, a 'second nature' distinct from the 'first nature' of use-values that were more predominant in pre-capitalist social formations. The constant technological innovation driven by inter-capitalist competition results in an unrelenting penetration of nature with the commodity form, thus subordinating an increasing amount of the world to the logic of capitalist development. The result is that first nature becomes produced as second nature. And insofar as the question of nature for Smith is in the end a question concerning the social relations of capitalism, the politics inherent in such a perspective are a politics of radical social transformation. He is critical of 'environmentalism' insofar as it is premised upon on illogical and inherently conservative appeal to a 'nature' independent of its social production. It is only in a classless society for Smith that nature might be produced in a way that satisfies human needs unmediated by the requirements of capital accumulation.

While Marxian analyses of agricultural biotechnology have echoed Smith's focus on the commodification of nature (Goodman, Sorj, and Wilkinson 1988; Kloppenburg 1991), Noel Castree (2001) is alone in making explicit use of the 'production of nature thesis' to theorize the more ontological significance of developments in biotechnology for the question of nature. Castree uses the case of agricultural biotechnology as stark evidence for Smith's original claim. While nature is always produced, and while under capitalism this production takes the form of commodity production, biotechnology produces nature at the genetic level thereby revealing more clearly than ever the fallacy of an independent, autonomous 'nature'. Genetically modified foods are socially 
produced 'all the way down' and thus confront society in the form of a commodity, as second nature, through and through. For Castree, the case of agricultural biotechnology is proof positive that understanding 'nature' requires that we understand capitalism, its social relations, and the way in which these relations increasingly come to shape the world around us in its entirety. Castree echoes Smith's castigation of 'environmentalism' and reaffirms his commitment to social transformation as the solution to the problem of nature.

Smith's production of nature thesis derives from a particular interpretation of Marx and there are substantive commonalities here with our own approach to the question of nature. First, Smith is similarly sensitive to the deep ontological significance of Marx's conception of labour. Rather than merely a category of people, or a position within a set of social relations, labour is for Smith a process through which nature is produced as such, that is, a material process. Second, the production of nature thesis addresses questions of nature in relation to capitalist development thereby going some distance toward dissolving the kind of rigid capitalism/technology-nature distinction that Castells wants to maintain. And finally, Smith conceptualizes technology, rather than simply as an instrument of class exploitation, instead as an instrument of production located within the material practices of the labour process. There are thus clear convergences between the production of nature thesis and our own labour process approach.

Yet, the production of nature thesis cannot in the end avoid the neo-Marxist tendency to conflate 'capitalism' with 'social relations', a conceptual move that precludes the possibility of changes in the meaning of nature engendered by technological change 
within capitalist development. In fact, the production of nature thesis is explicitly framed as an approach to the 'society-nature' relation that regards 'nature' as a 'social product'. What is unique to capitalism in not a particular 'mode of production' per se, but a particular set of 'social relations' that produce nature in the form of a commodity.

The primary difficulty here is that analytical attention shifts away from the material engagement of humans and non-humans in the labour process to questions of ownership and control of this process. Now, the labour process does play an important role in Smith's theory, as the process through which use-values must pass on their way to becoming commodities, but the emphasis remains on the commodity as the social product of this material engagement of human beings with nature. "No part of the earth's surface," writes Smith

the atmosphere, the geological substratum or the biological superstratum are immune from transformation by capital. In the form of a price-tag every use-value is delivered an invitation to the labour process, and capital - by its nature the quintessential socialite - is driven to make good on every invitation (56).

The significance of capitalism for 'nature' lies, then, in a kind of quantitative penetration of the world with the commodity form and the labour process is conceptualized primarily as the means through which this penetration is achieved. Absent, however, is systematic attention to the actual material engagement with the forces of nature that is the labour process itself; it is either taken for granted as a technical issue, distinct from the problem of 'capitalism' conceived as the 'social', or explained away as an epiphenomena of capitalist social relations.

In this light, Castree's focus on 'agricultural biotechnology' is telling. Castree is primarily interested in using biotechnology as a kind of case study to provide evidence 
for Smith's original thesis that nature is a product of capitalism, and thus assumes from the outset a distinction between capitalism, as the 'society' that does the producing, and 'nature', as the 'social product'. The question for Castree, then, does not so much concern the significance of biotechnology for the meaning of nature as such - this is assumed in the capitalism-commodity dyad - but rather the degree to which biotechnology evidences the capitalist production of nature as a commodity. An analytical focus on transgenic crops is telling in this regard because these are, afterall, products of genetic engineering, rather than technologies themselves. While they do, as products, provide evidence of the extension of the commodity form into the molecular depths of living nature, they tell us nothing, in themselves, about the ways in which the living forces of nature are being mobilized as technology. Rather, Castree assumes that 'technology', as the means by which capitalist 'society' produces 'nature' as a commodity, and 'life', as the particular form of nature produced, are ontologically distinct. Yet, as we have seen, it is the destabilization of this very distinction that is central to the disjuncture marked by biotechnology.

Castree's conclusion regarding the continuity of biotechnology with the capitalist production of nature more generally thus reflects a particular conception of capitalism and its relation to the materiality of nature. The latter is taken for granted as a function of the labour process understood as a transhistorical requirement for any social formation. The question of nature, for both Smith and Castree, concerns the particular set of social relations to which the labour process is subordinated. Capitalism is conceived, then, primarily as a social formation in which the labour process is subordinated to the production of nature as a commodity. To the extent that there is continuity in the social 
relations of capitalism, then, there is, by definition, continuity in the production of nature. Biotechnology can be novel insofar as it produces living nature as a commodity, but any greater significance for the meaning of nature is ruled out from the beginning.

Now, we have already revealed an ontological disjuncture that is obscured by this focus on the social relations of capitalism. In focusing squarely on the transgenic labour process we have seen the degree to which living nature, rather than merely produced as a commodity (e.g. through genetic engineering) is being employed as an instrument of production; and, indeed, as we saw in chapter 2 , this is in fact the only sense in which the term 'biotechnology' can be used meaningfully at all, that is, to refer to living instruments of production. This constitutes something more than simply a penetration of a new sphere of nature with the commodity form, but a repositioning of 'life-itself' as an industrial force of production.

Still, the production of nature thesis might still allow us to clarify the relation of this ontological disjuncture to capitalism. We saw in Castells that a rigid social/material dualism and a definition of capitalism as 'social relations' did not provide for an understanding of this relation at all. The production of nature thesis, on the other hand, would seem to give us the tools to delineate this relation insofar as the 'labour process' is regarded as a means for the extension of the commodity form and maintenance of a particular set of social relations. Might we not simply regard the repositioning of life as an instrument of production within the overall continuity of capitalism? Afterall, we would be hard pressed to argue that capitalist social relations are undergoing any qualitative shift with the advent of transgenic biotechnology. On the other hand, if we 
refuse to define capitalism in terms of 'social relations', we might yet find something more than just continuity in its development.

\section{Transgenic Biotechnology and Living Nature as Fixed Capital}

It will prove worthwhile to return to our conception of the labour process in order to make clear the degree to which it not only implies a particular conception of nature, but a particular conception of capitalism and its relation to nature. We saw in chapter 1 that capitalism is a 'mode of production' central to which is a specific form of the labour process whose movement is animated by self-expanding value. There are of course specific relations of production implied by this form of the labour process and the most important of these is the relation between those who own the means of production in the form of private property and those whose labour-power must be transformed into labour in order that capital might be valorized. However, Marx clearly attributes analytical primacy to the specific 'mode of production' of capitalism in determining these relations of production and their transformation, and regards machinery and large-scale industrial labour processes more generally as crucial to the ability of capital to 'stand on its own feet'. And insofar as machinery mark a disjuncture in the degree to which the labour process approximates a force of nature, we can see that capitalism is premised upon a particular relation to nature.

What is most important here for our purposes is that capitalism, in this view, is not understood as 'social' as opposed to the 'material' (Castells) or 'natural' (Smith) world. Rather, it is a process of self-expanding value that becomes truly so when it animates that materiality of the labour process. Now, there are two implications of this 
for our approach to the question of nature and, in particular, its relation to capitalism. First, it is the labour process itself that defines the relation of human beings to nature; changes in the former are changes in the latter and as we have seen this approach has allowed us to identify a crucial disjuncture in the meaning of nature with the advent of a unique labour process centered around transgenic biotechnology. The second implication, central to our present discussion, is that disjunctures in the labour process and the humannature relation are always already disjunctures in capitalism insofar as they are disjunctures in the material moment in the movement of capital. Labour process transformations are not 'material' transformations whose relation to 'capitalism' remains unclear, but transformations of capitalism itself.

With this shift of perspective we are now in a position to recognize the degree to which transgenic biotechnology marks a disjuncture in capitalist development. While we have done our best to this point to regard living technologies as productive forces in the abstract, we can admit now the degree to which the productive force of transgenic biotechnology is a productive force of capital and the degree to which life has become a moment in the movement of self-expanding value. And here is where the crucial disjuncture in capitalist development lies: life-itself - the capacities of living nature for self-assembly, consumption, reproduction, etc. - is, as a component of the transgenic labour process, a form of fixed capital.

Now there is of course nothing terribly novel in suggesting that biotechnology is a productive force in a capitalist mode of production; indeed, this has been the leit motif of the political economy of biotechnology since the early 1980s. Beginning in the 1970s, Marxists have viewed the real subordination of science and technology to commodity 
production as part of a strategy for overcoming the crisis of accumulation of the early 1970s (Rose and Rose 1976; Levidow and Young 1981; Levidow 1986). While much of this work has concerned microelectronics in particular, Yoxen saw earlier on the implications for the life sciences (1983; see also House 2001). The more empirical work of Kenney $(1986 ; 1998)$ and Krimsky $(1991 ; 2003)$ has demonstrated the universityindustry linkages in the still nascent biotechnology industry, giving the lie to the notion of the life sciences as a disinterested pursuit of truth. Rural sociologists have long emphasized the political economic continuities underlying the development of agricultural biotechnology (Goodman, Sorj, and Wilkinson 1987; Kloppenburg 1991; Magdoff 2000). And, most recently, Kaushik Sunder Rajan has analyzed the economic, political, and cultural processes through which life is being transformed into capital in a way that bridges a gap between Marxian political economy and the tradition of science studies.

In this sense, then, an industry centered on the creation and employment of transgenic biotechnology, while facing unique regulatory and other challenges, would be best considered a special case of these more general tendencies toward the incorporation of the life sciences into capitalist commodity production. As we have seen, the emergence of a transgenic labour process constitutes a convergence of practices of molecular biology, industrial microbiology, agriculture, and animal husbandry, all of which have become increasingly integrated with the capitalist mode of production with developments in recombinant DNA and other techniques over the past 30 years. Moreover, that we have defined biotechnology as an instrument of production throughout the analysis here, and distinguished it from bioscience, makes the question of its relation 
to capital less complex insofar as instruments of production in a society dominated by the capitalist mode of production inevitable take the form of capital. Thus, while the vast majority of plant and animal transgenic biotechnologies and their products remain in various stages of clinical trials (Thiel 2004; Elbehri), that these technologies will soon come to confront us as forms of fixed capital appears certain.

In any case, while recognizing the need for a more detailed political economy of transgenic biotechnology in particular, one that reveals the various ways in which transgenic life is being constituted as capital, our focus here is rather different insofar as we are interested in the degree to which, as living capital, transgenic biotechnology destabilizes our conception of the relation between nature and capitalism. Where 'fixed capital' has heretofore been composed of inert, inorganic material, here we have living things as instruments of production, living embodiments of capital.

While this disjuncture has to this point eluded political economists, there is considerably less uncertainty amongst those with a stake in the living technologies themselves. Take TranXenoGen, who, in an effort to demonstrate the advantages of their "transgenic manufacturing platform" over others, suggest the following answers to the question "Why Avian Transgenics?":

Prolific Reproduction - Rapid Flock Generation

TranXenoGen has addressed this critical issue [the costs associated with acquiring/building manufacturing capacity for biopharmaceuticals] by selecting what it considers to be the optimum production species: chickens. Chickens have the great advantage of short development cycles (21 days to hatch) and short maturation cycles (5 to 6 months).

\section{Fully Automated}

Transgenic chickens, in a fully automated, contained and controlled facility, should be able to produce...complex proteins for a fraction of the 
cost of mammalian cell processes. The fully automated nature of chicken husbandry... minimizes the human labour costs, the benefits of which are reflected in the final cost of goods. Proteins produced by transgenic chickens are expressed at commercial levels and delivered in a convenient, sterile package - an egg.

\section{Large Volume Logistics}

Avian transgenics has the distinct advantage that chickens lay 21 eggs a month...As a result, the rapid breeding process generates large flocks capable of producing large volumes of product in a short time.

\section{Rapid Ramp-up}

A flock of transgenic chickens can be multiplied up by a factor of ten or more in a twelve-month period... Of particular advantage is the fact that a small flock of transgenic chickens can be maintained to generate product for clinical trials, and this flock can be ramped up very rapidly, immediately prior to the market launch, and thus avoid the unnecessary expense of keeping large numbers of animals before the product is needed. This again helps to defer capital investment until product success is assured.

\section{A Controlled Environment}

Transgenic chickens have the advantage over other transgenic animals that they can be housed in a contained/ barrier facility from the moment they hatch from their shell. Chickens have been reared and housed this way for the egg production industry for decades. TranXenoGen can add the element of controlled, filtered air flow to its chicken production facility to provide a barrier to adventitious agents which could contaminate the production flock. The result is a totally enclosed, contained, and controlled environment.

\section{Containment}

The egg white is contained in the sterile environment of the eggshell, and the therapeutic protein is maintained in a sterile state until the shell is broken as it enters the purification process.

We can see here the degree to which the advantages of these transgenic biotechnologies as fixed capital lies precisely in those characteristic that are unique to chickens as specific forms of living nature. The life-process of chickens, the self-movement of living nature, 
thus becomes repositioned, and reimagined, as a material moment in the movement of capital.

With Tranxenogen's chickens in mind, we can see clearly the limitations of both Castells and Castree's arguments regarding the relation of biotechnology and the question of nature to the development of capitalism. Castells regards the ontological significance of biotechnology to lie in an end of nature in an 'informational mode of development' conceived as distinct from capitalism as social relations. Here we have an ontological disjuncture in the meaning of nature whose relation to capitalism, if any, is unclear. Castree, on the other hand, sees the significance of biotechnology in terms of the production of living nature as a commodity and subordinates this ontological significance to an overarching continuity of capitalism as social relations. Here we have an emphasis on 'capitalism', but, because capitalism is conceived as social relations, there is a failure to see the disjuncture in the meaning of nature. What both Castells and Castree fail to see is the degree to which living nature has itself become fixed capital and the degree to which this simultaneously constitutes a radical disjuncture both in the meaning of nature, life become capital, and in the meaning of capitalism, as the labour process that is at its heart moves as a living force of nature like never before.

Now, there is of course some irony in our use of the term 'fixed' to refer to the form of capital under which life is increasingly being subsumed, for it is precisely the unique movement of life that hold its unique productive force. And while we have already seen the advantages attributed to the specific life-processes of the various biotechnologies by their 'owners', they simultaneously pose new kinds of 'limits' to the movement of capital. Primary amongst these are limits posed by the 'self-reproduction' of living 
technologies. As we have seen, this capacity is itself the primary productive force of transgenic microbial systems, yet poses problems of 'containment' that are obviously absent in the case of non-living technologies. The limit to the movement of capital posed by 'batch' production might also be regarded as unique in the case of transgenic microbial production insofar as the obstacle to the development of 'continuous' methods lies primarily in that unfortunate tendency for organisms to die when 'de-natured' in the retrieval process, requiring the inoculation of a new 'batch' of living technologies.

Conceiving of such obstacles as 'natural limits', however, should not be allowed to obscure the ongoing process of material engagement through which they are being negotiated and transcended. As we have seen, 'natural limits' are only meaningful insofar as they are encountered through productive activity itself and engaged with through the labour process. Thus, fermentation technology, the central non-living instrument of production in a transgenic microbial system, can be understood precisely as a means of harnessing the reproductive capacities of microbial life as a productive force while simultaneously constraining these capacities. Indeed, the entire 'manufacturing plant' is constructed in such a way as to ensure the rapid reproduction of microbial life within certain limits, limits that are specified in the labour process itself.

Similarly, the field and greenhouse are constructed in such a way as to ensure the growth and development of transgenic plant biotechnologies, while 'ensuring' that cross fertilization with non-transgenic species does not occur. And, as we have seen in the case of TranXenoGen, the barnyard is best conceived as a means of harnessing the unique reproductive capacities of chickens, while simultaneously ensuring their 'containment'. Thus, the 'limits' to the harnessing of life as a productive force do not lie in living nature 
itself conceived as other, but are revealed through the material engagement of humans and non-humans that is the labour process.

And of course, genetic engineering allows this material engagement to go beyond altering the environment and system requirements of life. The case of Nexia's Bele goats is instructive here. BELE is an acronym for Breed Early, Lactate Early. The goats are genetically engineered, not only to produce a protein that they would not otherwise produce, but to do so in as short a period of time as possible, a period of time that is itself determined through the material engagement of the genetic engineer with the life-process of the goat. While the motivation toward decreasing production times through technical innovation derives from imperatives of competition in a capitalist mode of production, questions of efficiency are addressed here, not be building a better machine, but by engineering a 'better' life-process. Thus, with the advent of transgenic biotechnology life-itself, the self-movement that is the essence of nature, becomes itself a site of technological innovation subordinated to the requirements of capital accumulation - the movement of nature itself becomes a material moment in the self-expansion of capital.

Yet our conclusion here, that the disjuncture in the meaning of nature marked by a transgenic labour process is simultaneously a disjuncture in capitalist development, must in the end remain more suggestive than anything. While it has proven important for us to emphasize the materiality of the labour process in order to identify a disjuncture in the meaning of nature, we must be careful not to reduce capitalist development to transformations of the labour process. All labour process transformations imply changes in the social division of labour and its attendant property relations and class structure, in 
regulatory institutions, and in ideologies, and these changes in turn come to condition the development of the labour process itself.

Thus, while clearly only a kind of prolegomenon to a political economy of transgenic biotechnology, this final chapter does reveal the need to pose questions concerning the political economy of technology, and of capitalism more generally, in a way that highlights the materiality of the labour process and the meaning of nature. Questions of globalization, private property, and the ideology of nature, among others, can all be raised anew in light of the unique ontological significance of transgenic biotechnology. While the purpose of the analysis here has been to identify a disjuncture in the meaning of nature constituted by biotechnology, this disjuncture implies important changes in the broader constellation of social relations, institutions, and ideologies of contemporary capitalist society. By way of conclusion, we can suggest a number of areas of future research implied by the analysis here. 


\section{Conclusion}

This dissertation had two primary motivations. One was the desire to subject 'living factories' to sociological analysis in order to assess the degree to which they constitute a disjuncture in the meaning of nature. The other was a desire to demonstrate the value of Marx's concept of the labour process for addressing the whole range of ontological questions concerning technology. Allowing these two projects to play off one another has effectively revealed both the disjuncture in the meaning of nature marked by a labour process centered on transgenic biotechnology, as well as the power of a labour process perspective to answer questions concerning the meaning of nature in a way that avoids rigid ontological dualisms.

At the same time, however, these motivations have tended to place certain theoretical and methodological limits on the analysis, three of which seem particularly important for thinking about future research. First, as was discussed in chapter two during our engagement with actor-network theory, we explicitly excluded consideration of the production of scientific knowledge, despite the fact that transgenic biotechnology would appear to play the role of instrument of production that is, at least conceptually, similar to its role in the industrial production of things. We justified this exclusion by merely identifying the complexity of the issues surrounding the relation of science to industrial labour processes. However, the specific research questions implied here would seem clear: 1) to what degree can bioscience itself be regarded as a labour process? and 2) to what degree does the employment of transgenic organisms in the production of scientific knowledge constitute a disjuncture in the meaning of nature? And, as suggested in 
chapter two, answering these questions would go some distance to opening up a creative dialogue between Marxian political economy and ANT from which both would benefit.

The motivations for the analysis here have also been reflected in its particular methodology. Our approach has been admittedly abstract in its treatment of the labour process and our descriptions and analysis have tended to be divorced from the specific examples that have served merely to illustrate our more conceptual points. This was deemed worthwhile in light of our interest in uncovering 1) the essence of a labour process that is still emergent and whose development is particularly uneven; 2) the ontological, rather than 'shop floor' significance of this labour process; and 3) the value of Marx's concept of the labour process for addressing ontological questions more generally. However, more concrete empirical work at the 'shop floor' would no doubt be of value in delineating the details of this unique labour process. A case study approach would allow for interviews with 'workers', whose experience and perspective are of course always constitutive of any technological change, as well as more concrete comparisons with labour processes centered on machinery and information technology.

Finally, we must admit that, in light of our desire to demonstrate the value of the labour process in addressing the more ontological questions concerning technology, our analysis has been limited to changes in the human-nature relation. This has been reflective of our interest in biotechnology, whose involvement of life has unique significance in this regard. However, central to a labour process is the conviction that questions of nature are inextricably linked to questions of 'society' and 'ideology'. Indeed, the labour process is the primary site at which all three are continuously being produced and reproduced. Burawoy recognized this in his suggestion that the labour 
process is "not just the production of things but simultaneously the production of social relations and of ideas about those relations, a lived experience or ideology of those relations" $(1985,36)$. While this insight is generally lost in contemporary labour process studies, and in political economy more generally, it clearly opens up the whole range of ontological and epistemological questions - questions that are generally the purview of various strains of 'contemporary social theory' - to a labour process approach; it is in the labour process that matters of capitalism and ontology collide.

Beyond such immediate questions implied by the limits of the analysis here, there are broader questions concerning the political economy of biotechnology that would seem particularly important in light of our conclusions regarding the disjuncture in the meaning of nature as a disjuncture in capitalist development. First, while we have made much of the disjuncture marked by transgenic biotechnology in the material moment in the self-expansion of capital, we have said almost nothing about the social division of labour implied by this new form of the labour process and its spatial dimensions in particular. Certainly, there has been due attention paid by political economists to an increasingly 'global division of labour' and the role of information technologies in facilitating capital's transcendence of previous spatial constraints through transformations of the labour process (Castells 2000, Teeple 2000, Davis 1998). Yet, our analysis has revealed the degree to which the transgenic labour process is unique in the degree to which it is 'constrained' by the system requirements of its living technologies. Thus, while transgenic microbial production may be relatively mobile and companies like Lilly able to locate operations relatively unfettered by questions of geography, plant production is decidedly more 'rooted' than this and the 'happiness' of transgenic animals is clearly 
dependant on geographical considerations (food, temperature, etc.) in a way that is irrelevant in the case of non-living technologies. The transgenic labour process thus provides unique case through which to explore the materiality of the globalization of capitalism.

Second, while we have emphasized the disjuncture in the meaning of nature marked by living capital, we have said nothing about the broader political economic processes through which life is made into fixed capital. For example, while patents have long been used as a way of securing private property in instruments of production, the unique materiality of transgenic biotechnology raises new questions concerning the patentability of technology. Such questions in the case of non-living technologies have generally concerned identifying the social actors/ institutions responsible for the creation of the technologies, the 'artificiality' of the technology being taken-for-granted. As our analysis has revealed, however, the primary productive force of a transgenic biotechnology lies in the found capacities of living nature for self-activity, -mediation, and -reproduction. The development and proliferation of these technologies as capital will thus surely raise new questions concerning the 'nature/artifice' distinction and will require the reach of patent regimes into the self-movement of life that is the essence of nature itself.

And clearly, the mobilization of life as a force of capitalist production implies a shift in the ideological construction of nature as well, third area of research that would seem particularly important in light of our analysis here. As has been demonstrated in the case of machinery (L. Marx 1967) and information technologies (Mosco 2004), the development and proliferation of new technologies is facilitated by notions of progress, 
efficiency, and mastery of nature, what Leo Marx calls a 'rhetoric of the technological sublime' that appeals to the desires and needs of a social actors while obscuring the inequalities and contradictions that must inevitably frustrate their satisfaction. Insofar as there has been popular resistance to these non-living technologies it has centered primarily on the point of production with issues of control, deskilling, and unemployment being raised by labour; where issues of 'nature' have been raised by environmentalists these have concerned what these technologies do to nature. However, as our analysis has revealed, a transgenic labour process constitutes a harnessing of living things themselves as technologies and thus raises moral questions that are simply absent in the case of nonliving technologies. The role of the industry, the state, and biotechnophiles in constructing a 'rhetoric of the biotechnological sublime' that address these questions will require critical analytical attention.

Finally, we must admit that too little has been said concerning the significance of the analysis here for thinking about a biotechnological politics. While we emphasized in our interpretation of Marx a politics focused on the liberation of technology from its subordination to capital, we have left this question open in the case of biotechnology. Formulating concrete political strategies and discourses around any specific technology should never be done in haste and will require far more in the way of analysis and, in particular, answers to the broader political economic questions raised above. Nevertheless, we can emphasize the degree to which a politics of protecting nature from technology becomes difficult in the case of transgenic biotechnology. If this were ever a meaningful was of thinking about an oppositional politics, it becomes decidedly less so when living nature is the technology. On the other hand, the notion of liberating the 
forces of production from their alienated form as capital takes on new meaning here as such liberation would simultaneously be a liberation of nature, albeit a nature infused with human purpose.

There is something valuable in Latour's notion of an amodern constitution and its guarantee to "replace the clandestine proliferation of hybrids by their regulated and commonly-agreed-upon production," and his suggestion that "it is time, perhaps, to speak of democracy again, but a democracy extended to things themselves" $(1991,142)$. But have not Marxists told us all along that genuine democracy, whether extended to things or not, is merely illusory in a system of private property and exchange? Thus, while it is perhaps the animal rights movement that serves as the best model for a future politics of transgenic biotechnology, we must be willing to accept that the 'animals' will likely look quite different, and that guaranteeing their rights will require a radical critique and transcendence of a generalized system of commodity production. 


\section{Notes}

${ }^{1}$ The seminal critique of the classical tradition in this regard is Catton and Dunlap (1978). There have been numerous interpretations of Marx's conception of nature, many of which are dealt with in some detail in the present work (e.g. Dickens 1996; Grundmann 1991; A. Schmidt 1971; N. Smith 1984). Raymond Murphy (1997) is the leading proponent of a Weberian approach to the question of nature. While Durkheim's work remains the least explored in this regard, see Catton (2002). For a survey of the 'controversy' over the relation of environmental sociology to the classical tradition see Buttel (2002).

${ }^{2}$ While such 'analyses' of biotechnology are ubiquitous, see Tokar (2001) for a useful collection of 'critical' perspectives that neverthless tend to take the meaning of nature for granted. For Greenpeace's programs and policies surrounding biotechnology and genetic engineering see $\mathrm{http}: / / \mathrm{www}$.greenpeace.org/canada/en/campaigns/ge. NW Rage (Northwest Resistance Against Genetic Engineering) is a relatively high profile organization focused specifically on opposing biotechnology and genetic engineering on the basis of the threat posed to nature.

${ }^{3}$ For perspectives in 'labour process theory' that seek to conceptulize the labour process in relative abstraction from any specific 'shop floor' see, for example, Gartman (1999), Palloix (1976), Willmott (1989). For recent collections of 'labour process studies' see Berberoglu (2002), Shalla and Clement (2007), Wardell, Steiger, and Meiksins (1999).

${ }^{4}$ I am drawing heavily on Gary Teeple's interpretation of Marx here, from whom this turn of phrase is borrowed $(1984,182)$.

${ }^{5}$ The debate over the relation between forces and relations of production has been central to the development of Marxism throughout the $20^{\text {th }}$ century. Where the 'scientific' or 'analytical' Marxism of Mandel (1978), Cohen (1978), and others has tended to attribute primacy to the 'forces of production', the tradition of 'critical' Marxism' following in the wake of Lukacs (1966) and Marcuse (1964) has tended to emphasize the role of 'social relations' in 'producing', 'shaping', or 'conditioning' the forces of production. For a useful survey of these perspectives see Dyer-Witheford (1999, ch.3).Cotemporary debates between Marxists over the significance of 'information technologies' for capitalist development reflect these broader theoretical differences, with 'post-Fordists' suggesting a new stage of capitalism centered on information technologies (e.g. Harvey 1989 ) and critics of 'post-Fordism' emphasizing the continuity of capitalist 'social relations' (e.g. Wood 1998). See Bonefeld and Holloway (1991) for this debate.

${ }^{6}$ Glacken (1967) traces the development of the concept of nature from the ancient Greeks to the end of the $18^{\text {th }}$ century, although without due attention to the development of the labour process. Leiss (1974), L. Marx (1966), and Young (1973) all provide accounts of the concept of nature that locate its meaning in a specific socio-historical context; and each, in different ways, emphasizes the importance of industrial capitalism to this context. Escobar (1999), writing from a 'post-structuralist' perspective, distinguishes three 'regimes' of nature that broadly correspond to 'pre-industrial', 'industrial', and 'post-industrial' social formations.

${ }^{7}$ Thus, in a widely used reader on the 'social shaping of technology' (MacKenzie and Wajcman 1999) there is not a single selection that deals in any systematic way with questions of nature. Ecological thought, while of course often evaluating technology in 
terms of its 'sustainability' or 'compatability' with nature, nevertheless tends to neglect more ontological questions concerning the significance of technological change for the meaning of nature itself (Coupe 2000).

${ }^{8}$ I am indebted to Gary Teeple for his suggestion in this regard. See Winner $(1977,20-$ 21) for a dicussion of the relevance of Aristotle on this point to more contemporary debates surrounding technology and technological determinism.

${ }^{9}$ BioteCanada, for example, provides a timeline that locates the origin of biotechnology in the domestication of plants and animals during the Neolithic revolution of 8000 B.C. (http://www.biotech.ca/media.php?mid=844). BIO, headquartered in the US but representing the interests of a global biotechnology industry, claims that "using biological processes is hardly a noteworthy event. We began growing crops and raising animals 10,000 years ago to provide a stable supply of food and clothing. We have used the biological processes of microorganisms for 6,000 years to make useful food products, such as bread and cheese, and to preserve dairy products" (http://bio.org/speeches/pubs/er/technology_collection.asp).

${ }^{10}$ See, in particular, the website of NW RAGE (Northwest Resistance Against Genetic Engineering).

${ }^{11}$ See Buttel (2005) for a discussion of the confusion surrounding definitions of biotechnology and related terms in the politics of genetically modified food crops.

${ }^{12}$ For a critical survey of the philosophy and social theory of technology see the work of Andrew Feenberg (1991, 1995, 1999).

${ }^{13}$ See, in particular, Industry Canada's 'Life Sciences Gateway' and the websites of BioteCanada and BIO.

${ }^{14}$ See Tolkar (2001).

${ }^{15}$ The image of Dr. Frankenstein figures prominently in the opposition to biotechnology. For critical discussions see Rollin (1995) and Turney (1998).

${ }^{16} \mathrm{http}: / /$ www.biobasics.gc.ca/english/View.asp? $\mathrm{x}=561$.

${ }^{17}$ Thus, while Industry Canada defines biotechnology in a way that highlights its continuities with the domestication of life during the neolithic revolution, it nevertheless distinguishes 'traditional' and 'modern' biotechnology by virtue of the centrality of rDNA to the latter (http://www.biobasics.gc.ca/english/View.asp? $\mathrm{x}=562$ ).

${ }^{18}$ This distinction is in fact problematic and will be discussed further in chapters 4 and 5 .

${ }^{19}$ The most comprehensive and accessible information on the technology and products of these and the other companies discussed here is contained in their websites. But also see Markley et al. (2006) for an accessible discussion of Sembiosys' transgenic oilbody technology, and Gavin (2001) for a discussion of the employment of transgenic goats as instruments of industrial production.

${ }^{20}$ Animal cells (i.e. cells cultivated in vitro and grown in fermentation tanks 'outside' the animal) are also commonly used in the production of pharmaceuticals and are the focus of genetic engineering (Butler 2004; Wurm 2004). Plant cells, too, are increasingly being explored (Roberts, and Jayakumar 2003; Hellwig 2004). However, the focus here on single-celled organisms, and bacteria in particular, will make clearer the differences between 'microbes', 'plants', and 'animals' as distinct 'forms of life'. While there are differences between the creation and employment of microbial, animal, and plant cells (see Vinci and Parekh 2003), these can be ignored for the purposes of the analysis here. 
${ }^{21}$ See Feenberg for a critical survey of Marxian and non-Marxian contemporary social theories of technology. See O'Mahony (1999) for a collection of 'constructivist' approaches to the question of biotechnology and nature that draw, in particular, on the work of Haraway and the 'risk society' approch of Ulrik Beck. Braun and Castree have edited 2 collections $(1998,2001)$ whose intent is to explore the intersection of Neil Smith's 'production of nature thesis' and the 'actor network theory' of Latour, but there is little attention to the ontological significance of the labour process here - this work will be dealt with in more detail in the present and final chapters.

${ }^{22}$ Thus, amongst the contributions to MacKenzie and Wajcam's Social shaping of technology is an excerpt from Labour and monopoly capital, as well as contributions from later 'labour process' writers David Noble and Cynthia Cockburn.

${ }^{23}$ The relationship between Marx's political economy and the 'staples approach' of Harold Innis in many ways shaped the early development of the New Canadian Political Economy. For a critique of Innis on the basis of his supposed 'technological determinism' see McNally (1981). For a more sympathetic critique of Innis that seeks a "merger of the old and new political economies" see Watkins (1989). For Clement's own relationship to the staples tradition see Clement (1983).

${ }^{24}$ Technological change and labour process transformations are pivotal in all versions of the 'post-Fordist' thesis from Piore and Sabel's Second Industrial Divide (1984) to the neo-Schumpterian notion of an 'information technology paradigm' (Freeman and Louca 2001) to the 'flexible accumulation' regime of David Harvey (1989). For a collection of the various versions of the post-Fordist thesis see Amin (1994). For critiques of 'postFordism' that centre on its 'technological determinism' see Pelaez and Holloway (1991) and Wood (1998).

${ }^{25}$ See Pickering (1992) for a collection of articles that reflect the shift in science studies from science as knowledge to science as practice. The work of Bruno Latour (1987, 1993) has been particularly important in shifting the attention of science studies toward the practices in the lab. Latour's 'second principle of symmetry' encourages the sociology of science to apply the same 'constructivist' approach to 'society' that it applies to 'science' and 'nature' thus shifting attention away from that which is mediated toward the practices of mediation themselves. For work on the life sciences from this perspective see Knorr Cetina (1999).

${ }^{26}$ For comprehensive and accessible overviews of the creation and employment of microbial life as an instrument of industrial production that makes these continuities clear see Walsh (2003) and Okafor (2007).

${ }^{27}$ See Burden and Whitney (1995) and Wilson and Walker (2005) for technical descriptions of purification and other cell culture techniques employed by molecular biologists.

${ }^{28}$ There are numerous primers on molecular biology and genetic engineering accessible to non-specialists (e.g. Nicholl 2002). A useful on-line resource for non-specialists are 'Kimball's Biology Pages' published by Harvard biologist John W. Kimball; for the page devoted to techniques of transformation see http://users.rcn.com/jkimball.ma.ultranet/BiologyPages/R/RecombinantDNA.htm.

${ }^{29}$ For technical discussions of media prep techniques see Waites, et al. (2001, ch.5) and Okafor (2007, ch.4) 
${ }^{30}$ Greenshields and Rothman (1995) provide a brief history of fermentation technology that makes clear both the continuity of 'biotechnology' with industrial microbiology, as well as the renewed significance of fermentation and fermenters in light of rDNA and genetic engineering.

${ }^{31}$ See Walsh (2003) for the details of 'cell banking'.

${ }^{32}$ For a discussion of the difference see Butler (1996) and Walsh (2003).

${ }^{33}$ For accessible on-line information on 'how to make a transgenic plant' see 'Transgenic Crops: An Introduction and Resource Guide' published by the Department of Soil and Crop Sciences at Colorado State Univerity (www.colostate.edu/programs/lifesciences/TransgenicCrops/how.html). For a technical description of the purification and transformation of callus see Evans, Coleman, and Kearns (2003)

${ }^{34}$ For a technical description of methods of plant transformation see Voloudakis, Yin, and Beachy (1999)

${ }^{35}$ For a technical description of what they refer to as "shrapnel biology" see Petolino, Roberts, and Jayakumar (2003, 247).

${ }^{36}$ See Krikorian (2005) for a discussion of the concept of totipotency.

${ }^{37}$ For a comprehensive discussion of traditional breeding techniques and their centrality to the development of 'modern' plant biotechnology see OECD (1993).

${ }^{38}$ For an accessible on-line discussion of these techniques see the section on 'Transgenic Animals' of 'Kimball's Biology Pages'

(http://users.rcn.com/jkimball.ma.ultranet/BiologyPages/T/TransgenicAnimals.html\#step -1 ). For a more technical description of the creation and employment of transgenic chickens see Harvey, et al. (2002). For technical descriptions of the creation and employment of transgenic goats see Meade, et al. (1999) and Benboodi, et al. (2002).

${ }^{39}$ For a collection of theories of 'post-Fordism' see Amin (1994). For a review of various approaches to the notions of 'post-indsutrialism' and 'information society' see Webster (1995). For a collection of Marxian approaches to the question of periodization see Albritton, at al. (2001).

${ }^{40}$ On the notion of 'de-materialization' from a neo-Schumpterian perspective see Junne, Komen, and Tomei (1989). For a debate over the degree to which biotechnology constitutes a pillar of a new 'techno-economic paradigm' see Fransman, Junne, and Roobeek (1995, Pt. 1).

${ }^{41}$ For various perspectives on the shifting locus of value creation in an 'informational' form of capitalism see Davis, Hirschl, and Stack (1997). The question of 'biotechnology' and value creation is explored in the recent work of Sunder Rajan (2006).

${ }^{42}$ See also Kloppenberg (1991) for a discussion of the unique characteristics of the 'seed' as themselves obstacles to the capitalist commodification of agriculture.

${ }^{43}$ See Burden and Whitney (1995) and Butler (2004) for detailed discussions.

${ }^{44}$ See Kloppenberg (1991) and Fitzgerald (2003).

${ }^{45}$ See O'Connor (1998) and Burkett (1999). The degree to which Marx was an 'ecological thinker' is a constant theme in the pages of the journal Capitalism, Nature, Socialism. For a collection of excerpts from Marx and Engels work that highlights their 'ecological' tendancies see Parsons (1977). 
${ }^{46}$ This phrase was used by Chief Justice Warren Berger of the U.S. Supreme Court in the majority decision to allow the first patent on a genetically engineered life-form (Rifkin, 43). For a critical analysis of this decision see Kevles (1998).

${ }^{47}$ On the notion of technological determinism in general see Smith and L. Marx (1994). For a now classic analysis of the theme of technological determinism in social and political thought see Winner (1977). For discussions of the degree to which Marx was a technological determinist see Bimber (1990), Duquette (1992), and Roseberg (1981). ${ }^{48}$ For examples of work from a constructivist perspective in the sociology of technology see Mackenzie and Wajcman (1999) and Bijker, Hughes, and Pinch (1987).

${ }^{49}$ For Marx's critique of 'materialism' see his 'Theses on Feuerbach' reproduced as a supplementary text to the German Ideology (Marx 1970, 121-123). For Marx's critique of Hegel that similarly reveals the centrality of 'labour' as his primary ontological category see his 'Critique of Hegel's dialectic and general philosophy' (1963, 195-219). ${ }^{50}$ Such perspectives range from the relatively conservative claim that our conception of nature is always ideologically conditioned (e.g. Lukacs 1971) to the more radical claim that nature as a material reality is itself produced by capitalism, that nature is 'social all the way down' (Smith 1984; Castree 2000). For a critical survey of the concept of nature in Lukacs and others in the tradition of 'critical theory' see Vogel (1996).

${ }^{51}$ For a critique of Castells on this point see Hrynyshyn (2002). For a similar critique that focuses on the usefullness of Castells conceptual framework for understanding 'gene science' in particular see Loeppky (1999). 


\section{References}

Ag Biotech Infonet. 1999. Industrial biotechnology will eclipse GMO foods. http://www.biotech-info.net/industrial_biotech.html

Aglietta, M. 1979. A theory of capitalist regulation: The U.S. experience. London.

Albritton, R., et al., eds. 2001. Phases of capitalist development: Booms, crises, and globalizations. New York.

Alford, J., and D. Clapp. 2004. Eli Lilly and Co.'s fermentation process control and data historian computer system: A model in 'the practice' of implementing new computer science techniques and technologies.

http://www.castdiv.org/archive/Alford_article_for_CAST.pdf. Accessed 2007.

Amin, A. 1994. Post-Fordism: Models, fantasies, and phantoms of transition. In PostFordism: A reader, ed. A. Amin, 1-39. Oxford.

Aristotle. 1961. Aristotle's physics. Trans. Richard Hope. University of Nebraska Press.

---. 1997. The politics of aristotle. Trans. P. L. Phillips Simpson. Chapel Hill, NC.

Avise, J. 2004. The hope, hype, and reality of genetic engineering: Remarkable stories from agriculture, industry, medicine, and the environment. Oxford.

Barnes, B., D. Bloor, and J. Henry. 1996. Scientific knowledge: A sociological analysis. Chicago.

Bartok, John. 2004. Grower 101: Workstations - Designed for efficiency. Greenhouse Product News 14 (1). http://www.gpnmag.com/Grower-101-Workstations-Designedfor-Efficiency-article4794. Accessed 2007.

Behboodi, E., et al. 2002. Transgenic cloned goats and the production of therapeutic proteins. In Principles of cloning, eds. J. Cibelli, et al., 459-474. Amsterdam.

Benton, T. 1989. Marxism and natural limits: An ecological critique and reconstruction. New Left Review 178 (November-December): 1-26.

http://newleftreview.org/?page=article \&review $=145$.

---. 1992. Ecology, socialism and the mastery of nature: A reply to Reiner Grundmann. New Left Review 194 (July-August): 1-14.

http://newleftreview.org/?page=article $\&$ view $=1680$.

---. 1993. Natural relations: Ecology, animal rights, and social justice. London.

---., ed. 1996. The greening of Marxism. New York. 
Berberoglu, B, ed. 2002. Labor and capital in the age of globalization. Lanham, MD.

Berger, P. L. and T. Luckmann. 1966. The social construction of reality: A treatise in the sociology of knowledge. Garden City, NY.

Bernal, J.D. 1969. Science in history. 3 vols. Middlesex, UK.

Bijker, W., T. Hughes, and T. Pinch, eds. 1987. The social construction of technological systems. Cambridge, MA.

Bimber, B. 1990. Karl Marx and the three faces of technological determinism. Social Studies of Science 20:333-351.

Biolex Therapeutics. http://www.biolex.com.

Blackburn, P., R. Coombs, and K. Green. 1985. Technology, economic growth, and the labour process. Basingstoke, U.K.

Bloor, D. 1976. Knowledge and social imagery. London.

Bonefeld, W. and J. Holloway, eds. 1991. Post-Fordism and social form: A Marxist debate on the post-Fordist state. London.

Braun, B., and N. Castree, eds. 1998. Remaking reality: Nature at the millenium. London.

---. 2001. Social nature: Theory, practice, and politics. Malden, MA.

Braverman, H. 1974. Labor and monopoly capital. New York.

Bud, R. 1993. The uses of life: A history of biotechnology. Cambridge, UK.

Burawoy, M. 1979. Manufacturing consent: Changes in the labour process under monopoly capitalism. Chicago.

--- 1985. The politics of production: Factory regimes under capitalism and socialism. London.

Burawoy, M., et al. 2000. Global ethnography. Berkeley, CA.

Burden, D. and D. Whitney. 1995. Biotechnology: Proteins to PCR: A course in strategies and lab techniques. Boston.

Burkett, P. 1999. Marx and nature: A red and green perspective. New York.

Butler, M. 2004. Animal cell culture and technology. London. 
Buttel, F. H. 2002. Environmental sociology and the classical tradition: Some observations on current controversies. In Sociological theory and the environment: Classical foundations, contemporary insights, eds. R. Dunlap, et al., 35-50. Lanham, MY.

---. 2005. The environmental and post-environmental politics of genetically modified crops and foods. Environmental Politics 14 (3): 309-323.

Canadian Biotechnology Strategy. 1998. The 1998 Canadian biotechnology strategy: An ongoing renewal process. Ottawa.

Canadian Council on Animal Care. 1993. Farm animal facilities and environment. In Guide to care and use of experimental animals. $2^{\text {nd }}$ ed. http://www.ccac.ca/en/CCAC_Programs/Guidelines_Policies/Guides/English?V1_93/ CHAP/CHIV.HTM. Accessed 2007.

Carchedi, G. 1991. Frontiers of political economy. London.

Castells, M. 2000. Rise of the network society. $2^{\text {nd }}$ ed. Oxford.

Castree, Noel. 2000. Marxism and the production of nature. Capital and Class 72 (Autumn): 5-36.

Catton, W. R., Jr. 2002. Has the Durkheim legacy misled sociology? In Sociological theory and the environment: Classical foundations, contemporary insights, eds. R. Dunlap, et al., 90-115. Lanham, MY.

Catton, W. R., Jr. and R. E. Dunlap. 1978. Environmental sociology: A new paradigm. The American Sociologist 13:41-49.

Ciccotti, G., M. Cini, and M. de Maria. 1976. The production of science in advanced capitalist society. In The political economy of science: Ideology of/ in the natural sciences, eds. H. Rose and S. Rose, 32-57. London.

Clement, W. 1981. Hardrock mining: Industrial relations and technological changes at INCO. Toronto.

--- 1983. Transformations in mining: A critique of H.A. Innis. In Class, power, and property: Essays on Canadian society, ed. W. Clement. Toronto.

Clement, W., and G. Williams, eds. 1989. The new Canadian political economy. Montreal.

Cockburn, C. 1985. Machinery of dominance: Women, men and technical know-how. London. 
Cohen, G. A. 1978. Karl Marx's theory of history: A defence. Princeton, NJ.

Collins, H., and T. Pinch. 1993. The Golem: What everybody should know about science. Cambridge, UK.

Cooley, M. 1976. Contradictions of science and technology in the productice process. In The political economy of science: Ideology of/ in the natural sciences, eds. H. Rose and S. Rose, 73-95. London.

---. 1981. The Taylorization of intellectual work. In Science, technology, and the labour process, eds. L. Levidow and B. Young, 46-65. London.

Coupe, Laurence, ed. 2000. The green studies reader: From romanticism to eco-centrism. London.

Davis, J., T. Hirschl, and M. Stack, eds. 1997. Cutting edge: Technology, information, and social revolution. London.

Demeritt, D. 1998. Science, social constructivism, and nature. In Remaking reality: Nature at the millenium, eds. B. Braun and N. Castree, 173-193. London.

Department of Soil and Crop Sciences, Colorado State University. Transgnic crops: An introduction and resource guide.

http://www.colostate.edu/programs/lifesciences/TransgenicCrops

Dickens, P. 1996. Reconstructing nature: Alienation, emancipation, and the division of labour. London.

Dobb, M. 1946. Studies in the development of capitalism. London.

Doyle, R. 1997. On beyond living: Rhetorical transformations of the life sciences. Stanford.

Duncan, C. 1996. The centrality of agriculture: Between humankind and the rest of nature. Montreal.

Dunlap, R., et al., eds. 2002. Sociological theory and the environment: Classical foundations, contemporary insights. Lanham, MD.

Duquette, D. 1992. A critique of the technological interpretation of historical materialism. Philosophy of the Social Sciences 22 (2): 157-186.

Dyer-Witheford, N. 1999. Cyber-Marx: Cycles and circuits of struggle in hightechnology capitalism. Urbana, IL. 
Earth First. http://earthfirst.org. Accessed 2007.

Ehret, D., et al. 2001. Automated monitoring of greenhouse crops. Agronomie 21:403414.

Elbehri, Aziz. 2005. Biopharming and the food system: Examining the potential benefits and risks. Agbioforum 8 (1): 18-25.

Escobar, Arturo. 1999. After nature: Steps to an antiessentialist political ecology. Current Anthropology 40 (1): 1-30.

Evans, D., J. Coleman, and A. Kearns. 2003. Plant cell culture. London.

Feenberg, A. 1991. Critical theory of technology. New York.

---. 1995. Alternative modernity. Berkeley.

--.. 1999. Questioning technology. London.

Fernandez, J. M., and J. P. Hoeffler, eds. 1999. Gene expression systems: Using nature for the art of expression. San Diego.

Fitzgerald, D. 2003. Every farm a factory: The industrial ideal in American agriculture. New Haven, CT.

Forester, T. 1987. High-tech society: The story of the information technology revolution. Oxford.

Foster, J. 2000. Marx's ecology. New York.

Fox, B., and P. Sugiman. 2006. Flexible work, flexible workers: The restructuring of clerical work in a large telecommunications company. In Working in a global era: Canadian perspectives, ed. V. Shalla. Toronto.

Franchi, S. and G. Guzeldere. 2005. Mechanical bodies, computational minds: artificial intelligence from automata to cyborgs. Cambridge, MA.

Fransman, M., G. Junne, and A. Roobeek, eds. 1995. The biotechnology revolution? Oxford.

Freeman, C. and F. Louca. 2001. As time goes by: From the industrial revolution to the information revolution. Oxford.

Freeman, C. and L. Soete. 1997. The economics of industrial innovation. Cambridge, MA. 
Fujimura, J. H. 2005. Postgenomic futures: Translations across the machine-nature border in systems biology. New Genetics and Society 24 (2): 195-225.

Fukuyama, F. 2002. Our posthuman future: Consequences of the biotechnology revolution. New York.

Gartman, D. 1999. Marx and the labour process: An interpretation. Critical Sociology 25 (2-3): 384-403.

Gavin, W. G. 2001. The future of transgenics. Regulatory Affairs Focus, May: 13-18.

Glacken, C. J. 1967. Traces on the Rhodian shore: Nature and culture in western thought from ancient times to the end of the $18^{\text {th }}$ century. Berkeley.

Goodman, D. 2001. Ontology matters: The relational materiality of nature and agro-food studies. Sociologia Ruralis 41 (2): 182-200.

Goodman, D. and M. Redclift. 1991. Refashioning nature: Food, ecology, and culture. London.

Goodman, D., B. Sorj, and J. Wilkinson. 1987. From farming to biotechnolog: A theory of agro-industrial development. Oxford.

Greenpeace. http://www.greenpeace.org/canada/.

Greenshields, R. and H. Rothman. 1995. Fermentation and fermenters. In The biotechnology revolution, eds. M. Fransman, G. Junne, and A. Roobeek. Oxford.

Grundmann, R. 1991a. The ecological challenge to Marxism. New Left Review 187 (MayJune): $1-15$. http://newleftreview.org/?page $=$ article $\&$ view $=1639$.

--. 1991b. Marxism and ecology. Oxford.

GTC Biotherapeutics. www.transgenics.com.

Haraway, D. 1997. Modest_Witness@Second_Millenium. FemaleMan ${ }^{\Theta}$ Meets_OncoMouse ${ }^{\mathrm{TM}}$ : Feminism and Technoscience. New York.

Harvey, A., et al. 2002. Expression of exogenous protein in the egg white of transgenic chickens. Nature Biotechnology 20. http://www.nature.com/nbt/journal/v20/n4/full/nbt0402-396.html.

Harvey, D. 1989. The condition of postmodernity: An enquiry into the origins of cultural change. Oxford.

---. 1996. Justice, nature, and the geography of difference. Cambridge, MA. 
Hegel, G. 1977. Phenomenology of spirit. Trans. A.V. Miller. Oxford.

Hellwig, S., et al. 2004. Plant cell cultures for the production of recombinant proteins. Nature Biotechnology 22 (11): 1415-1422.

Hines, A. 1994. Jobs and infotech: Work in the information society. Futurist 28 (1): 9-13.

Hogeveen, H., and W. Ouweltjes. 2003. Sensors and management support in hightechnology milking. Journal of Animal Science 81 (Suppl. 3): 1-10.

House, D. 2001. Agent of changelessness: The development and commodification of biotechnology. Organization 8 (2): 251-258.

Hrynyshyn, D. 2002. Technology and globalization. Studies in Political Economy 67:83106.

Hyams, E. 1972. Animals in the service of man: 10,000 years of domestication. London.

Industry Canada. n.d. Life Sciences Gateway. http://strategis.ic.gc.ca/epic/site/lsgpdsv.nsf/en/Home.

--- 2002. Follow the leaders: Celebrating Canada's biotechnology innovators. Ottawa.

Janne, J., et al. 1998. Transgenic bioreactors. In Biotechnology Annual Review, Vol. 4, ed. M. R. El-Gewely, 55-74. Amsterdam.

Jordan, K., and M. Lynch. 1992. The sociology of a genetic engineering technique: Ritual and rationality in the performance of the 'plasmid prep'. In The right tools for the job: At work in the $20^{\text {th }}$ century life sciences, eds. A. E. Clarke and J. H. Fujimura, 77-114. Princeton, NJ.

Junne, G., J. Komen, and F. Tomei. 1989. Dematerialization of production: Impact on raw material exports of developing countries. Third World Quarterly 11 (2): 128-142.

Kay, L. 1998. Problematizing basic research in molecular biology. In Private science: Biotechnology and the rise of the molecular sciences, ed. A. Thackray, 20-38. Philadelphia.

---. 2000. Who wrote the book of life: The history of the genetic code. Stanford, CA.

Keating, P., C. Limoges, and A. Cambrosio. 1999. The automated laboratory: The generation and replication of work in molecular genetics. In The practices of human genetics, eds. M. Fortun and E. Mendelsohn, 125-142. London. 
Keller, E. 2002. Making sense of life: Explaining biological development with models, metaphors, and machines. Cambridge, MA.

Kelly, K. 1994. Out of control: The rise of neo-biological civilization. Reading, MA.

Kenney, M. 1986. Biotechnology: The university-industrial complex. New Haven, CT.

--- 1997. Value creation in the late twentieth century: The rise of the knowledge worker. In Cutting edge: Technology, information, and social revolution, eds. J. Davis, T. Hirschl, and M. Stack, 87-102. London.

--. 1998. Biotechnology and the creation of a new economic space. In Private science: Biotechnology and the rise of the molecular sciences, ed. A. Thackray, 131-143. Philadephia.

Kevles, D. 1998. Diamond v. Chakrabarty and beyond: The political economy of patenting life. In Private science: Biotechnology and the rise of the molecular sciences, ed. A. Thackray, 65-79. Philadephia.

Kimball, J. W. 2006. Kimaball's Biology Pages. http://users.rcn.com/jkimball.ma.ultranet/BiologyPages/.

King, J. 1997. The biotechnology revolution: Self-Replicating factories and the ownership of life forms. In Cutting edge: Technology, information, and social revolution, eds. J. Davis, T. Hirschl, and M. Stack, 145-156. London.

King, J., and D. Stabinsky. 1999. Biotechnology under globalisation: The corporate expropriation of plant, animal, and microbial species. Race and Class 40:73-89.

Kloppenburg, J. R. 1991. First the seed: The political economy of plant biotechnology. Madison, WI.

Knights, D. and H. Willmott. 1989. Power and subjectivity at work: From degradation to subjugation in social relations. Sociology 23:535-558.

Knoll, A., et al. 2004. Flexible automation of cell culture and tissue engineering tasks. Biotechnology Progress 20:1825-1835.

Knorr Cetina, K. 1999. Epistemic cultures: How the sciences make knowledge. Cambridge. MA.

KPMG. 2000. Engineering work in Canada: Biotechnology, software development, information technology. Prepared for the Canadian Engineering Resources Board of the Canadian Council of Professional Engineers 
Krikorian, A. 2005. Totipotency and proof of the concept: An historical perspective. In Journey from a single cell to a plant, eds. S. Murch and P. Saxena. Enfield, NH.

Krimsky, S. 1982. Genetic alchemy: The social history of the recombinant DNA controversy. Cambridge, MA.

---. 2003. Science in the private interest: Has the lure of profits corrupted biomedical research? Lanham.

Krimsy, S., J. Ennis, and R. Weissman. 1991. Academic-corporate ties in biotechnology: A quantitative study. Science, Technology, and Human Values 16 (3): 275-287.

Lampman, A. 1900. The city of the end of things. In The poems of Archibald Lampman, ed. Duncan Campbell Scott. Toronto.

Large Scale Biotechnology. http://www.lsbc.com/biomanufacturing.html.

Latour, B. 1987. Science in action: How to follow scientists and engineers through society. Cambridge, MA.

--- 1993. We have never been modern. Trans. Catherine Porter. Cambridge, MA.

Law, J., and J. Hassard. 1999. Actor network theory and after. Malden, MA.

Lefebvre, H. 1969. The sociology of Marx. Trans. Norbert Guterman. New York.

Leiss, W. 1974. The domination of nature. Boston.

Lennox, B., et al. 2002. Automated production support for the bioprocess industry. Biotechnology Progress 18:269-275.

Levidow, L., ed. 1986. Radical science essays. London.

Levidow, L., and B. Young.1981. Science, technology, and the labour process, eds. L. Levidow and B. Young, 66-122. London.

Levins, R., and R. Lewontin. 1985. The dialectical biologist. Cambridge, MA.

Lewchuk, W., and D. Robertson. 1997. Production without empowerment: Work reorganization from the perspective of motor vehicle workers. Capital and Class 63 (Autumn): 37-64.

Lewontin, R. 2000. It aint necessarily so: The dream of the human genome and other illusions. London. 
Liodakis, G. 2003. The role of biotechnology in the agro-food system and the socialist horizon. Historical Materialism 11 (1): 37-74.

Loeppky, R. D. 1998. Control from within? Power, identity, and the Human Genome Project. Alternatives 23:245-266.

---. 1999. Gene production: A political economy of human genome research. Studies in Political Economy 60 (Autumn): 29-57.

Lukacs, G. 1966. Technology and social relations. New Left Review 39 (Sept/Oct): 27-34.

---. 1971. History and class consciousness: Studies in Marxist dialectics. Trans. R. Livingstone. London.

MacKenzie, D. 1996. Knowing machines: Essays on technical knowledge. Cambridge, MA.

---, and J. Wajcman, eds. 1999. The social shaping of technology. $2^{\text {nd }}$ ed. Buckingham, UK.

McNally, D. 1981. Staples theory as commodity fetishism: Marx, Innis and Canadian political economy. Studies in Political Economy. 1981 (autumn): 35-63.

Magdoff, F., J. Foster, and F. Buttel. 2000. Hungry for profit: The agribusiness threat to farmers, food, and the environment. New York.

Mandel, Enrest. 1978. Late capitalism. Trans. Joris De Bres. London.

---. 1995. Long waves of capitalist development: A Marxist interpretation. London.

Marcuse, H. 1964. One-dimensional man. Boston.

Markley, N., et al. 2006. Producing proteins using transgenic oilbody-oleosin technology. Biopharm International, June.

Marx, K. 1963. Early Writings. Trans. T. Bottomore. New York.

---. 1970. The German Ideology, Part One. International Publishers.

---. 1973. Grundrisse. Trans. M. Nicolaus. London.

--- 1976. Capital. Vol.1. Trans. B. Fowkes. London.

--.. 2000. Selected Writings. $2^{\text {nd }}$ ed. Editor. D. Maclellan. Oxford. 
Marx, L. 1964. The machine in the garden: technology and the pastoral ideal in America. New York.

Massachusetts Biotechnology Industry Directory. http://massbio.org/directory.

Meade, H. M., et al. 1999. Expression of recombinant proteins in the milk of transgenic animals. In Gene expression systems: Using nature for the art of expression, eds. J. M. Fernandez and J. P. Hoeffler, 399-427. San Diego.

Medicago. http://www2.medicago.com.

Meiksins, P. 1998. Work, new technology, and capitalism. In Capitalism and the information age, eds. R. McChesney, E. Wood, and J. B. Foster, 151-164. New York.

Menzies, H. 1989. Biotechnology and the business of life. In Fast forward and out of control: How technology is changing your life, 155-196. Toronto.

Mermin, N. 1996. What's wrong with sustaining this myth. Physics Today 49:11-13.

Miller, P. and N. Rose. 1995. Production, identity and democracy. Theory and Society 24 (3): 427-467.

Morris-Suzuki. 1997. Capitalism in the computer age. In Cutting edge: Technology, information, and social revolution, eds. J. Davis, T. Hirschl, and M. Stack, 57-71. London.

---. Robots and capitalism. In Cutting edge: Technology, information, and social revolution, eds. J. Davis, T. Hirschl, and M. Stack, 13-27. London.

Mosco, V. 2004. The digital sublime: Myth, power, and cyberspace. Cambridge, MA.

Murphy, R. 1997. Sociology and nature: Social action in context. Boulder, CO.

Nexia Biotechnologies. http://www.nexiabiotech.com.

Nicholl, D. 2002. An introduction to genetic engineering. $2^{\text {nd }}$ Ed. New York.

Noble, D. 1977. America by design: Science, technology, and the rise of corporate capitalism. Oxford.

---. 1984. Forces of production: A social history of industrial automation. New York.

Norris, S. 2005. Molecular farming. Report prepared for Parliamentary Information and Research Service. http://www.parl.gc.ca/information/library/PRBpubs/prb0509-e.htm. Accessed 2007. 
Northwest Resistance Against Genetic Engineering. http://www.nwrage.org/

Nye, D. 1994. American technological sublime. Cambridge, MA.

O’Connor, J. 1998. Natural causes: Essays in ecological Marxism. New York.

Okafor, N. 2007. Modern industrial microbiology and biotechnology. United States Science Publishers.

O’Mahony, P., ed. 1999. Nature, risk and responsibility: Discourses of biotechnology. New York.

O'Riain, S. 2000. Net-working for a living: Irish software developers in the global workplace. In Global ethnography. M. Burawoy, et al. Berkeley, CA.

Organization for Economic Co-Operation and Development. 1993. Traditional crop breeding practices: An historical review to serve as a baseline for assessing the role of modern biotechnology. Paris.

---. 1998. Biotechnology for clean industrial products and processes: Towards industrial sustainability. Paris.

Osborne, L. 2002. Got silk? New York Times, June.

Oyama, S. 2000. The ontogeny of information: Developmental systems and evolution. Durham, NC.

Palloix, C. 1976. The labour process: from Fordism to neo-Fordism. In The labour process and class strategies: From Fordism to neo-Fordism. London.

Parsons, H., ed. 1977. Marx and Engels on ecology. Westport, CT.

Pelaez, E., and J. Holloway. 1991. Learning to bow: Post-Fordism and technological determinism. In Post-Fordism and social form: A Marxist debate on the post-Fordist state, eds. W. Bonefeld and J. Holloway, 135-144. London.

Perez, C. 1983. Structural change and assimilation of new technologies in the economic and social systems. Futures 15:357-375.

---. 1985. Microelectronics, long waves and world structural change: New perspectives for developing countries. World Development 13:441-463.

Petolino, J. F., J. L. Roberts, and P. Jayakumar. 2003. Plant cell culture: A critical tool for agricultural biotechnology. In Handbook of industrial cell culture: Mammalian, microbial, and plant cells, eds. V. A. Vinci and S. R. Parekh, 243-255. Totowa, NJ. 
Pickering, A., ed. 1992. Science as practice and culture. Chicago.

Pickvance, S. 1986. "Life" in a biology lab. In Radical science essays, ed. L. Levidow, 141-153. London.

Piore, M. and C. Sabel. 1984. The second industrial divide: Possibilities for prosperity. New York.

Pollack, A. 2007. Initial benefit of genetic engineering likely to be medicine. New York Times.

(http://www.nytimes.com/2007/07/30/business/30animalside.html?_r=3\&adxnnl=1\&or ef=slogin\&adxnnlx $=1185805836-$

jDThp7Ybcru3SjzgAP+81g\&oref=slogin\&oref=slogin

Rabinow, P. 1996. Making PCR: A story of biotechnology. Chicago.

Rheinberger, H-J. 1997. Toward a history of epistemic things: Sythesizing proteins in the test tube. Stanford.

Rifkin, J. 1998. The Biotech Century: Harnessing the gene and remaking the world. New York.

Rinehart, J., D., et al. 1994. Reunifying conception and execution of work under Japanese production management? In Global Japanization? The transnational transformation of the labour process, eds. T. Elger and C. Smith, 152-174. London.

Rinehart, J., and C. Huxley, and D. Robertson. 1997. Just another car factory? Lean production and its discontents. Ithaca, NY

Robins, K., and F. Webster. 1981. Luddism: New technology and the critique of political economy. In Science, technology, and the labour process, eds. L. Levidow and B. Young, 11-48. London.

Rollin, B. 1995. The Frankenstein syndrome: Ethical and social issues in the genetic engineering of animals. Cambridge, UK.

Rose, N. 2007. Politics of life itself: Biomedicine, power, and subjectivity in the twentyfirst century. Princeton, NJ.

Rose, H., and S. Rose. 1976. The incorporation of science. In The political economy of science: Ideology of/ in the natural sciences, eds. H. Rose and S. Rose, 14-31. London.

Rosenberg, N. 1981. Marx as a student of technology. In Science, technology, and the labour process, eds. L. Levidow and B. Young, 8-31. London. 
Russell, N. 1986. Like engend'ring like: Heredity and animal breeding in early modern England. Cambridge, U.K.

Schiller, D. 1994. From culture to information and back again: Commoditization as a route to knowledge. Critical Studies in Mass Communication 11:92-115.

Schmidt, A. 1971. The concept of nature in Marx. Trans. B. Fowkes. London.

Sembiosys. http://www.sembiosys.ca.

Shalla, V. 2006. Jettisoned by design? The truncated employment relationship of customer sales and service agents under airline restructuring. In Working in a global era: Canadian perspectives, ed. V. Shalla. Toronto.

Shalla, V. and W. Clement, eds. 2007. Work in tumultuous times: Critical perspectives. Montreal.

Shiva, V. 1997. Biopiracy: The plunder of nature and knowledge. Toronto.

Shiva, V., and Ingunn Moser, eds. 1995. Biopolitics: A feminist and ecological reader. London.

Silver, L. 2006. http://www.leemsilver.net/challenging/CNsummary.htm

Sismondo, S. 2004. An introduction to science and technology studies. Malden, MA.

Smith, M. A. L. and J. F. Reid. 1996. Automation in secondary metabolite bioprocess control. In Plant cell culture secondary metabolism: Toward industrial application, eds. F. DiCosmo and M. Misawa, 53-77. Boca Raton.

Smith, M. R., and L. Marx. 1994. Does technology drive history: The dilemma of technological determinism. Cambridge, MA.

Smith, N. 1984. Uneven development: Nature, capital and the production of space. London.

Sunder Rajan, K. 2006. Biocapital: The constitution of postgenomic life. Durham, NC.

Taplin, I. A. 1995. Flexible production, rigid jobs: Lessons from the clothing industry. Work and Occupations 22 (4): 412-438.

Teeple, G. 1984. Marx's critique of politics 1842-1847. Toronto.

---. 1990. The doctoral dissertation of Karl Marx. History of Political Thought 11 (1): 81118. 
---. 2000. Globalization and the decline of social reform: Into the twenty-first century. $2^{\text {nd }}$ ed. Aurora, ON.

Thackray, A., ed. 1998. Private science: Biotechnology and the rise of the molecular sciences. Philadephia.

Thiel, K. 2004. Biomanufacturing, from bust to boom...to bubble? Nature Biotechnology 22:1365-1372.

Thompson, P. 1989. The nature of work: An introduction to debates on the labour process. Basingstoke, U.K.

Tokar, B., ed. 2001. Redesigning life? The worldwide challenge to genetic engineering. Montreal.

Tranxenogen. http://www.tranxenogen.com

Traynor, P. L., D. Adair, and R. Irwin. 2001. A practical guide to containment: greenhouse research with transgenic plants and microbes. Blacksburg, VA.

Turney, Jon. 1998. Frankenstein's footsteps: Science, genetics and popular culture. New Haven, CT.

United States Food and Drug Administration. n.d. Points to consider in the manufacture and testing of therapeutic products for human use derived from transgenic animals. http://www.fda/gov/cber/gdlns/ptc/tga.txt

Vallas, S. P. 1999. Rethinking post-Fordism: The meaning of workplace flexibility. Sociological Theory 17 (1): 68-101.

Vinci, V. A., and S. R. Parekh, eds. 2003. Handbook of industrial cell culture: Mammalian, microbial, and plant cells. Totowa, NJ.

Vogel, S.1996. Against nature: The concept of nature in critical theory. Albany, NY.

Voloudakis, A. E., Yanhai Yin, and Roger N. Beachy. 1999. Recombinant protein expression in plants. In Gene expression systems: using nature for the art of expression, eds. J. M. Fernandez and J. P. Hoeffler, 429-453. San Diego.

Waites, M., et al. 2001. Industrial microbiology. Oxford.

Walsh, G. 2003. Biopharmaceuticals: Biochemistry and biotechnology. West Sussex.

Wardell, M., T. L. Steiger, and P. Meiksins, eds. 1999. Rethinking the labour process. Albany, NY. 
Watkins, M. 1989. The political economy of growth. In The new Canadian political economy, eds. W. Clement and G. Williams, 16-35. Montreal.

Watson, J. D. 1968. The double helix: A personal account of the discovery of the structure of DNA. New York.

Webster, F. 1995. Theories of the information society. London.

Wilson, K. and J. Walker, eds. 2005. Principles and techniques of biochemistry and molecular biology. New York.

Winner, L. 1977. Autonomous technology: Technics-out-of-control as a theme in political thought. Cambridge, MA.

Wood, E. M. 1998. Modernity, postmodernity, or capitalism. In Capitalism and the information age, eds. R. McChesney, E. Wood, and J. B. Foster, 27-49. New York.

Wurm, Florian. 2004. Production of recombinant protein therapeutics in cultivated mammalian cells. Nature Biotechnology 22 (11): 1393-1398.

Yearley, S. 2002. The social construction of environmental problems: A theoretical review and some not-very-Herculean labors. In Sociological theory and the environment: Classical foundations, contemporary insights, ed. R. Dunlap, et al., 274285. Lanham, MD.

Young, R. M. n.d. Is nature a labour process? http://human-nature.com/rmyoung/papers/paper52h.html. Accessed 2006.

--- 1973. The historiographic and ideological contexts of the nineteenth-century debate on man's place in nature. In Changing perspectives in the history of science: Essays in honour of Joseph Needham, eds. M. Teich and R. Young, 344-438. London.

--- 1977. Science is social relations. Radical Science Journal 5:65-129.

Yoxen, E. 1981. Life as a productive force: capitalizing on the science and technology of molecular biology. In Science, technology, and the labour process, eds. L. Levidow and B. Young, 66-122. London.

Zehr, L. 1999. Power plants: In the world of molecular farming, plants are living factories that produce cheap drugs, plastics, even human blood protein. Globe and Mail, November 4. 
${ }^{25}$ Okafor 2007 and text guy

${ }^{26}$ something on purification of microbes

${ }^{27}$ something on transformation of microbes

${ }^{28}$ something on media prep

${ }^{29}$ something on fermentation design (from Biotech Revolution)

${ }^{30}$ something on cell banking (from text guy)

31

${ }^{32}$ something on plant genetic engineering in general and maybe callus in particular

${ }^{33}$ something on techniques of plant transformation

${ }^{34}$ Shrapnel biology, Petolino, 247

${ }^{35}$ something on totipotency

${ }^{36}$ something on cross breeding techniques

${ }^{37}$ something on transformation techniques of animals

${ }^{39}$ On the notion of 'de-materialization' and raw material see...

${ }^{40}$ For discussion of shift of site of value creation toward knowlegd see articles in cutting edge

${ }^{41}$ See also Kloppenberg for seed as limit

42 list of instruments

${ }^{43}$ woman on agricultural automation, Kloppenberg, something on robots in field.

${ }^{44}$ Examples of eco-Marxists

${ }^{45}$ Justice Berger in Rifkin

${ }_{47}^{46}$ post-Fordism and critics 